\title{
Recent Findings on Thymoquinone and Its Applications as a Nanocarrier for the Treatment of Cancer and Rheumatoid Arthritis
}

\author{
Ravi Raj Pal ${ }^{1}$, Vasundhara Rajpal ${ }^{2}$ (D) Priya Singh ${ }^{1}$ (D) and Shubhini A. Saraf ${ }^{1, *(\mathbb{D})}$ \\ 1 Department of Pharmaceutical Sciences, Babasaheb Bhimrao Ambedkar University (A Central University), \\ VidyaVihar, Raebareli Road, Lucknow 226025, Uttar Pradesh, India; ravirajpal.rs@bbau.ac.in (R.R.P.); \\ priyas.rs@bbau.ac.in (P.S.) \\ 2 Department of Biotechology, Babasaheb Bhimrao Ambedkar University (A Central University), VidyaVihar, \\ Raebareli Road, Lucknow 226025, Uttar Pradesh, India; vasundhararaj05@gmail.com \\ * Correspondence: sasaraf@bbau.ac.in; Tel.: +91-962-8176-500
}

Citation: Pal, R.R.; Rajpal, V.; Singh, P.; Saraf, S.A. Recent Findings on Thymoquinone and Its Applications as a Nanocarrier for the Treatment of Cancer and Rheumatoid Arthritis. Pharmaceutics 2021, 13, 775. https:// doi.org/10.3390/pharmaceutics13060775

Academic Editor: Armin Mooranian

Received: 31 March 2021

Accepted: 18 May 2021

Published: 22 May 2021

Publisher's Note: MDPI stays neutral with regard to jurisdictional claims in published maps and institutional affiliations.

Copyright: (c) 2021 by the authors. Licensee MDPI, Basel, Switzerland. This article is an open access article distributed under the terms and conditions of the Creative Commons Attribution (CC BY) license (https:// creativecommons.org/licenses/by/ $4.0 /)$.

\begin{abstract}
Cancer causes a considerable amount of mortality in the world, while arthritis is an immunological dysregulation with multifactorial pathogenesis including genetic and environmental defects. Both conditions have inflammation as a part of their pathogenesis. Resistance to anticancer and disease-modifying antirheumatic drugs (DMARDs) happens frequently through the generation of energy-dependent transporters, which lead to the expulsion of cellular drug contents. Thymoquinone (TQ) is a bioactive molecule with anticancer as well as anti-inflammatory activities via the downregulation of several chemokines and cytokines. Nevertheless, the pharmacological importance and therapeutic feasibility of thymoquinone are underutilized due to intrinsic pharmacokinetics, including short half-life, inadequate biological stability, poor aqueous solubility, and low bioavailability. Owing to these pharmacokinetic limitations of $\mathrm{TQ}$, nanoformulations have gained remarkable attention in recent years. Therefore, this compilation intends to critically analyze recent advancements in rheumatoid arthritis and cancer delivery of TQ. This literature search revealed that nanocarriers exhibit potential results in achieving targetability, maximizing drug internalization, as well as enhancing the anti-inflammatory and anticancer efficacy of TQ. Additionally, TQ-NPs (thymoquinone nanoparticles) as a therapeutic payload modulated autophagy as well as enhanced the potential of other drugs when given in combination. Moreover, nanoformulations improved pharmacokinetics, drug deposition, using EPR (enhanced permeability and retention) and receptor-mediated delivery, and enhanced anti-inflammatory and anticancer properties. TQ's potential to reduce metal toxicity, its clinical trials and patents have also been discussed.
\end{abstract}

Keywords: thymoquinone; cancer; arthritis; nanotechnology; synovial delivery; toxicity reduction

\section{Introduction}

As per the $\mathrm{WHO}$, approximately $80 \%$ of the global population utilizes indigenous systems of medicine for their primary health care [1]. Recently, various potential phytocandidates such as $\beta$-elemene, brazilin, bufalin, cardamonin, cryptotanshinone, isogarcinol, curcumin, celastrol, lapachol, nobiletin, oroxylin A, thymoquinone, resveratrol, torilin, and swertiamarin have been identified to have pharmacological properties [2]. Thymoquinone (TQ) is a crucial active ingredient obtained from the black seed of the plant Nigella sativa (NS) and Caramcarvil, with potential antioxidant and anti-inflammatory activities [3]. It holds a wide range of other therapeutic properties, including hepatoprotective, cardioprotective, anticancer, antidiabetic, and antimicrobial properties [4]. Moreover, TQ also nullifies oxidative stress and prevents any damage to the tissue or cellular environment [5].

The seeds of $N$. sativa contain a combination of volatile oils $(0.40-0.45 \%)$, fixed oils $(>30 \%, w t / w t)$ with two terpene alkaloids and eight fatty acids. Dithymoquinone, TQ, trans-anethol, (2-isopropyl-5-methylbenzo-1, 4-quinone), limonine, carvone, nigellidine, hedrin and p-cymene are some of the majorly identified terpenes. Moreover, the seeds 
also contain isoquinoline (nigellicimine-N-oxide and nigellicimine) and indazole alkaloids (nigellicimine and nigellidine) [6]. TQ exists in tautomeric forms in which the keto fraction $(\sim 90 \%)$ majorly exerts pharmacological actions [7]. The 2D and 3D structures of TQ are depicted in Figure 1.<smiles>CC1=CC(=O)C(C(C)C)=CC1=O</smiles>

Figure 1. 2D and 3D structure of thymoquinone, $\mathrm{C}_{10} \mathrm{H}_{12} \mathrm{O}_{2}$.

TQ is a pharmacologically active agent used as a therapeutic agent as well as for preventive measures [8]. Oral dosing of Nigella sativa (NS) seeds at a quantity of 2 gm daily can effectively treat diabetes, as per reports [9]. However, it is associated with various pharmacokinetic issues that halt its pharmacodynamic activities. TQ is a hydrophobic molecule with low aqueous solubility and is associated with thermal instability and photosensitivity [10], which makes it systematically less bioavailable. Moreover, the bioavailability of TQ is mainly dependent upon its administration route. The absolute bioavailability (BA) of TQ in rabbits after oral $(20 \mathrm{mg} / \mathrm{kg}$ PO) and IV $(5 \mathrm{mg} / \mathrm{kg})$ administration revealed a $* 58 \%$ lag time of $23 \mathrm{~min}$ with slower absorption and rapid elimination rates [11]. It is an acidic molecule with a pKa value of 5.1 [12] that is extensively degraded in the aqueous medium, especially at higher $\mathrm{pH}$ concentrations [1]. Low aqueous solubility, bioavailability, thermal, and photodegradability are some major drawbacks in utilizing its maximum potential as therapeutic.

Orally administered TQ is biotransformed into hydroquinone by DT-diaphorase (a quinine reductase enzyme) [13]. Enzyme glutathione and NADPH (nicotinamide adenine dinucleotide phosphate oxidase) quinine oxidoreductase converted it into glutathionyldihydrothymoquinone and thymohydroquinone, respectively, via the redox mechanism [14]. TQ catalyzes in a two-step one-electron reduction or a two-electron one-step reduction. In one-electron two-step reduction of TQ, microsomal NADH cytochrome-b5 reductase, mitochondrial NADH ubiquinone oxidoreductase, and microsomal NADPH cytochrome P450 reductase convert TQ into semiquinone, which is further biotransformed into thymohydroquinone $[15,16]$. Conversely, a one-step two-electron reduction directs the conversion of TQ into thymohydroquinone [17]. Semiquinone of TQ is also known to possess oxidative stress-producing capabilities in cancerous tissues. Superoxide anion produced via oxidation can be nullified by TQ administration [18]. Due to the lack of detoxifying enzymes, which is quite common in cancer cells, the accumulated superoxide may exert the pro-oxidant effect of TQ [19]. The physiological catalysis of TQ is summarized in Figure 2. 


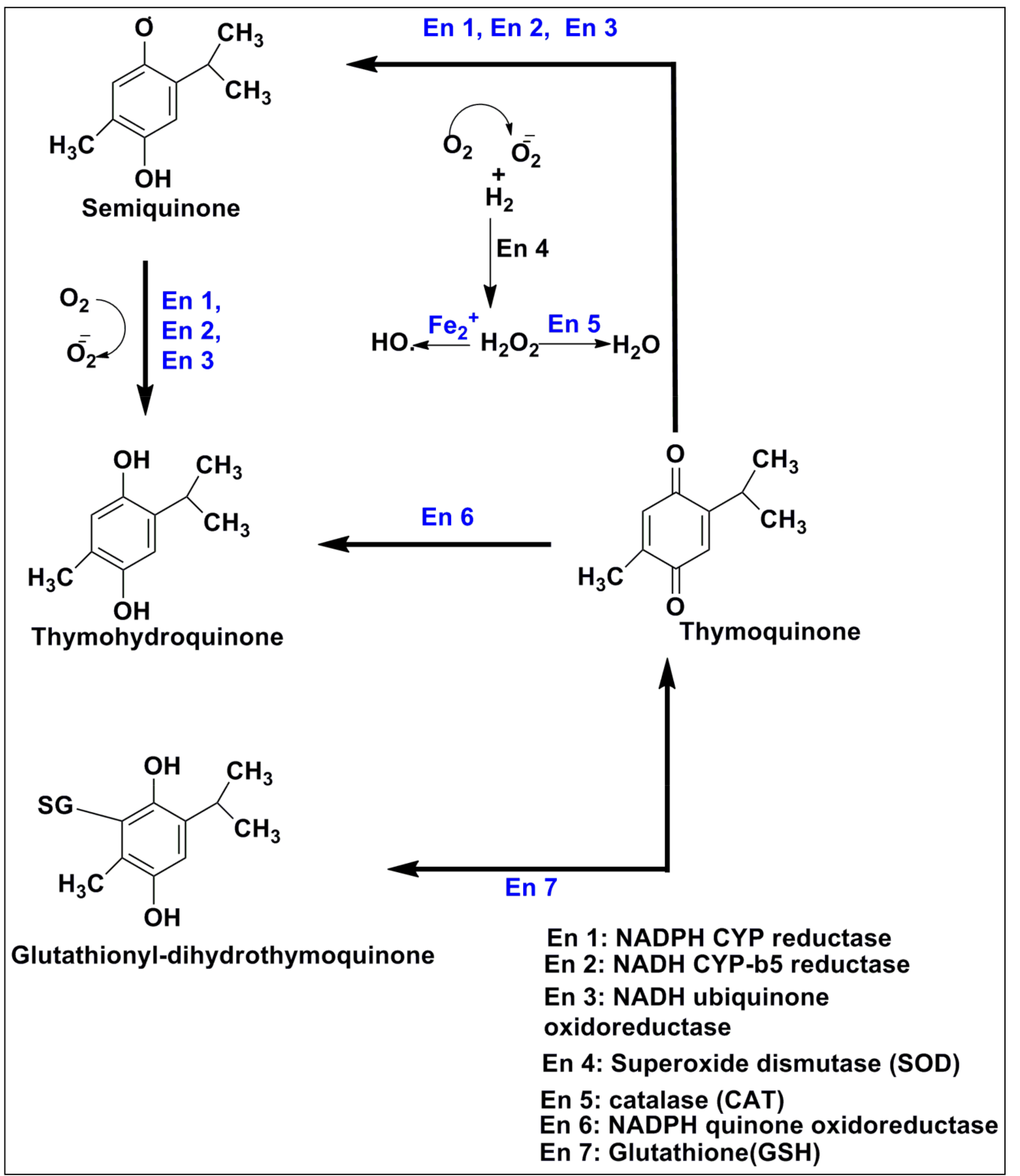

Figure 2. Enzymatic catalytic pathway of TQ under physiological conditions.

\section{Method for Literature Search and Studies Selection}

The authors searched a number of electronic databases, namely Science Direct, Scopus, PubMed, US National Library of Medicine Clinical Trials (https:/ / clinicaltrials.gov; accessed on 12 January 2021), and the Clinical Trial Registry of India (http:/ / ctri.nic.in/; accessed on 12 January 2021). The following keywords were selected based on MeSH terms: thymoquinone, nanoparticle, nanocarrier, targeted nanoparticle, rheumatoid arthritis, nano, inflammation, cancer, neoplasm, toxicity, and antioxidant. These keywords were searched individually and in combination. At the first stage of screening, only English language articles were selected if the title, abstract, or full text contained the word "thymoquinone". The initial database search found 5522 articles: 1389 from PubMed, 2191 from Scopus, 1933 from Science Direct, 7 from ClinicalTrials.gov, and 3 from the Clinical Trial Registry of India. In this process of analysis, 4240 articles were excluded due to them being indexed in two or more databases and were considered as duplicates. The remaining 1282 articles were screened out by analyzing the article's title and abstract according to the inclusion criteria. After the second stage of screening, only 184 studies (158 experimental articles, 16 patents, 10 clinical txrials) were found to be appropriate according to the inclusion criteria. Studies 
of clinical trials in humans of any age, gender, or nationality, case-control studies, cohort studies, and randomized, double-blind, placebo-controlled, and parallel-group trials were considered for the review. Studies demonstrating the safety and efficacy of thymoquinone in in silico models were excluded for this review. Conference abstracts without full data or experimental information, letters to editors, and opinion papers, with potential influences of funding sources on the study results, were also excluded. The progression of thymoquinone articles from the year 2011 to 2021 is reported in Table 1. Furthermore, our review analysis indicated that TQ alone or in combination has beneficial roles in arthritic inflammation and various type of cancers.

Table 1. Progression of thymoquinone article from the year 2011 to 2021.

\begin{tabular}{ccccccccccccc}
\hline Database & \multicolumn{10}{c}{ Year Wise Progression of Articles } \\
\hline & $\mathbf{2 0 2 1}$ & $\mathbf{2 0 2 0}$ & $\mathbf{2 0 1 9}$ & $\mathbf{2 0 1 8}$ & $\mathbf{2 0 1 7}$ & $\mathbf{2 0 1 6}$ & $\mathbf{2 0 1 5}$ & $\mathbf{2 0 1 4}$ & $\mathbf{2 0 1 3}$ & $\mathbf{2 0 1 2}$ & $\mathbf{2 0 1 1}$ \\
\hline PubMed & 87 & 172 & 140 & 157 & 118 & 130 & 111 & 98 & 78 & 65 & 64 \\
\hline Scopus & 121 & 285 & 201 & 212 & 203 & 177 & 155 & 127 & 78 & 96 & 89 \\
\hline Science Direct & 177 & 277 & 188 & 202 & 158 & 128 & 106 & 112 & 78 & 88 & 54 \\
\hline
\end{tabular}

\section{Rheumatoid Arthritis}

Rheumatoid arthritis (RA) is recognized by the way the body's immune system attacks the lining of the joints and results in significant mortality and morbidity rates. The lifetime risk of developing RA is increasing globally such as in the United States-1.7\% (1 in 59) for men and 3.6\% (1 in 28) for women; it varies within gender and individuals over time [20]. It is a long-lasting degenerative joint disease with an unknown etiology; however, it is thought to have multifactorial pathogenesis, including genetic and environmental defects as well as impaired immune regulation [21]. RA is characterized by joint inflammation, synovial membrane hyperplasia, excessive chemokines infiltration, leukocyte migration, and autoantibody production [22]. In the altered immune system, $T$ cells fail to control inflammation and may initiate RA or other immune-related disease [23]. Additionally, the cell metabolism, whose primary work is to combat against the autoantigen attack, does not respond properly and effectively in RA conditions, which leads to chronic inflammation. Long-term RA inflammation alters cytokine release; overexpression of pro- and antiinflammatory cytokines results in bone and cartilage damage. Patients with rheumatoid arthritis have unusual autoantibodies such as anticitrullinated antibodies and Rheumatoid Factor (RF), etc., that continue to circulate in the blood and thus, target their own body tissues, leading to polyarticular inflammation of the synovial membrane, wrists and feet along with nodule formation [24]. The synovium of RA is persistently upregulated by the induction of several chemokines and cytokines, including TNF- $\alpha$, IL-1, IL-6, IL18, IL-15, and IL-12 [25]. Moreover, Toll-like receptors (TLR7, TLR4, TLR3, and TLR2) are also found to be upregulated in arthritic synovium [26] along with other inflammatory molecules, followed by the destruction of cartilage and bone [27]. Osteoclasts, the major bone resorbing cells, are mainly responsive to autoantibodies and inflammatory cytokines, in particular IL-1, IL-6 and TNF, which all induce osteoclast differentiation either directly or by inducing receptor activator of nuclear factor kappa B ligand (RANKL) activity [28]. Subsequently, stimulation of lymphocytes triggers cellular proliferation, differentiation, and also increased inflammatory cytokine synthesis (TNF- $\alpha$, IL-7, and IL-1) [23,29]. In addition, RA patients also show pulmonary, cardiovascular, and other systemic complications [30].

The diversified pathogenesis of RA demands pharmacological and non-pharmacological approaches and sometimes, rotating interventions to achieve satisfactory therapeutic outcomes as well as patient compliance. Appropriate knowledge about the disease, preventive measures, optimized therapeutic regimens, and treatment goals for patients and health care providers might produce an appropriate impact upon RA amelioration.

Nevertheless, various non-pharmacological and pharmacological approaches, including recognition and avoidance of causative factors, non-steroidal anti-inflammatory drugs 
(NSAIDs), immunosuppressant therapies, herbal therapies (plant extract, oils), and physical measures (physiotherapy), have been used, either alone or in combination for the management of acute to chronic RA. The initial phase of RA can potentially be treated with NSAIDs; however, the chronic phase requires intensive therapies of disease modifying antirheumatic drugs (DMARDs), including modern biologics [31]. DMARDs such as methotrexate, leflunomide, sulfasalazine, and mycophenolate, etc., and modern biologics that specifically target cytokines and inflammation-inducing cells are used to ameliorate pain and prevent bone damage [31]. Besides their potential application in RA, DMARDs and biologics are also associated with numerous side effects such as TNF- $\alpha$ inhibition, which is associated with the risk of tuberculosis [32]; and tocilizumab, which is associated with a risk of lower intestinal perforation [33]. A large number of patients are resistant to current drugs with only 20-30\% reaching low disease activity status and none of them can completely cure RA [31].

Currently, there is no absolute regimen for RA and cancer management owing to a multifaceted pathogenic interaction between a patient's immunity, gene abnormality, and environmental susceptibility. Recently, bioactive compounds of natural origin such as thymoquinone and their nanoformulations were utilized for the treatment of cancer and rheumatoid arthritis. The potential of TQ and its nanoformulations-based targeted delivery for the management of cancer and arthritis is critically analyzed and reported in the following sections.

\subsection{Thymoquinone Works as an Anti-Arthritic}

Thymoquinone is a naturally occurring bioactive molecule reported to ameliorate rheumatic conditions in multiple pathways. TQ $(10 \mathrm{mg} / \mathrm{kg}$ body weight) significantly downregulated the elevated level of Toll-like receptor (TLR) and other inflammatory cytokines (TNF- $\alpha$, IL-1, and IL-6) in a Freund's complete adjuvant (FCA)-induced arthritis rat in vivo model [34]. TQ ( $5 \mathrm{mg} / \mathrm{kg}$ body weight) significantly downregulated the level of pro-inflammatory mediators (IL-1b, IL-6, TNF- $\alpha$, and prostaglandin $\mathrm{E}_{2}$ ) to reduce arthritis scoring and bone leaching in collagen-induced arthritis in a Wistar rats in vivo model [35]. In an in vivo study, Boudiaf et al. demonstrated that TQ $(10-50 \mathrm{mg} / \mathrm{kg}$, intraperitoneal) potentially inhibits $\mathrm{N}$-formyl-methionyl-leucyl phenylalanine-induced neutrophil functions, and superoxide production [36]. In another in vitro study, the inhibition of phospho-p38 and phospho-JNK expression by TQ $(0.1-5 \mu \mathrm{M})$ through apoptosis-regulated signaling kinase 1(ASK1) was reported to ameliorate rheumatic tissue damage [37]. Similarly, phosphorylation of p38 mitogen-activated protein kinase was blocked by TQ as investigated in both in vitro (isolated human RA fibroblast-like synoviocytes, dose 0-10 $\mathrm{mM}$ ) and in vivo (rat adjuvant-induced arthritis, dose $5 \mathrm{mg} / \mathrm{kg}$ /day of TQ) studies; besides this, LPSinduced overexpression of inflammatory markers such as interleukin-1beta (IL-1b), TNF- $\alpha$, cyclooxygenase-2, nuclear factor-kappa B-p65 metalloproteinase-13, and prostaglandin $\mathrm{E}_{2}$ (PGE2) were also regulated [8,38]. TQ decreases receptor-activated nuclear factor kappa-B ligand (RANKL)-induced osteoclastogenesis (in vitro in RAW 264.7 cells, TQ dose: $2.5,5$, and $7.5 \mu \mathrm{M})$ by inhibiting mitogen-activated protein kinase signaling and NF- $\mathrm{kB}$ (nuclear factor kappa light chain enhancer of activated B cells) as well as prevention of LPS (lipopolysaccharides)-induced bone erosion at a dose of $5 \mathrm{mg} / \mathrm{kg}$ as investigated in an in vivo C57/BL6 male mice model [39]. A similar potential of TQ (dose: $10 \mu \mathrm{M})$ in LPS-activated BV-2 murine microglial cells were also reported in an in vitro model [40]. TQ (intra-articularly injection of $0.3 \mathrm{~mL} ; 10 \mathrm{mmol} / \mathrm{L}$ ) also upregulated the expression of MMP-1 (matrix metalloproteinase-1) (tissue inhibitors) and downregulated MMP-13 in both rabbit chondrocytes and animal models of osteoarthritis induced by anterior cruciate ligament transaction [41]. The anti-inflammatory potential of TQ (dose of $2.5 \mathrm{mg} / \mathrm{kg}$ and $5 \mathrm{mg} / \mathrm{kg}$ ) was found to be comparable with methotrexate (MTX) in an in vivo model of Freund's incomplete adjuvant-induced arthritis [42]. Similar results were also observed to decrease carrageenan-induced inflammation in an in vivo rat model with an intraperitoneal dose of TQ (10 and $50 \mathrm{mg} / \mathrm{kg}$ ) [36]. Moreover, the immunomodulatory effects of TQ 
(10 mg/ kg of body weight, intraperitoneally) are almost similar to the therapeutic effects of MTX ( $0.5 \mathrm{mg} / \mathrm{kg}$ of body weight, intraperitoneally) as investigated in an FCA-induced arthritic in vivo model in rat [34]. An in vivo study by Pop et al. [43] has reported the anti-inflammatory and analgesic potential of NS oil in oral doses of 1,2 , and $4 \mathrm{~mL} / \mathrm{kg}$ in comparison with diclofenac ( $5 \mathrm{mg} / \mathrm{kg}$ ), as investigated in the carrageenan and Freund's adjuvant-induced inflammatory in vivo model. In the same study, the antioxidant effects were studied and a decrease in malondialdehyde levels as well as oxidized glutathione was recorded. When caspase- 1 cleaves, it leads to an increase in pro-inflammatory markers: for example, IL-1 $\beta$, IL-18, post-NLRP3 (NOD-like receptor family pyrin domain containing 3) inflammasome activation [44]. TQ has been reported to block this cascade of events. [45]. The anti-arthritic mechanism of TQ is diagrammatically represented in Figure 3 and the applications of thymoquinone in the treatment of inflammation and arthritis are recorded in Table 2.

Table 2. Applications of thymoquinone in the treatment of inflammation and arthritis ( $\downarrow$ : decrease, $\uparrow:$ increase).

\begin{tabular}{|c|c|c|c|c|c|}
\hline S.N & Dose and Route & Animal Model/Cell Line & Molecular Target & Outcome & Reference \\
\hline 1 & TQ (2-5 mg/mL/kg) & $\begin{array}{l}\text { Pristane induced RA in } \\
\text { female SD rats }\end{array}$ & $\begin{array}{c}\downarrow \mathrm{IL}-1 \beta, \downarrow \mathrm{TNF}-\alpha, \downarrow \mathrm{IL}-6, \downarrow \mathrm{IL}-10, \\
\downarrow \text { IFN- } \gamma, \text { and } \downarrow \text { PGE2 }\end{array}$ & RA amelioration & [7] \\
\hline 2 & TQ (10 mg/kg BW) & $\begin{array}{c}\text { Freund's complete } \\
\text { adjuvant (FCA) induced } \\
\text { RA in rat }\end{array}$ & $\begin{array}{c}\downarrow \text { TLR2, } \downarrow \text { TLR4, } \downarrow \text { TNF- } \alpha, \downarrow \text { IL-1, } \\
\text { and } \downarrow \text { NF- } k B\end{array}$ & RA amelioration & {$[34]$} \\
\hline 3 & TQ $(1-5 \mu \mathrm{M})$ & $\begin{array}{l}\text { TNF- } \alpha \text {-induced synovial } \\
\text { fibroblast activated RA }\end{array}$ & $\begin{array}{c}\downarrow \text { phospho-p38 and } \\
\text { phospho-JNK expression } \\
\text { through apoptosis regulated } \\
\text { signaling kinase } 1\end{array}$ & $\downarrow$ tissue damage & {$[37]$} \\
\hline 4 & $\begin{array}{l}\mathrm{TQ}(10 \text { and } \\
50 \mathrm{mg} / \mathrm{kg}, \\
\text { Intrapleural })\end{array}$ & $\begin{array}{l}\text { pleurisy induced by } \\
\lambda \text {-carrageenan in rats }\end{array}$ & $\begin{array}{c}\text { impaired the } \\
\text { phosphorylation on Ser-304 and } \\
\text { Ser-328 of p47PHOX, a cytosolic } \\
\text { subunit of the NADPH oxidase; } \\
\downarrow \text { fMLF-induced } \\
\text { neutrophil functions }\end{array}$ & $\begin{array}{l}\downarrow \text { of neutrophil accumulation in } \\
\text { the pleural space, produce an } \\
\text { anti-inflammatory response }\end{array}$ & [36] \\
\hline 5 & $5 \mathrm{mg} / \mathrm{kg}$, oral & $\begin{array}{c}\text { Nf- } \mathrm{kB} \text { induced } \\
\text { osteoclastogenesis } \\
\text { (in vitro) and LPS } \\
\text { induced bone loss } \\
\text { (in vivo) }\end{array}$ & $\begin{array}{c}\downarrow N f-\kappa B \text { and MAPK, ROS, } \\
\downarrow c-F o s, \text { and NFATc1 }\end{array}$ & $\downarrow$ osteoclastogenes $\downarrow$ bone loss & [39] \\
\hline 6 & $5 \mathrm{mg} / \mathrm{kg}$, oral & $\begin{array}{l}\text { Collagen-induced RA } \\
\text { in rat }\end{array}$ & $\begin{array}{l}\downarrow \mathrm{IL}-1 b, \mathrm{IL}-6, \mathrm{TNF} \alpha, \mathrm{IFN}-\mathrm{c}, \\
\text { and PGE2 }\end{array}$ & $\begin{array}{l}\downarrow \text { arthritis scoring and } \\
\text { bone restoration }\end{array}$ & {$[35]$} \\
\hline 7 & TQ $5 \mathrm{mg} / \mathrm{kg}$ oral & $\begin{array}{l}\text { Isolated human fibroblast; } \\
\text { adjuvant-induced RA }\end{array}$ & $\begin{array}{l}\downarrow \mathrm{IL}-1 \beta, \mathrm{TNF} \alpha, \mathrm{MMP}-13, \\
\text { cyclooxygenase-2, and PGE } \\
\downarrow \text { phosphorylation of p38, } \\
\text { MAPK, and NF- } \mathrm{B} \text {-p65 }\end{array}$ & $\downarrow$ RA pathogenesis & {$[38]$} \\
\hline 8 & $\begin{array}{c}\text { Intra-articularly of } \\
0.3 \mathrm{~mL} \text { of TQ } \\
(10 \mu \mathrm{mol} / \mathrm{L})\end{array}$ & $\begin{array}{l}\text { Anterior cruciate } \\
\text { ligament transaction } \\
\text { induced OA }\end{array}$ & $\begin{array}{c}\downarrow \mathrm{MMP}-3, \mathrm{MMP}-13 \\
\uparrow \mathrm{MMP}-1 \text { expression }\end{array}$ & Attenuated osteoarthritis (OA) & {$[41]$} \\
\hline 9 & TQ (2.5-5 mg/kg) & FCA induced RA & $\downarrow$ IL-1 $\beta, \downarrow$ TNF- $\alpha$ & $\downarrow$ RA symptoms & {$[42]$} \\
\hline 10 & TQ $(0.1-100 \mu \mathrm{M})$ & $\begin{array}{l}\text { Simpson-Golabi-Behmel } \\
\text { syndromehuman } \\
\text { pre-adipocytes. }\end{array}$ & $\downarrow \mathrm{IL}-6, \downarrow \mathrm{IL}-1 \beta$ & $\begin{array}{c}\text { } \text { antioxidant and } \\
\uparrow \text { anti-inflammatory potential }\end{array}$ & {$[46]$} \\
\hline
\end{tabular}

Abbreviations: TQ—-thymoquinone; SD—Sprague Dawley; OA—osteoarthritis; MMP—matrix metalloproteinase; OA—osteoarthritis; TLR-Toll-like receptors; PGE2—Prostaglandin E2; FCA-Freund's complete adjuvant; IL—Interleukin; TNF- $\alpha$-Tumor necrosis factor alpha; NF- $\mathrm{B}$ - Nuclear factor kappa light chain enhancer of activated B cells; IFN- $\gamma$-Interferon gamma; MAPK-Mitogen-activated protein kinase; NFATc1-Nuclear factor of activated T-cells cytoplasmic 1; ROS-reactive oxygen species; JNK-c-Jun N-terminal kinase; $\mathrm{NADPH}-$ Nicotinamide adenine dinucleotide phosphate oxidase; fMLF-N-Formylmethionine-leucyl-phenylalanine]. 


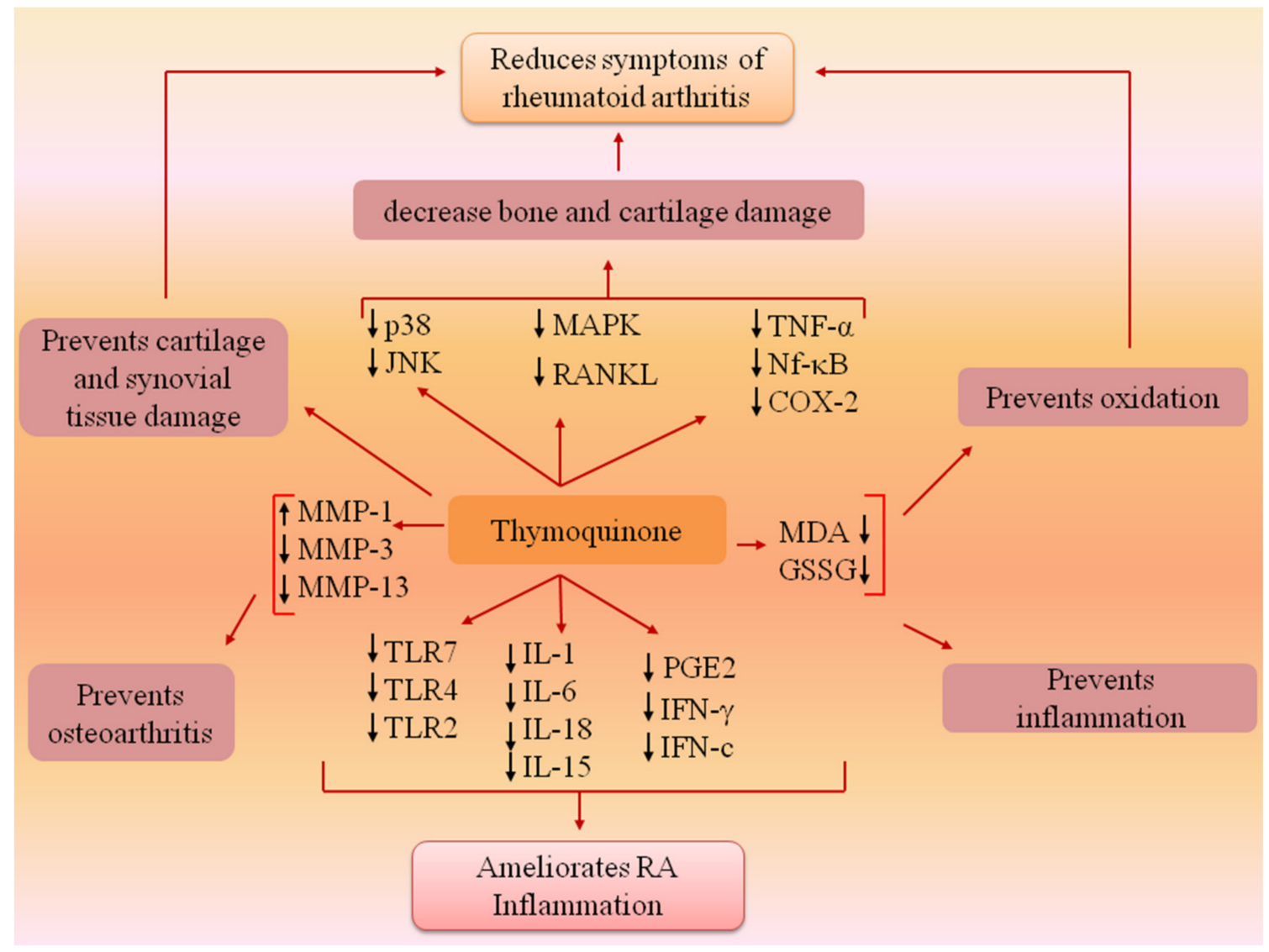

Figure 3. Anti-arthritic mechanism of TQ. TQ significantly downregulated the elevated levels of TLR-7, TLR-4, MMP-13, MMP-3, and other inflammatory cytokines, including TNF- $\alpha$, IL-1 $\beta$, PGE2, and IL- 6 and upregulated the expression of MMP1 to reduce arthritis scoring and bone leaching in arthritis. TLR—Toll-like receptor; IL—interleukin; PGE2-prostaglandin E2; MDA—malondialdehyde; GSSG—glutathione; MMP—matrix metalloproteinase; RANKL—receptor-activated nuclear factor kappa-B ligand; COX_cyclooxygenase-2; MAPK—-mitogen-activated protein kinase.

\subsection{Encapsulated $T Q$ Nanocarriers in the Treatment of Arthritic Inflammations}

The tumorigenic tissues and RA synovium exhibit likeness; for instance, EPR and hypoxia happen in both. The aim and strategies of nanoparticulate delivery for tumors can be similar to that of RA. The altered fenestrated synovial membrane in RA and tumor EPR could be a potential object for nanoparticulate-based drug delivery. The fenestrated and leaky vasculature of the synovial membrane favors penetration and retention of NP [47]. The nanocarriers have specific targeting ability to the inflammatory cells and thereafter, efficiently downregulate the pro-inflammatory sequence of events and can ameliorate RA indications and consequent bone damage; for example, macrophages increase at the arthritic inflammatory site and can engulf nanoparticles, resulting in passive targeting [48]. Moreover, NPs could also decrease the dose and off-target toxicities, thereby enhancing treatment potential for arthritic drug delivery $[49,50]$. To improve the stability and oral bioavailability of $\mathrm{TQ}$, various nanoformulations, including an oral phospholipidic nanomatrix (particle size $>100 \mathrm{~nm}$ ) [1], topical ethosomes (particle size $105.2 \pm 8.0$ ) [51], and liposomal chitosan gel [52], were developed which enhanced the therapeutic efficacy of TQ as investigated in a carrageenan-induced paw inflammation model. The phospholipidic nanomatrix made up of lipidic core and surfactant mixture enhances TQ aqueous solubility and intestinal absorption relative to TQ suspension [1]. Besides this, lipidic NPs are directly taken up by intestinal lymph and deliver the drugs directly into the bloodstream, which leads to avoidance of the first-pass metabolism process. As a result, lipidic NPs enhance the anti-inflammatory potential of TQ, vis TQ suspension as observed in the carrageenan-induced paw edema rat model. 


\section{Neoplasm and Its Pathogenesis}

A large group of individuals are diagnosed with cancer annually, being the second leading cause of mortality worldwide [53]. Its pathogenesis is very complex and is often difficult to identify, and most of the time, it is multifactorial. The tendency to multiply some groups of cells beyond their limit leads to abnormal development in a specific body part, which is called neoplasm or cancer [54]. Generally, metastasis-suppressor genes are involved in the inhibition of motility, invasiveness, colony formation, growth arrest, differentiation, proliferation, adhesion to extracellular matrix components, cell-cell adhesion and aggregation, and the immune sensitivity of cells $[55,56]$. All of these tasks require precise timing, which is controlled by a variety of cellular functions. Signaling, transcriptional activation, integrin expression and signaling, cell adhesion, and motility, cell communication, cytokine stress-induced signaling, serine protease expression, and nucleotide diphosphate kinase activity are among these functions [57]. Failing any of the above-said factor or group of factors may initiate cancer genesis [58]. Epigenetic changes also play a crucial role in disease initiation. Lower levels of H3K4me2, H3K18ac and H3K9me are linked to a poor prognosis in prostate, lung, and kidney cancers, respectively; similarly, higher levels of $\mathrm{H} 3 \mathrm{~K} 9 \mathrm{ac}$ expression in lung cancer patients are linked to a shorter survival period $[59,60]$. Thymoquinone has recently been shown to modulate epigenetic machinery, such as histone acetylation and deacetylation, DNA methylation, and demethylation, all of which are significant epigenetic changes that may lead to carcinogenesis [61]. TQ has antineoplastic activity against human tumors, antioxidant effects and anti-inflammation in animal models and cell culture systems, chemopreventive effects, and most notably, anti-multidrug-resistant variants of human malignant cell [62].

\subsection{The Mechanistic Approach to Treat Cancer Using TQ Drug Molecule}

The pharmacological effects of TQ on different cell lines and animal models demonstrated substantial antineoplastic activities in numerous cancers, including breast, prostate, brain, pancreas, gastric, colon, bladder, lungs, bone, cervical, and many more [63]. Mechanistically, it can suppress various properties, including multiplication in cancer cells, apoptosis, activation of detoxifying enzymes, metastasis, suppression of tumor-angiogenesis invasion, and cell cycle control [64-72].

Kinases are cellular enzyme stimuli, essential for cellular metabolic functions, and their overexpression is closely linked with cancer [73]. TQ effectively targets many phosphoinositides, including 3-kinase (PI3K) [74], mitogen-activated protein kinase (MAPK)/Janus kinase signal transducers and transcription (JAK/STAT) [75,76], polo-like kinase 1 (PLC1) [77] and tyrosine kinase [78].

Responsive and resistive MCF-07 breast cancer cell lines displayed good anticarcinogenic activities with TQ analogs such as caryophyllyl and germacrylic conjugates as well as fatty acid conjugates [79]. The TQ neutralizes oxidative free radicals and ameliorates doxorubicin-induced nephrotoxicity [80]. The carcinogenesis produces eicosanoids, and peroxidizes membrane lipid suppressive activities [81]. Furthermore, TQ displayed a hyperproliferative effect in rats and also abrogated Fe (III) nitrilotriacetic acid (Fe-NTA) induced oxidative stress [63]. TQ reduced Cyclin A, Cyclin B1, Cyclin D1 and Cyclin E [82-85] expression and increased levels of p21 and p53 [86,87]. TQ is capable of decreasing Bcl-2 and increasing cleaved caspase-3, 9, and 7, and Bax proteins, as well as modulating the expression of microRNA (miRNA) and long non-coding RNAs (lncRNA), acetylation/deacetylation of histone along with methylation/demethylation of DNA, resulting in mitochondrial apoptosis induction $[61,63,88,89]$. TQ also halts the PI3K/AKT signaling pathway by upregulating PTEN, thus interfering with GSK-3 $\beta$ activity, enhancing $\beta$-catenin degradation, and decreasing MMP-9 and MMP-2 levels in esophageal cancer cells (Eca109 cells) [83]. MicroRNA-34a (miR-34a) expression is vital to cancer development and metastasis [90], and its expression is reduced by TQ in human metastatic breast cancers (MBC) compared to normal breast tissues [91]. Altogether, microRNA-34a can act as therapy either alone or in combination with $\mathrm{TQ}$, and synergize therapeutic potential [92]. TQ 
exerts antiproliferative activities in cancer cells by modulating the structure of DNA $[93,94]$. TQ synergized pancreatic cancer cells (MIA Paca-2 cells) cytotoxicity along with juglone via ferroptosis, an iron-dependent mechanism [95]. The mechanistic approach of TQ for cancer treatment is depicted in Figure 4 and in vitro and in vivo applications of TQ are reported in Tables 3 and 4, respectively.

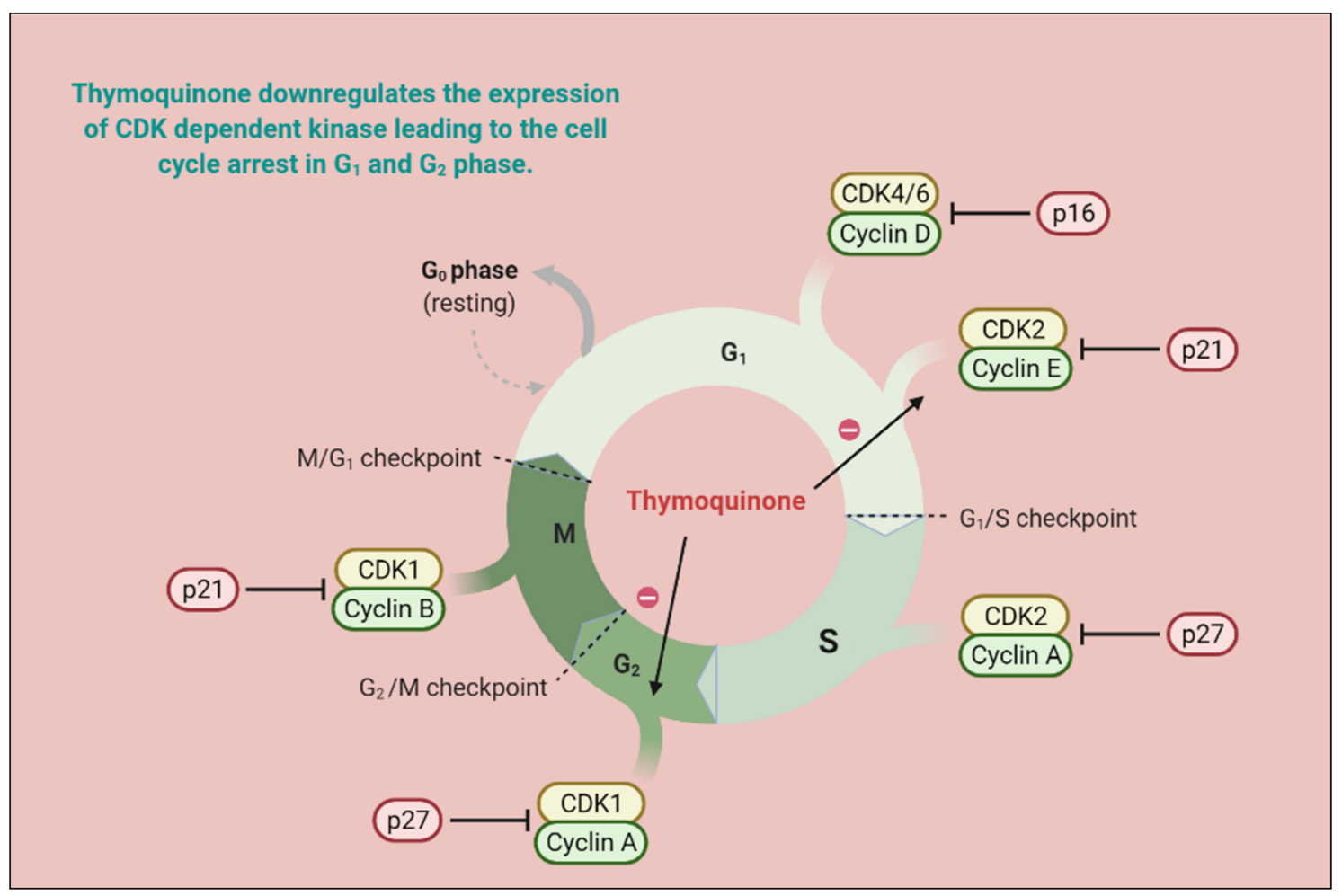

Figure 4. TQ prevents carcinogenic intermediate synthesis by inhibiting the G2/M phase of the cell cycle. It also inhibits ROSmediated DNA damage to prevent tumorigenesis. TQ upregulates pro-apoptotic genes (p21 and p27) and downregulates the anti-apoptotic gene (Bcl-2), thereby arresting the G2/M phase of the cell cycle. (CDK-cyclin-dependent kinases; CYP-cytochrome P; TQ-Thymoquinone).

Table 3. In vitro applications of thymoquinone in the treatment of cancer ( $\downarrow$ : decreases, $\uparrow:$ increase).

\begin{tabular}{|c|c|c|c|c|c|}
\hline S.N & Drug and Dose & Cell Line & Molecular Target & Outcome & Ref. \\
\hline 1 & $\begin{array}{c}\text { TQ } \\
(25-75 \mu \mathrm{M})\end{array}$ & Eca109 cells & $\begin{array}{c}\uparrow \mathrm{p} 21 \text {, and p53 levels; } \downarrow \text { Cyclin } \mathrm{A}, \\
\text { Cyclin B1, and Cyclin E } \\
\text { expression; } \uparrow \beta \text {-catenin } \\
\text { degradation, and } \downarrow \text { MMP- } 2,9 \\
\text { levels; } \downarrow \text { in Bcl- } 2 \text { and } \uparrow \text { caspase- } 3,7 \\
\text { and } 9 \text { cleavages, } \uparrow \text { Bax, } \uparrow \text { PTEN }\end{array}$ & $\begin{array}{l}\text { Induced cell cycle arrest in } \\
\text { the G2/M phase; } \downarrow \text { cell } \\
\text { proliferation and invasion }\end{array}$ & {$[83,96]$} \\
\hline 2 & $\begin{array}{l}\text { TQ }(511.19 \mu \mathrm{M}) \text { and } \\
\text { juglone }(40.90 \mu \mathrm{M})\end{array}$ & $\begin{array}{c}\text { MIA PaCa-2, BXPC-3, } \\
\text { and Panc- }-1 \text { pancreatic } \\
\text { cancer cells }\end{array}$ & Ferroptosis & $\begin{array}{c}\text { Synergism in } \\
\text { anticancer potential }\end{array}$ & [95] \\
\hline 3 & $\mathrm{TQ}(2.5-200 \mu \mathrm{M})$ & C6 rat glioma cells & $\begin{array}{c}\text { Induced DNA damage, apoptosis, } \\
\text { and } \uparrow \text { iROS. } \downarrow \text { GSH; } \uparrow \text { intracellular } \\
\text { calcium level which initiates } \\
\text { apoptosis } \downarrow \text { Bcl- } 2 \text { and pSTAT3; } \\
\uparrow \text { Bax, } \uparrow \text { Caspase-3,9; } \downarrow \text { MMP and } \\
\text { GSH levels }\end{array}$ & $\begin{array}{l}\text { Dose-dependent apoptosis } \\
\text { induction }\end{array}$ & [97] \\
\hline 4 & $\mathrm{TQ}(1-50 \mu \mathrm{M})$ & $\begin{array}{c}\text { MDA-MB-231, } \\
\text { MDA-MB-436, and BT-20 }\end{array}$ & $\begin{array}{c}\downarrow \text { expression of eEF-2K, Src/FAK, } \\
\text { and Akt; } \downarrow \text { NF- } \mathrm{kB} / \mathrm{miR}-603 \\
\text { signaling axis }\end{array}$ & $\begin{array}{c}\text { Dose-dependent } \downarrow \text { cell } \\
\text { proliferation and migration }\end{array}$ & [98] \\
\hline
\end{tabular}


Table 3. Cont.

\begin{tabular}{|c|c|c|c|c|c|}
\hline S.N & Drug and Dose & Cell Line & Molecular Target & Outcome & Ref. \\
\hline 5 & $\begin{array}{l}\text { TQ, artemisinin } \\
\text { hybrids }\end{array}$ & $\begin{array}{l}\text { CCRF-CEM and } \\
\text { Multidrug-Resistant } \\
\text { CEM/ADR500 } \\
\text { Leukemia Cells }\end{array}$ & Specifically inhibit cancer cells & $\begin{array}{l}\text { Low toxicity/high } \\
\text { selectivity profile }\end{array}$ & [99] \\
\hline 6 & $\begin{array}{c}\mathrm{TQ}(5 \mu \mathrm{g} / \mathrm{mL}) \text { and } \\
\text { Emodin }(25 \mu \mathrm{g} / \mathrm{mL})\end{array}$ & $\begin{array}{l}\text { MCF-7, MDA-MB 231, } \\
\text { MDA-MB } 468 \text { and T47D }\end{array}$ & $\begin{array}{c}\uparrow \text { ROS generation; } \downarrow \text { FAK and } \\
\text { Integrins, } \uparrow \text { p53, } \uparrow \text { Bax, and } \\
\uparrow \text { cleaved caspase } 3 \text { expressions; } \\
\downarrow \text { Bcl-2 }\end{array}$ & $\begin{array}{c}\uparrow \text { apoptosis, } \downarrow \text { cell migration, } \\
\text { and } \downarrow \text { stemness efficiently in } \\
\text { breast cancer }\end{array}$ & {$[100]$} \\
\hline 7 & $\begin{array}{l}\text { TQ, TQ+cisplatin } \\
\text { TQ+DOX }\end{array}$ & $\begin{array}{l}\text { HCC HepG2 } \\
\text { and SMMC-7721 } \\
\text { HL-7702 cells }\end{array}$ & $\uparrow \operatorname{ROS}, \uparrow$ caspase 3 & $\begin{array}{c}\uparrow \text { apoptosis and selectively } \\
\downarrow \text { cell viability }\end{array}$ & {$[101]$} \\
\hline 8 & TQ $(2-150 \mu \mathrm{M})$ & A375, B16F10 & $\begin{array}{c}\downarrow \text { NLRP3 (NACHT, LRR, and } \\
\text { pyrin domain-containing protein } \\
3 \text { ); } \downarrow \text { proteolytic cleavage of } \\
\text { caspase- } 1 ; \downarrow \text { IL-1 } \beta \text { and } \downarrow \text { IL-18, } \\
\downarrow \text { NF- } \mathrm{B}, \downarrow \text { ROS }\end{array}$ & $\begin{array}{l}\text { Inactivation of caspase- } 1, \\
\downarrow \text { melanoma cells migration }\end{array}$ & [102] \\
\hline 9 & TQ $20 \mathrm{gm} / \mathrm{kg}$ & HCT116 & $\begin{array}{c}\downarrow \mathrm{CD} 44, \downarrow \text { EpCAM, } \downarrow \text { Ki67, } \uparrow \mathrm{p} 53, \\
\uparrow \mathrm{p} 21, \downarrow \mathrm{PCNA}, \uparrow \mathrm{TUNEL} \text { positivity, } \\
\downarrow \gamma \text {-H2AX }\end{array}$ & $\begin{array}{l}\downarrow \text { viability of 5FU-sensitive } \\
\text { and resistant HCT116 }\end{array}$ & {$[103]$} \\
\hline 10 & DOX, TQ, TQ/DOX & $\begin{array}{l}\text { HepG2, } \\
\text { Huh7 }\end{array}$ & $\begin{array}{l}\uparrow \mathrm{miR}-16 \text { and } \mathrm{miR}-375 \text {, } \\
\uparrow \text { caspase } 3 ; \downarrow \text { Bcl-2 }\end{array}$ & $\begin{array}{l}\downarrow \text { apoptosis; } \\
\downarrow \text { cell viability }\end{array}$ & [104] \\
\hline 11 & $\begin{array}{l}\text { TQ, cisplatin, } \\
\text { geraniol }\end{array}$ & MCF-7 & $\begin{array}{c}\uparrow S O D, \downarrow \text { myeloperoxidase, } \downarrow \text { lipid } \\
\text { peroxidation; } \downarrow \text {-isoprostane } \\
\text { levels }\end{array}$ & $\downarrow$ cisplatin neurotoxicity & {$[105]$} \\
\hline 12 & $\mathrm{TQ}(8 \mu \mathrm{M})$ & HEp-2 & $\begin{array}{l}\downarrow \mathrm{MMP} ; \downarrow \text { mitochondrial } \\
\text { cytochrome c release }\end{array}$ & $\uparrow$ apoptosis of tumor cells & {$[106]$} \\
\hline 13 & $\begin{array}{c}\text { TQ }(20 \mathrm{mM} \text { or } 40 \\
\mathrm{mM})\end{array}$ & $\begin{array}{l}\text { Human glioblastoma } \\
\text { cells T98G and U87MG, } \\
\text { Gli36DEGFR }\end{array}$ & $\begin{array}{c}\text { 个recruitment and accumulation of } \\
\text { the microtubule-associated } \\
\text { protein light chain 3-II (LC3-II); } \\
\text { accumulation of the } \\
\text { LC3-associated protein p62 }\end{array}$ & $\begin{array}{l}\text { } \text { autophagy and induces } \\
\text { cathepsin-mediated, } \\
\text { caspase-independent cell } \\
\text { death }\end{array}$ & [107] \\
\hline 14 & TQ (10-40 mM)) & HaCaT, HEK001 HeLa & $\begin{array}{c}\uparrow G S N \text { levels, } \uparrow \text { p27, } \uparrow \text { cleaved } \\
\text { PARP; } \uparrow \text { UHRF1 by HPV E6/E7 } \\
\text { causes GSN silencing }\end{array}$ & $\begin{array}{l}\text { } \text { apoptosis and cell cycle } \\
\text { arrest in early stage }\end{array}$ & {$[108]$} \\
\hline 15 & $\begin{array}{l}\text { Indirubin-3- } \\
\text { monoxime and } \\
\text { TQ }\end{array}$ & A549 & 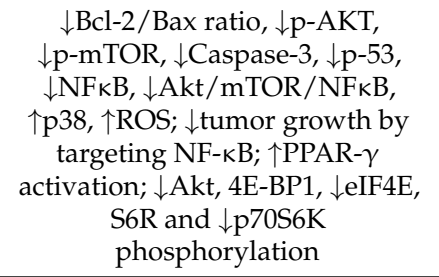 & $\begin{array}{c}\downarrow \text { metastasis, } \uparrow \text { cell cycle arrest; } \\
\downarrow \text { tumor growth }\end{array}$ & {$[85,109]$} \\
\hline 16 & $\mathrm{TQ}(5 \mu \mathrm{M}-10 \mu \mathrm{M})$ & $\begin{array}{l}\text { clone E6-1, HL-60, } \\
\text { K-562 }\end{array}$ & $\begin{array}{c}\uparrow \text { thymine glycol metabolite; } \\
\text { induce DNA damage; } \downarrow \text { guanine } \\
\text { levels }\end{array}$ & $\uparrow$ antiproliferation, $\uparrow$ apoptosis & {$[110]$} \\
\hline 17 & TQ $(10 \mu \mathrm{M})$ & $\begin{array}{l}\text { OVCA429, SKOV3, } \\
\text { HeyA8, OVCAR3, } \\
\text { OVCAR8 }\end{array}$ & $\begin{array}{c}\downarrow \mathrm{JNK}, \downarrow \text { Src }, \downarrow \text { FAK are involved in } \\
\text { LPA-induced invasive cell } \\
\text { migration }\end{array}$ & $\begin{array}{c}\downarrow \text { migration of cancer cells in a } \\
\text { dose-dependent manner }\end{array}$ & {$[111]$} \\
\hline 18 & TQ $(20-40 \mu \mathrm{mol} / \mathrm{L})$ & T24, 253J SV-HUC-1 & $\begin{array}{l}\downarrow \text { activation of Wnt } / \beta \text {-catenin } \\
\text { signaling pathway, } \uparrow \text { E-cadherin, } \\
\text { and } \downarrow N \text {-cadherin, } \downarrow \text { vimentin, } \\
\downarrow \text { MYC, } \downarrow \text { Axin- } 2, \downarrow \text { MMP7, } \\
\downarrow \text { CyclinD1, } \downarrow \beta \text {-catenin }\end{array}$ & $\begin{array}{l}\downarrow \text { epithelial-mesenchymal } \\
\text { transition in bladder cancer } \\
\text { cells }\end{array}$ & [112] \\
\hline 19 & $\begin{array}{c}\text { TQ }(5 \mu \mathrm{M}) \text { and } \\
\text { alpha-hederin }(50 \\
\mu \mathrm{M})\end{array}$ & PC3, НТ-29, НСТ116 & Zinc level modulations & Dose-dependent cytotoxicity & {$[113]$} \\
\hline 20 & TQ $(1-100 \mu \mathrm{M})$ & 786-O cells & $\begin{array}{c}\uparrow \text { sub-G1 population and \% of } \\
\text { apoptotic cells. } \downarrow \text { collective } \\
\text { migration }\end{array}$ & $\begin{array}{c}\text { Induces dose and } \\
\text { time-dependent cytotoxicity, } \\
\downarrow \text { invasive potential }\end{array}$ & {$[114]$} \\
\hline
\end{tabular}


Table 3. Cont.

\begin{tabular}{|c|c|c|c|c|c|}
\hline S.N & Drug and Dose & Cell Line & Molecular Target & Outcome & Ref. \\
\hline 21 & TQ and paclitaxel & MCF-7, T47D & $\begin{array}{c}\uparrow \text { Pre-G phase cells, } \downarrow \text { TWIST-1 } \\
\text { gene, and } \uparrow \text { SNAIL- } 1, \uparrow \text { SNAIL-2 } \\
\text { genes. }\end{array}$ & $\begin{array}{l}\downarrow \text { paclitaxel resistance, } \\
\uparrow \text { apoptosis, } \uparrow \text { necrosis, }\end{array}$ & [115] \\
\hline 22 & $\begin{array}{c}\text { TQ }(50 \mu \mathrm{M}), \text { Cur } \\
(15 \mu \mathrm{M}), \\
\text { Caff }(10 \mathrm{mM}), \text { DOX }\end{array}$ & HCT116, MCF7 & $\begin{array}{l}\downarrow \text { bromodeoxyuridine } \\
\text { incorporation, } \uparrow \text { accumulation of } \\
\text { senescence-associated } \\
\beta \text {-galactosidase (SA- } \beta \text {-gal), } \uparrow \text { cell } \\
\text { cycle arrest, and } \uparrow \mathrm{p} 53, \uparrow \mathrm{P} \text {-p } 53, \\
\text { and } \uparrow \mathrm{p} 21 \text { proteins }\end{array}$ & $\begin{array}{l}\uparrow \text { DOX sensitivity and } \\
\text { apoptosis towards } \\
\text { proliferative cells }\end{array}$ & [116] \\
\hline 23 & TQ & MDA-MB-231 & $\begin{aligned} \downarrow \text { Beclin- } 1, & \downarrow \text { VEGF, } \downarrow \text { Integrin- } \beta 1, \\
& \downarrow \text { MMP- } 2,9\end{aligned}$ & $\begin{array}{c}\downarrow \text { proliferation and migration, } \\
\downarrow \text { Autophagy, } \downarrow \text { colony } \\
\text { formation }\end{array}$ & [117] \\
\hline 24 & TQ & $\begin{array}{l}\text { DU-145, PC-3, } \\
\text { LNCaP }\end{array}$ & $\begin{aligned} \downarrow \mathrm{p}-\mathrm{Akt}, & \downarrow \mathrm{NF}-\mathrm{kB} \downarrow \mathrm{MMP}-3, \\
& \downarrow \mathrm{MMP}-7\end{aligned}$ & $\begin{array}{l}\downarrow \text { IL-7-induced tumor } \\
\text { progression and metastatic } \\
\text { invasion in PC-3 cells }\end{array}$ & [118] \\
\hline
\end{tabular}

$\downarrow$ sphingosine-1-phosphate (S1P),

$\downarrow$ ceramide-1-phosphate (C1P),

$\downarrow N F-\kappa B 1$ mRNA, $\downarrow N F-\kappa B, \downarrow$ p $65 \quad \uparrow$ ceramide accumulation and protein levels, $\uparrow$ neutral ER stress in conjunction with

sphingomyelinase (N-SMase) $\quad \downarrow S 1 P, C 1 P$, and NF- $k B$

enzyme activity, $\uparrow$ cellular levels of mediated cell survival

C16-C24 ceramides and $\uparrow$ cleaved $\uparrow$ cancer cell death by

caspase-3; $\uparrow$ glucose-regulated triggering apoptosis

protein 78-kd (GRP78) mRNA

and protein

\begin{tabular}{|c|c|c|c|c|c|}
\hline 26 & $\begin{array}{l}\text { TQ }(10 \mathrm{mM})+\text { Difluo- } \\
\text { romethylornithine } \\
\quad(0.5 \mathrm{mM})\end{array}$ & $\begin{array}{l}\text { T lymphoblastic leukemia } \\
\text { (ALL) Jurkat cell line }\end{array}$ & $\downarrow U H R F 1, \downarrow D N M T 1, \downarrow$ HDAC1 & $\begin{array}{l}\text { Synergism, } \downarrow \text { cancer cell } \\
\text { viability and } \uparrow \text { apoptosis }\end{array}$ & [120] \\
\hline 27 & TQ and Cur & NLF, NB69, SK-N-BE(2) & & $\downarrow$ proliferation, $\uparrow$ apoptosis & [121] \\
\hline 28 & $\begin{array}{c}\text { TQ }(50-100 \mu \mathrm{M})+\mathrm{FA} \\
(450 \mu \mathrm{M})\end{array}$ & MDA-MB 231 & $\downarrow \mathrm{PI}_{3} \mathrm{~K} / \mathrm{Akt}$ pathway & $\begin{array}{l}\text { Synergism in } \downarrow \text { cancer cell } \\
\text { proliferation }\end{array}$ & [122] \\
\hline 29 & TQ (20-100 $\mu \mathrm{M})$ & C6 glioma cells & $\begin{array}{c}\uparrow \mathrm{H}_{2} \mathrm{O}_{2} \text { generation, } \\
\uparrow \text { microconidial ROS, } \\
\downarrow \text { intracellular GSH level, } \downarrow \text { NF- } \kappa \mathrm{B}, \\
\downarrow \mathrm{PI} 3 \mathrm{~K} \text {, and AKT activation }\end{array}$ & $\begin{array}{l}\uparrow \text { apoptosis, } \downarrow \text { proliferation, } \\
\text { and } \downarrow \text { glioma cell viability }\end{array}$ & [123] \\
\hline 30 & TQ $(20-60 \mu \mathrm{M})$ & $\begin{array}{c}\text { 786-O, } \\
\text { 786-O-SI3, BFTC-909 }\end{array}$ & $\begin{array}{c}\downarrow \text { Nanog, } \downarrow \text { Nestin, } \downarrow \text { Bid, } \uparrow \text { RO } \\
\downarrow \text { CD44, } \downarrow \text { Oct-4, } \downarrow \text { Bcl- } 2, \\
\uparrow \text { cytochrome c, } \downarrow \text { phosphorylation } \\
\text { of mTOR (Ser2448 and 2481) and } \\
\text { AKT (Ser473) }\end{array}$ & $\begin{array}{l}\downarrow \text { the proliferation of renal cell } \\
\text { carcinoma cells via } \\
\text { ROS-induced apoptosis }\end{array}$ & [124] \\
\hline 31 & $\mathrm{TQ}(0.5 \mu \mathrm{M})$ & HeLa cells & $\downarrow$ ROS generation & $\downarrow$ cancer cells proliferation & [125] \\
\hline 32 & $\mathrm{TQ}(1-30 \mu \mathrm{M})$ & A431 cells & $\begin{array}{c}\uparrow \text { intracellular ROS, } \uparrow \text { p53, } \uparrow \text { Bax, } \\
\downarrow \text { Mdm2, } \downarrow \text { Bcl-2, } \downarrow \text { Bcl-xl, } \downarrow \text { STAT3, } \\
\uparrow \text { caspase-9,7 and 3; } \\
\downarrow \text { phosphorylation of the upstream } \\
\text { kinase, } \downarrow \text { Src, } \downarrow \text { cyclin D1, } \downarrow \text { survivin }\end{array}$ & $\begin{array}{l}\uparrow \text { apoptosis, } \downarrow \text { cell viability in } \\
\text { dose-dependent manner }\end{array}$ & {$[126]$} \\
\hline 33 & 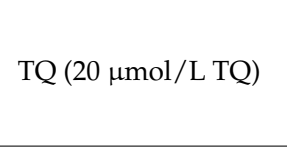 & LoVo & $\begin{array}{c}\uparrow \mathrm{p}-\mathrm{PI} 3 \mathrm{~K}, \downarrow \mathrm{p}-\mathrm{Akt}, \downarrow \mathrm{p}-\mathrm{GSK} 3 \beta, \\
\downarrow \beta \text {-catenin, } \downarrow \text { COX-2 expression; } \\
\downarrow \text { PGE2 levels and the suppression } \\
\text { of EP2 and EP4 activation }\end{array}$ & $\begin{array}{c}\downarrow \text { cancer cell proliferation. } \\
\downarrow \text { cell migration }\end{array}$ & [127] \\
\hline 34 & $\mathrm{TQ}(5 \mu \mathrm{M})$ & A549 & $\begin{array}{c}\uparrow \mathrm{Bax} \text { and } \downarrow \mathrm{Bcl} 2 \text { and } \uparrow \mathrm{Bax} / \mathrm{Bcl} 2 \\
\text { ratio, } \downarrow \text { cyclin D and } \uparrow \mathrm{p} 21, \uparrow \mathrm{TRAIL} \\
\text { receptor } 1 \text { and } 2, \downarrow N F \kappa \mathrm{B}, \downarrow \text { IKK } 1\end{array}$ & $\begin{array}{l}\uparrow \mathrm{G} 2 / \mathrm{M} \text { cell cycle arrest, } \\
\text { } \text { apoptosis }\end{array}$ & [128] \\
\hline 35 & $\mathrm{TQ}+\mathrm{DTX}$ & $\begin{array}{l}\text { DU145, } \\
\text { C4-2B }\end{array}$ & $\begin{array}{c}\downarrow \mathrm{PI} 3 \mathrm{~K} / \mathrm{AKT}, \uparrow \mathrm{BAX} \text { and } \uparrow \mathrm{BID}, \\
\uparrow \text { caspase-3, } \uparrow \mathrm{PARP} \text { and } \downarrow \mathrm{BCL}-\mathrm{XL}\end{array}$ & $\uparrow$ cytotoxicity and $\uparrow$ apoptosis & [129] \\
\hline 36 & $\begin{array}{l}\text { TQ }(10-40 \mu \mathrm{M})+\text { Dox } \\
\quad(50-100 \mathrm{nM})\end{array}$ & $\begin{array}{l}\text { HTLV-1 positive } \\
\text { (HuT-102) and HTLV-1 } \\
\text { negative (Jurkat) CD4+ } \\
\text { malignant T-cell lines }\end{array}$ & $\uparrow$ ROS,$\downarrow$ tumor volume, $\downarrow$ MMP & $\begin{array}{l}\downarrow \text { cell viability, induced } \\
\text { apoptosis }\end{array}$ & [130] \\
\hline
\end{tabular}


Table 3. Cont

\begin{tabular}{|c|c|c|c|c|c|}
\hline S.N & Drug and Dose & Cell Line & Molecular Target & Outcome & Ref. \\
\hline 37 & TQ $(2 \mu \mathrm{M})$, & $\begin{array}{c}\text { Irinotecan-resistant } \\
\text { (CPT-11-R) LoVo colon } \\
\text { cancer cells }\end{array}$ & Activate JNK and P38 and MOMP & $\begin{array}{l}\uparrow \text { the total cell death index } \\
\text { and } \uparrow \text { apoptosis }\end{array}$ & [131] \\
\hline 38 & TQ $(2-100 \mu \mathrm{M})$ & A431 and Hep2 & $\begin{array}{c}\uparrow \mathrm{Bax} / \mathrm{Bcl}-2 \text { ratio, } \downarrow \text { Akt and JNK } \\
\text { phosphorylations }\end{array}$ & $\begin{array}{c}\downarrow \text { tumor volume and mass; } \\
\uparrow \text { apoptosis; } \downarrow \text { cell proliferation }\end{array}$ & [132] \\
\hline 39 & TQ (10-60 mM) & B16-F10 & $\begin{array}{c}\downarrow \text { p-STAT3, p-JAK2 expression, } \\
\text { and p-STAT3, } \uparrow \text { Bax and } \\
\uparrow \text { caspase-3, } \downarrow \text { VEGF-A, } \downarrow \text { MCP- } 1, \\
\downarrow \text { TGF-b1, } \downarrow \text { RANTES, and } \downarrow \text { IL- } 1 \beta\end{array}$ & $\uparrow$ cytotoxicity; $\uparrow$ apoptosis & {$[133]$} \\
\hline 40 & TQ (10 mM) & A549 & $\begin{array}{c}\uparrow \mathrm{Bax} / \mathrm{Bcl}-2, \uparrow \mathrm{p} 53 ; \uparrow \text { caspases-3 } \\
\text { and } 9\end{array}$ & $\downarrow$ cells viability; $\uparrow$ apoptosis & [134] \\
\hline 41 & $5-\mathrm{FU}+\mathrm{TQ}$ & НCT116 & $\begin{array}{c}\downarrow \mathrm{WNT} / \text { B-Catenin and PI3K/AKT, } \\
\text { ß-Catenin }\end{array}$ & $\downarrow$ angiogenesis & [135] \\
\hline 42 & TQ (10 mg/kg) & MDA-MB-231 & $\uparrow$ E-cadherin mRNA expression & $\begin{array}{l}\downarrow \text { proliferation, migration, } \\
\downarrow \text { invasion of cancer cells. }\end{array}$ & [136] \\
\hline 43 & $\begin{array}{l}\text { TQ }(36 \mu \mathrm{g} / \mathrm{mL})+ \\
\text { tylophorine } \\
(88 \mu \mathrm{g} / \mathrm{mL})\end{array}$ & Hela cells & & $\begin{array}{l}\uparrow \text { cell arrest in the } \mathrm{G} 2 / \mathrm{M} \\
\text { phase }\end{array}$ & [137] \\
\hline 44 & $\mathrm{TQ}(20 \mu \mathrm{M})$ & $\begin{array}{c}\text { Jurkat cells, MDAMB-468 } \\
\text { cells }\end{array}$ & $\begin{array}{c}\downarrow \text { UHRF1), } \downarrow \text { DNMT1 G9A, } \\
\downarrow \text { HDAC, DNA methylation and } \\
\text { histone post-translational } \\
\text { modifications }\end{array}$ & $\uparrow$ tumor suppressor genes & {$[64]$} \\
\hline 45 & TQ $(40 \mu \mathrm{M})$ & A498 & $\begin{array}{l}\uparrow \text { Bax, } \downarrow \text { Bcl-2, } \downarrow \text { Akt } \\
\text { phosphorylation }\end{array}$ & $\downarrow$ proliferative, $\uparrow$ apoptosis & [138] \\
\hline 46 & $\mathrm{TQ}(1-10 \mu \mathrm{M})$ & $\begin{array}{l}\text { HEK293 cells, Caki-1, } \\
\text { A498 }\end{array}$ & $\begin{array}{c}\downarrow \text { HIF-1 } \alpha \text {-mediated glycolysis via } \\
\text { ubiquitination-proteasome } \\
\text { dependent pathway }\end{array}$ & $\downarrow$ cancer cell angiogenesis & [139] \\
\hline 47 & TQ $(10-100 \mu \mathrm{M})$ & $\begin{array}{l}\text { HeLa cells } \\
\text { (Cancer) }\end{array}$ & & $\begin{array}{l}\downarrow \text { dose-dependent cellular } \\
\text { viability }\end{array}$ & [140] \\
\hline 48 & $\begin{array}{c}\text { TQ }(0.5 \mathrm{mM})+ \\
\text { cyclophosphamide } \\
(20 \mu \mathrm{M})\end{array}$ & $\begin{array}{l}\text { Her2+SKBR-3 and Her2- } \\
\text { MDA-231 }\end{array}$ & $\begin{array}{c}\downarrow \text { PI3K/ Akt signaling, } \uparrow \text { PTEN, } \\
\downarrow \downarrow \text { cyclin D }\end{array}$ & synergistic cells death & {$[141]$} \\
\hline 49 & $\mathrm{TQ}(0.003 \mathrm{mg} / \mathrm{mL})$ & $\begin{array}{c}\text { HSC-3, HSC-4, oral } \\
\text { fibroblast, HACAT cell } \\
\text { line }\end{array}$ & & $\begin{array}{l}\text { Dose and time-dependent } \\
\text { cytotoxicity }\end{array}$ & [142] \\
\hline 50 & $\mathrm{TQ}(0-80 \mu \mathrm{M})$ & PC3 cell line & 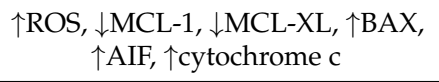 & induced apoptosis & {$[143]$} \\
\hline 51 & TQ & AGS(CRL-1739) cell line & VEGF-A gene expression & induced apoptosis & {$[144]$} \\
\hline 52 & $\mathrm{TQ}$ & KB cells & \activation of PI3K/Akt pathway. & $\begin{array}{l}\downarrow \text { proliferation, } \downarrow \text { migration, } \\
\quad \text { and invasion }\end{array}$ & {$[145]$} \\
\hline 53 & $\mathrm{TQ}(60 \mu \mathrm{mol} / \mathrm{L})$ & 786-O, ACHN & $\uparrow \mathrm{p}-\mathrm{AMPK} w, \downarrow \mathrm{p}-\mathrm{mTOR}, \uparrow \mathrm{p}-\mathrm{S} 6 \mathrm{~K}$ & $\begin{array}{c}\downarrow \text { metastasis, induce } \\
\text { autophagy }\end{array}$ & [146] \\
\hline 54 & TQ+ gemcitabine & MCF-7, T47D & $\downarrow \mathrm{CD} 44^{+} / \mathrm{CD} 24^{-}$cell clone & $\begin{array}{c}\text { Potentiate gemcitabine } \\
\text { efficacy }\end{array}$ & {$[147]$} \\
\hline 55 & TQ $(0.5-20 \mu \mathrm{M})$ & 769-P and 786-O & $\begin{array}{c}\uparrow \text { E-cadherin, } \downarrow \text { Snail, } \downarrow \text { ZEB1 } \\
\text { expression, } \uparrow \text { LKB1 } \\
\text { phosphorylation, } \uparrow \text { AMPK }\end{array}$ & $\downarrow$ metastasis & {$[148]$} \\
\hline 56 & TQ $(40-80 \mu \mathrm{M})$ & $\begin{array}{l}\text { T24 and 253J bladder } \\
\text { cancer cell }\end{array}$ & $\begin{array}{c}\downarrow \text { Bcl-2, } \downarrow \text { Bcl-xl, } \uparrow \text { Bax, } \uparrow \text { release of } \\
\text { cytochrome C and AIF, } \uparrow \text { cleaved } \\
\text { subunits of caspase- } 3,8,7 \text {, and } \\
\text { PARP }\end{array}$ & $\begin{array}{l}\text { Induce proliferation and } \\
\text { apoptosis }\end{array}$ & {$[149]$} \\
\hline 57 & TQ $(20-80 \mu \mathrm{M})$ & $\begin{array}{l}\text { U87MG, U118MG, and } \\
\text { A172 }\end{array}$ & $\begin{array}{c}\uparrow \text { Par- } 4, \uparrow \mathrm{p} 53, \uparrow \mathrm{p} 21, \uparrow \mathrm{Rb}, \downarrow \text { lamin } \\
\mathrm{B} 1, \downarrow \text { cyclin E, } \downarrow \text { cyclin-dependent } \\
\text { kinase-2 (CDK-2) }\end{array}$ & $\downarrow$ Glioblastoma & [150] \\
\hline 58 & $\begin{array}{c}\text { Temozolomide } \\
(100 \mu \mathrm{M})+\mathrm{TQ} \\
(50 \mu \mathrm{M})\end{array}$ & U87MG cell line. & $\downarrow$ MMP 2, $\downarrow$ MMP-9 & $\uparrow$ cytotoxicity, $\downarrow$ cells invasion & {$[151]$} \\
\hline
\end{tabular}


Table 3. Cont.

\begin{tabular}{|c|c|c|c|c|c|}
\hline S.N & Drug and Dose & Cell Line & Molecular Target & Outcome & Ref. \\
\hline 59 & TQ $(1-30 \mu \mathrm{M})$ & $\begin{array}{l}\text { Jurkat, HL60 and HeLa } \\
\text { cell line }\end{array}$ & $\begin{array}{c}\uparrow U H R F 1 \text { degradation, } \uparrow \text { cleaved } \\
\text { caspase- } 3 \text { and } \uparrow p 73\end{array}$ & $\uparrow$ apoptosis & [152] \\
\hline 60 & $\begin{array}{l}\mathrm{TQ}(10 \mathrm{mg} / \mathrm{kg} \\
5-200 \mu \mathrm{M})\end{array}$ & B16, F10 & $\begin{array}{c}\downarrow \mathrm{p} \text {-STAT3, } \uparrow \text { DNA damage, and } \uparrow \\
\text { intracellular ROS }\end{array}$ & $\uparrow$ apoptosis & [153] \\
\hline 61 & $\begin{array}{c}\text { TQ }(20,100 \mathrm{mg} / \mathrm{kg}) \\
\text { IV }\end{array}$ & $\begin{array}{l}\text { MDA-MB-231, } \\
\text { MDA-MB-436, }\end{array}$ & $\begin{array}{c}\downarrow \text { elongation factor } 2 \text { kinase, } \\
\downarrow \text { Src/FAK, } \downarrow \text { Akt, } \uparrow \text { miR-603, } \\
\downarrow \text { NF-kB }\end{array}$ & $\downarrow$ tumor growth & [98] \\
\hline
\end{tabular}

Abbreviations: MMP—-matrix metalloproteinase; STAT3—Signal transducer and activator of transcription-3; PTEN-Phosphatase and tensin homolog; eEF-2K -Eukaryotic elongation factor-2 kinase; NLRP3-NACHT, LRR, and pyrin domain-containing protein 3; ROSreactive oxygen species; DOX-doxorubicin; SOD—Superoxide dismutase; LC-3—light chain 3-II; PPAR- $\gamma$-Peroxisome proliferatoractivated receptor gamma; Ubiquitin-like; containing PHD and RING finger domains-1; p-mTOR-phosphorylated mechanistic target of rapamycin; NFKB-Nuclear factor kappa-light-chain-enhancer of activated B cells; 4E-BP1—Eukaryotic translation initiation factor 4E-binding protein 1; eIF4E-Eukaryotic translation initiation factor 4E; p70S6K-Ribosomal protein S6 kinase beta-1, also known as p70S6K kinase; FAK—focal adhesion kinase; FA—Ferulic Acid; Hes1—hairy and enhancer of split-1; VEGF-Vascular endothelial growth factor; IRAK1 - Interleukin-1 receptor-associated kinase 1; TWIST1-Twist-related protein 1; DNMT1-DNA Methyltransferase 1; HDAC1Histone deacetylase 1; Oct-4—octamer binding transcription factor-4; Nestin—Neuroepithelial stem cell protein; MDM2—Mouse double minute 2 homolog; p-GSK3 $\beta$ Glycogen synthase kinase 3 beta; IKK1-Inhibitor of nuclear factor kappa B; PRAP-prolactin receptor associated protein; MOMP-Mitochondrial outer membrane permeabilization; RANTES—Regulated upon Activation, Normal T Cell Expressed and Presumably Secreted; UHRF1—Ubiquitin-like, containing PHD and RING finger domains, 1; HDAC-Histone deacetylases; BAX-BCL2-Associated X; ZEB1—Zinc Finger E-Box Binding Homeobox 1; LKB1—liver kinase B1; AMPK—AMP-activated protein kinase; AIF-apoptosis-inducing factor; CDK-2—cyclin-dependent kinase-2.

Table 4. In vivo applications of thymoquinone in the treatment of cancer ( $\downarrow$ : decrease, $\uparrow:$ increase).

\begin{tabular}{|c|c|c|c|c|c|}
\hline S.N & Drug and Dose & Animal Model & Molecular Target & Outcome & Ref. \\
\hline 1 & TQ, DOX, and TQ+DOX & Wistar albino rats & $\begin{array}{c}\text { } \text { apoptotic index, caspase } 3 \text {, and } \\
\text { HSP90 expressions in the DOX group }\end{array}$ & $\downarrow$ DOX toxicity & [154] \\
\hline 2 & $\begin{array}{l}\text { Cisplatin+ TQ+ } \\
\quad \text { vitamin E }\end{array}$ & Wistar rats & $\begin{array}{c}\downarrow \text { Catalase, } \downarrow \text { glutathione peroxidase, } \\
\downarrow \text { SOD, and } \downarrow \text { reduced glutathione } \\
\text { levels }\end{array}$ & $\begin{array}{c}\uparrow \text { cisplatin effect, } \downarrow \text { oxidative stress, } \\
\downarrow \text { cisplatin toxicity }\end{array}$ & [155] \\
\hline 2 & TQ $(5-25 \mu \mathrm{M})$ & $\begin{array}{c}\text { LPS/D-galactosamine } \\
\text { induced acute hepatitis and } \\
\mathrm{HCl} / \text { EtOH-induced gastritis } \\
\text { mouse model }\end{array}$ & $\begin{array}{c}\downarrow \text { (AP)-1/NF- } k \text { B pathways, } \downarrow \text { iNOS; } \\
\downarrow \text { NO, } \downarrow \text { TNF- } \alpha ; \downarrow \text { COX-2, } \downarrow \text { IL-6, } \downarrow \text { PGE2, } \\
\downarrow \text { IL- } 1 \beta ; \downarrow \text { IRAK1 }\end{array}$ & $\downarrow$ inflammatory response & {$[156,157]$} \\
\hline 3 & TQ $(1-25 \mu \mathrm{M})$ & $\begin{array}{l}\text { Caki- } 1 \text { cells, xenograft } \\
\text { mouse model }\end{array}$ & $\begin{array}{c}\uparrow \mathrm{p} 53 ; \uparrow \mathrm{Bax} ; \downarrow \mathrm{Bcl}-2 ; \downarrow \mathrm{Bcl}-\mathrm{xl}, \downarrow \text { cyclin D1, } \\
\downarrow \text { cyclin D2, and } \downarrow \text { survivin via } \\
\text { suppression of JAK2 } \\
\text { pathway }\end{array}$ & $\begin{array}{l}\text { Induces apoptosis via } \\
\text { accumulation of ROS, } \downarrow \text { tumor } \\
\text { growth }\end{array}$ & [84] \\
\hline 4 & $\begin{array}{l}\mathrm{TQ}(20 \mathrm{mg} / \mathrm{kg}) \text { and } \\
\text { pentoxifylline } \\
(15 \mathrm{mg} / \mathrm{kg})\end{array}$ & female albino mice & $\begin{array}{c}\downarrow \text { Notch1, } \downarrow \text { Hes } 1, \downarrow \text { Jagged1, } \\
\downarrow \beta \text {-catenin, } \downarrow \text { TNF- } \alpha, \downarrow \text { IL- } 6, \downarrow \text { IFN- } \gamma, \\
\text { and } \downarrow \text { VEGF with } \uparrow \text { in IL- } 2, \uparrow \text { CD } 4, \\
\uparrow \text { CD8, and } \uparrow \text { apoptotic cells }\end{array}$ & $\begin{array}{c}\uparrow \text { chemotherapeutic effect of } \\
\text { cisplatin by targeting Notch } \\
\text { signaling pathway, } \\
\downarrow \text { tumor growth }\end{array}$ & [158] \\
\hline 4 & TQ $50 \mathrm{mg} / \mathrm{kg}$ & Colorectal cancer in SD rats & $\uparrow$ Antioxidant activity & $\begin{array}{c}\text { Protective and preventive } \\
\text { measure in cancer management }\end{array}$ & [159] \\
\hline 5 & TQ (20 mg/kg) & SD rat & $\begin{array}{c}\uparrow \text { TRAIL/TRAILR2, } \uparrow \text { caspase- } 3 \text {, and } \\
\downarrow \text { Bcl-2 downregulation, } \downarrow \text { TGF- } \beta 1 \\
\text { gene expression level. } \uparrow \text { hepatic GSH } \\
\text { level and marked } \downarrow \text { hepatic MDA level, } \\
\downarrow \text { alpha-fetoprotein level }\end{array}$ & $\downarrow$ HCC progression, $\uparrow$ apoptosis & [160] \\
\hline 6 & $20 \mathrm{mg} / \mathrm{kg} \mathrm{BW}$ & $\begin{array}{l}\text { Diethylnitrosamine induced } \\
\text { HCC in rats. }\end{array}$ & $\downarrow$ EGFR/ERK1/2 activation & protective effect against HCC & [161] \\
\hline 7 & TQ & $\begin{array}{l}\text { Hamster oral cancer } \\
\text { Induced by DMBA }\end{array}$ & $\begin{array}{c}\downarrow \mathrm{PI} 3 \mathrm{~K} / \mathrm{AKT} / \mathrm{mTOR} \text { signaling } \\
\text { pathways } \\
\downarrow \\
\downarrow \text { the mRNA expression level of } \\
\text { NF- } \mathrm{\kappa} \text { Bp50/p65 }\end{array}$ & $\uparrow$ chemopreventive activity & [162] \\
\hline 8 & $\begin{array}{l}\mathrm{TQ}(5 \mathrm{mg}), 6-\mathrm{MP} \\
(5 \mathrm{mg} / \mathrm{kg})\end{array}$ & Albino rats & $\begin{array}{l}\uparrow \text { spermatogenesis, } \downarrow \text { P } 53, \downarrow \text { caspase- } 3 \\
\text { apoptotic pathway, } \uparrow \mathrm{PI} 3 \mathrm{~K} ; \downarrow \text { TNF- } \alpha\end{array}$ & $\begin{array}{c}\downarrow 6-\mathrm{MP} \text { induced testicular } \\
\text { damage, } \uparrow \text { its anticancer potential }\end{array}$ & [163] \\
\hline
\end{tabular}

Abbreviations: HSP90-heat shock protein 90; DOX-doxorubicin; SOD—Superoxide dismutase; COX-Cyclooxygenase; IRAK1— interleukin-1 receptor-associated kinase 1; STAT-3-Signal transducer and activator of transcription 3; NOTCH1-Notch homolog 1, translocation-associated (Drosophila); TRAIL_-Tumor necrosis factor-related apoptosis-inducing ligand; ERK1-Extracellular signalregulated kinase 1 ; HCC—hepatocellular carcinoma; TGF- $\beta 1$-Transforming growth factor beta 1 ; PI3K-Phosphoinositides, including 3-kinase; 6-MP -6-mercaptopurine; DMBA — dimethylbenz(a)anthracene. 


\subsection{TQ Nanocarrier for the Treatment of Cancer}

Many drugs do not reach the antineoplastic drug pipeline because of low aqueous solubility, high toxicity, large doses, and shorter half-life. Nanoformualtions provide opportunities to improve the pharmacokinetics of these drugs for precise treatment at the molecular level with reduced off-target effect $[164,165]$. The tumor tissues that exhibit enhanced permeability and retention (EPR) and hypoxia-like properties could be utilized for targeted drug delivery. The NPs take advantage of the EPR effect and accumulate in the cancer cells, providing maximum therapeutic efficacy with minimum off-target effect [166]. The nanoformulations, including polymeric (natural/synthetic), lipidic (liposomes, niosomes, ethosomes, cubosomes, solid lipid nanoparticles (SLN), nanoemulsion, and microemulsion), pretentious (bovine serum albumin, human serum albumin) and metallic (silver, gold, iron, etc.), in combination with surface modification, are utilized for targeted delivery of therapeutic drugs in tumor sites [167,168]. NPs deliver drugs at the selective tumor site utilizing multiple approaches, including passive targeting and active targeting. Some of them are explained in the following sections to deliver TQ at the target site. Applications of TQ nanocarriers and surface-modified TQ nanocarriers for the management of cancer and inflammation are reported in Tables 5 and 6, respectively. Moreover, therapeutic importance of TQ-loaded nanoparticulate-based therapies for RA management is also reported in Table 5 with comparison to the conventional formulations and pure TQ.

\subsubsection{Passive Targeting Approach in Cancer Drug Delivery \\ Passive Targeting Utilizes the Tumor Microenvironment for Drug Delivery}

Tumor vasculature is different from normal cell vasculature. Blood vessels of cancer tissue have comparatively larger fenestration with poor lymphatic drainage system, which results in enhanced retention and permeation of the nano-sized particulate matter [169]. Based on the delivery site, the size and surface of the NPs can be modulated. NPs' size and surface architecture modulation also avoid reticuloendothelial system (RES) uptake and make it circulate for a long period of time. This could be explored in passive drug delivery. Various strategies depicting passive targeting of TQ via nanoparticles are reported in Figure 5.

\section{Passive Targeting through Long-Circulating Nanocarriers}

Chitosan-grafted lipid nanocapsules [170] and PEGylated liposomes [171] were reported for the co-delivery of TQ and docetaxel (DTX) against drug-resistant breast cancer. Chitosan grafting improved cellular uptake and escaped endosomal effect; PEGylation increased circulation time of the dual payload [172], resulting in increased cytotoxicity against triple-negative breast cancer (TNBC) cells (MDA-MB-231 and MCF-7). A longcirculating PEGylated vitamin E lipidic nanocapsule loaded with TQ and DTX was also investigated against resistant breast cancer cells (MCF-7 and MDA-MB-231) [173]. PEGylation in vitamin E lipidic nanocapsules inhibits p-glycoprotein efflux, re-sensitizes the resistant TNBC cells and provides enhanced antimetastatic effects with reduced multiple side effects. Co-encapsulation of TQ with DTX improved loading efficiency into PEGylated liposomes and vitamin E lipidic nanocapsules as well as the chemosensitivity of DTX against breast cancer cells (MCF7 and MDA-MB-231).

PLGA-PEG-Pluronic TQ NPs were designed for sustained delivery of TQ into tamoxifenresistant breast cancer cells (UACC 732, MCF-7) [174]. TQ-NPs reduce the dose and synergize tamoxifen chemoprevention potential with selective tumor cell toxicity. PEGylated LMW chitosan nanocapsules selectively deliver TQ into cancer cells (MCF 7 cells) [175] as chitosan (with pKa 6-6.5) solubilizes in the inter, as well as intracellular acidic microenvironment of cancer cells, thereby delivering $\mathrm{TQ}$ in a targeted manner. 


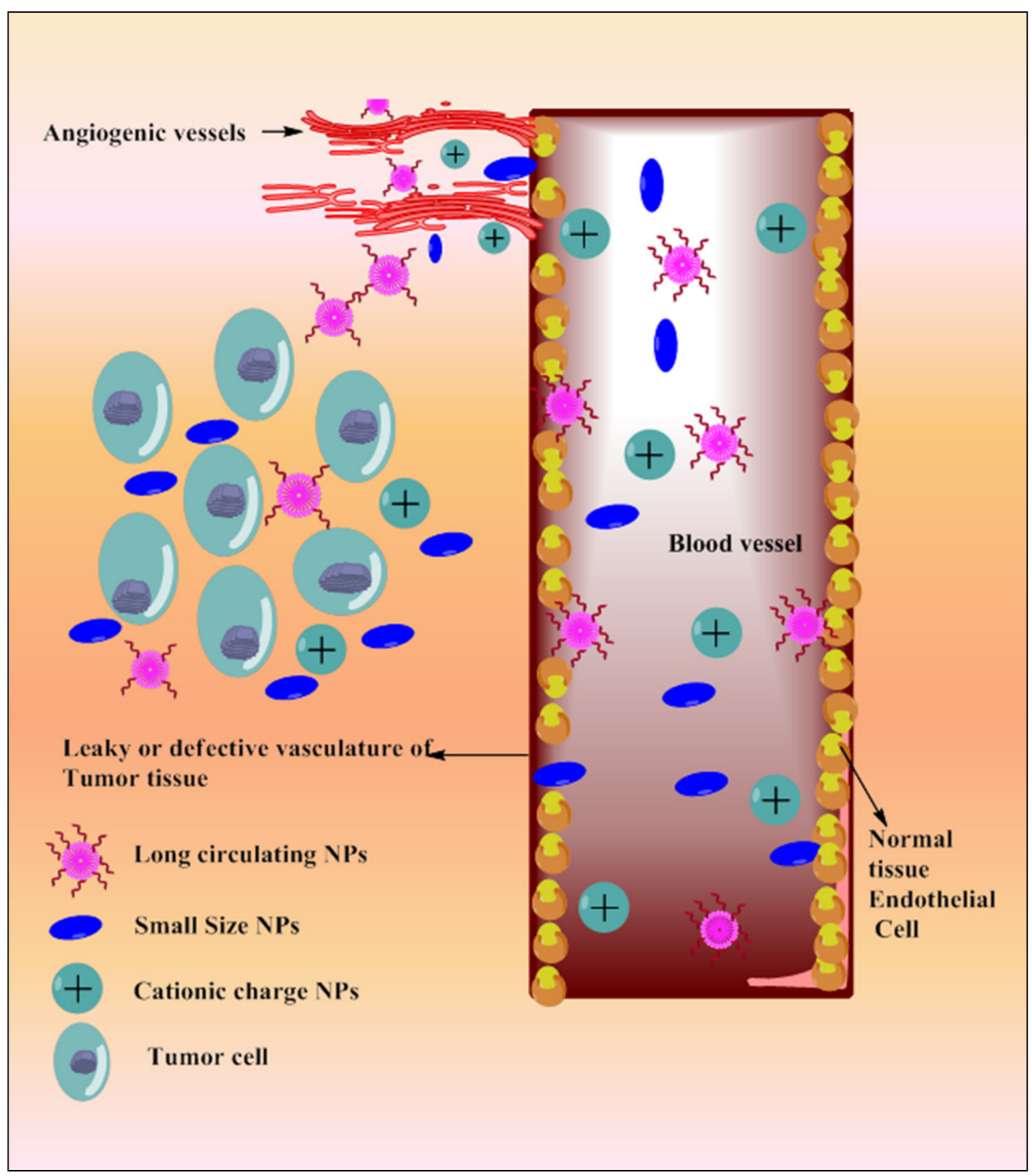

Figure 5. Systemic diagram depicting diverse approaches intended for passive targeting of TQ via nanoparticles.

Passive Targeting through Surface Charge and Size of NPs

Nanocarriers overcome TQ pharmacokinetics issues and deliver it at the specific site with enhanced efficacy. A co-liposphere of Cabazitaxel (CBZ) and TQ was made of vitamin E-TPGS tricaprin, and egg phosphatidylcholine improved cellular internalization, which potentiates dose-dependent apoptosis as well as anticancer efficacy against MDA-MB-231 and MCF-7 cell lines [176]. The poly-L-lysine (PLL) and polyethylene glycol surfacedecorated nanocontainers (NC-PLL) complex of diethylaminoethyl dextran/xanthan gum enhanced intracellular accumulation of TQ [177]. The positive surface charge of the NCPLL significantly favored nanocontainer binding on the negatively charged cell membrane as compared to nonmodified nanocontainers, resulting in negatively charged NC-PEG. NC-PLL dominated in terms of cytotoxic efficacy, as investigated in MCF-7, likely due to enhanced accumulation in cancer cells.

Mesoporous silica NPs (TQ-MSNPs) improved TQ aqueous solubility and photostability as well as reduced the therapeutic dose (8-fold), which delayed cell migration and enhanced cytotoxic and apoptotic potential, as evaluated in the MCF-7 and HeLa cell lines [178]. The core-shell NPs of mesoporous silica delivered TQ to glioma cells selectively, which triggered cytochrome $\mathrm{c}$, increased caspase- 3 activation, and cell cycle arrest at the G2/M phase [179]. Chitosan-coated PLGA NPs containing TQ enhanced cytotoxic potential when compared with surface-decorated TQ-poly(lactic co-glycolic acid) NPs and TQ alone; this was investigated through the MDA-MB-231 and MCF-7 cell lines [180]. The 
antimetastatic potential of TQ was enhanced by chitosan nanoparticles against HepG2 cell lines through longer duration inhibitory actions when compared with free TQ [181]. TQNLC-NPs accumulated in cancer cells and inhibited their proliferation through time and dose-dependent modulation in the cellular morphology, as investigated in HepG2 cancer cells [182]. The polymeric NPs of methoxy poly(ethylene glycol)-b-poly(-caprolactone) improved the systemic bioavailability of TQ (1.3-fold) with slower elimination rates, which provides greater antiproliferative efficacy against varieties of pure cell cultures of human carcinoma (PANC-1, MCF-7, and Caco-2) [78,183]. The nanoarchitecture of polymeric shells increased TQ solubility, intestinal absorption, and bioavailability rates, resulting in higher cancer cell selectivity compared to free TQ. A soy phytosomal formulation of TQ with a dual release pattern (initial burst followed by prolonged release) revealed excellent anticancer activity against a lung cancer cell line (A539) [184]. The sustained release of TQ from phytosome accumulates TQ in the G2-M and pre-G1 phases of cancer cells, which initiate dose-dependent apoptosis and cell necrosis activities via caspase-3 activation. A Soluplus ${ }^{\circledR}$-Solutol ${ }^{\circledR}$ HS15 micelles formulation enhanced the antimigratory efficacy of TQ $(1.5-10 \mu \mathrm{M})$ through improving aqueous solubility (10 times) and encapsulation efficacy, as investigated in SH-SY5Y human neuroblastoma cells [185]. The synergistic potential of TQ loaded in cockle-shell-derived aragonite $\mathrm{CaCl}_{3}-\mathrm{NPs}$ was reported with doxorubicin to reduce cellular migration in mammary gland carcinoma stem cells (MDA MB 231) [186]. A cubosomal formulation of TQ improved cellular accumulation, which leads to increased apoptotic activity migration in mammary gland carcinoma cell lines (MDA-MB-231 and MCF-7) [187]. Chitosan-coated TQ-PLGA-NPs accumulated in melanoma cancer cells (A375) by taking advantage of the EPR effect and positive surface charge of chitosan, which facilitate binding with the negatively charged cell membrane and induce cellular retention as well as time-dependent cytotoxicity [188]. TQ loading into niosomes improved cellular internalizations with controlled release of TQ, which markedly inhibits the migration of pro-inflammatory markers in mammary gland carcinoma with respect to pure TQ [10].

\subsubsection{Active Targeting}

Receptors Based Active Targeting

A variety of surface receptors have been found to be upregulated in certain physiological conditions, including cancer, and are widely utilized for delivery via surface-decorated nanoparticles (NPs). The surface-coated NPs can target those cells which overexpress specific receptors on their surface and because of this, the nanoparticles attach to these [10]. The same is shown in Figure 6. The ligands which are used for surface modification include hyaluronic acid, anisamide, transferrin, folic acid, and many more utilized for active targeting of TQ into cancer. These have been reported in the following sections. This receptor is overexpressed in various types of cancers, including colon, brain, breast, lung, prostate, and kidney $[189,190]$. Anisamide is a benzamide analog, which exhibits a higher affinity towards sigma receptor-expressing cells [191] Anisamide-conjugated polymeric nanocapsules of eudragit-S100 delivered TQ into the colon-specific region through binding with overexpressed colonic sigma receptor [192]. The RNA aptamer, A10-coated planetary ball-milled starch NPs of TQ exclusively delivered drug into docetaxel-resistant prostate cancer cell lines (C4-2B-R and LNCaP-R) through overexpressed prostate-specific membrane antigen and inhibited drug efflux, which improves cancer potential [193]. The PEG and PCL, in the ball-milled NPs, decrease non-specific binding to the cell membrane and allow prolonged circulations. Hyaluronic acid (HA)-decorated Pluronic ${ }^{\circledR}$ NPs of TQ accumulated in TNBC cells through selective binding with overexpressed CD44 receptor of cancer cells [194]. Pluronic-enhanced TQ encapsulation and HA facilitate CD44 targeting and make it have prolonged circulation, which reduced the dose for cell migration by modulating both miR-361/Rac1 and RhoA/actin stress fibers and the miR-361/VEGF-A mechanism that attenuate angiogenesis and metastasis of TNBC cells. Radio-iodinated NPs of folic acid-chitosan specifically bind to overexpressed folate receptors of human ovarian cancer cells (SKOV3) and improve anticancer efficacy through improved cellular 
internalization and retention [195]. A PEGylated-PLGA-TQ-NP surface decorated with transferrin potentiated anticancer efficacy of TQ through specific binding with the overexpressed transferring receptor on tumor cells, which decreases dose and improved cellular accumulations of NPs through EPR, as investigated in lung carcinoma A549 cells [196]. The as1411-conjugated nanodroplets delivered TQ into cancer cells through specific binding with overexpressed nucleolin on the cancer cells surface as investigated in MDA-MB-231 cells [197]. The as1411-conjugation facilitates rapid cellular uptake and dose-dependent cytotoxicity via nucleolin-stimulated Rac1 activation [198].

$\mathrm{PI} 3 \mathrm{~K} /$ Akt activation in cancer cells leads to resistance to traditional chemotherapeutics [199]. $\mathrm{pH}$-sensitive gold niosomes of TQ along with Akt-siRNA were utilized to deliver TQ into tamoxifen-resistant breast cancer cells as well as knockdown of Aktoverexpression $[96,200]$. These niosomes resensitized cancer cells to TQ through Akt silencing and enhanced apoptosis by inhibiting MDM2 expression as well as inducing p53 [200].

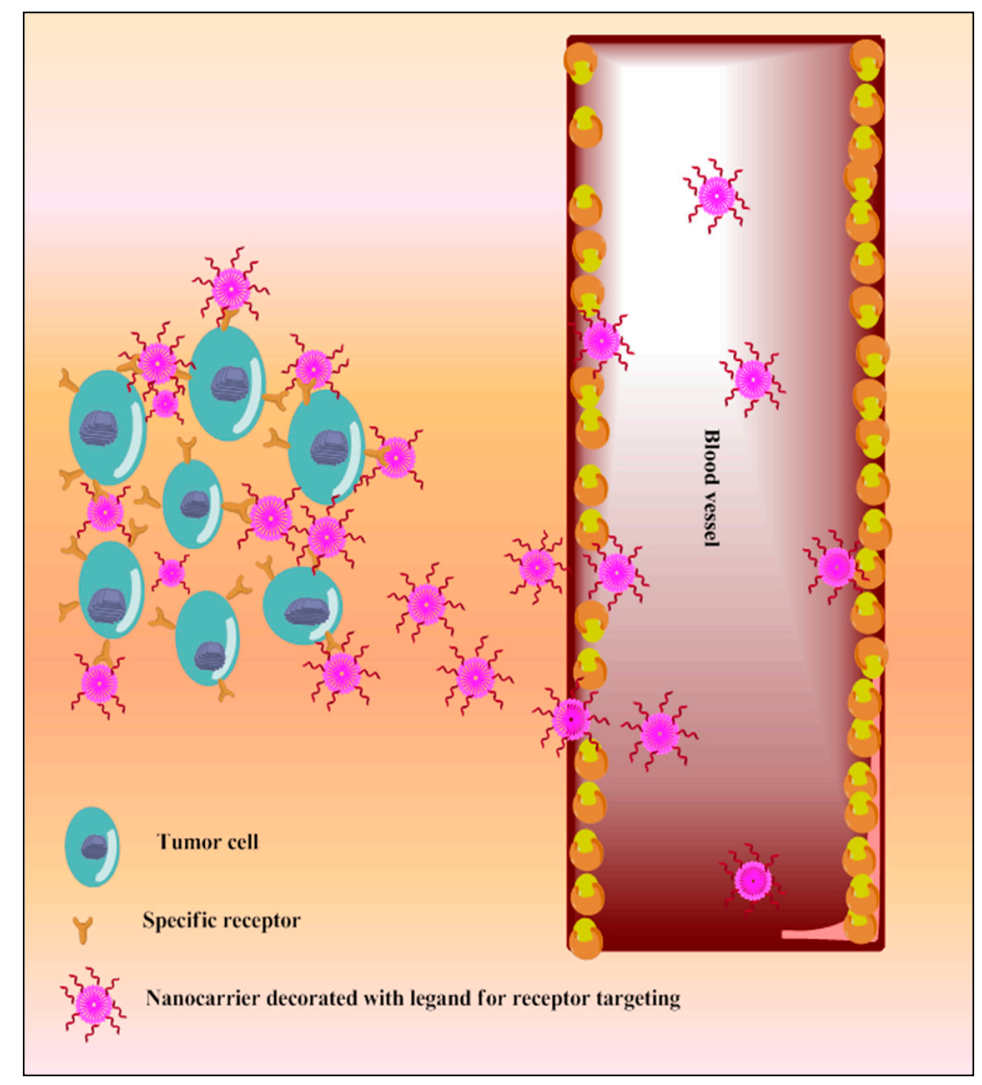

Figure 6. Schematic diagram of TQ nanocarriers for receptor-based active targeting.

Stimulus-Responsive NPs for Active Targeting

Designing stimuli-responsive NPs for active targeted drug delivery is dependent upon tumor microenvironments such as $\mathrm{pH}$, hyperthermia, catalytic enzymes, or external stimuli such as pressure, ultrasonication, or magnetic field. The stimuli-responsive NPs retain their physicochemical properties, including structure, during their circulation. They are stimulated upon exposure to small changes in the tumor microenvironment or external stimuli and undergo rapid changes (aggregation, permeability, and disruption) to release the encapsulated drug. Various TQ-loaded stimuli-responsive NPs with enhanced anticancer potentials have been discussed in the following sections. A TQ-loaded $\mathrm{Fe}_{3} \mathrm{SO}_{4} \mathrm{NPs}$ surface decorated with ethylene glycol and polyvinylpyrrolidone (PVP) pH-dependently delivered TQ in TNBC cells (MDA-MB-231) [201]. PVP surface decoration improved water solubility and delivered drugs in the acidic environment, which maximized tumoricidal efficiency. 
Eudragit L-100-coated nanoconjugates of chitosan, HPMC, and PVA pH dependently delivered TQ into the colon for cancer management [202]. This study finds that at $\mathrm{pH}$ 7 concentration, eudragit L-100 dissolves and chitosan becomes degraded by anaerobic bacteria. The bacterial fermentation end-product butyrate forms polysaccharides with anticancer potential; TQ is released with butyrate and reaches into cancer cells, showing higher cytotoxicity. A technetium-99m $\left({ }^{99 \mathrm{~m}} \mathrm{Tc}\right.$ )-labeled TQ formulation was designed for theranostic application against skeletal muscle malignancy (rhabdomyosarcoma) [203] The ${ }^{99 \mathrm{~m}} \mathrm{TC}$ with TQ synergizes anticancer potential through rapid internalization and slower externalization, which enhanced theranostic applications. A fluorescent liposome co-delivered TQ and curcumin into lung cancer cells (A549) and potentially inhibited cellular proliferation compared with TQ or curcumin alone or the lipidic formulation of either of them, probably due to improved internalization [204]. A TQ-capped magnetic nanoparticle of iron oxide improved endocytotic internalization in breast cancer cells (MDA-MB-231 cells) and displayed a potent synergistic chemo-photothermal effect compared with free TQ [205]. Guar gum microvehicles rapidly release TQ in the intracellular acidic environment of cancer cells ( $\mathrm{pH} \sim 5.5)$ compared to physiological $\mathrm{pH}(\sim 7.4)$, due to breakdown of the interlinking bonds in an acidic environment, leading to prolonged TQ release, with synergistic anticancer activity, as investigated in HepG2 cell line [206].

Table 5. TQ nanocarrier in the management of cancer and inflammation ( $\downarrow$ : decrease, $\uparrow:$ increase).

\begin{tabular}{|c|c|c|c|c|}
\hline S.N & Formulations & Animal Model/Cell Line & Major Finding & Ref. \\
\hline 1 & $\begin{array}{l}\text { Core-shell NPs of } \\
\text { mesoporous silica }\end{array}$ & $\begin{array}{l}\text { SW1088, A172, } \\
\text { HCN2 }\end{array}$ & $\begin{array}{l}\mathrm{pH} \text { driven TQ release in tumor } \\
\text { acidic environment } \uparrow \text { cell } \\
\text { cycle arrest }\end{array}$ & [179] \\
\hline 2 & $\begin{array}{c}\text { Docetaxel (DTX) and TQ in borage } \\
\text { oil-based nanoemulsion }\end{array}$ & $\begin{array}{c}\text { MCF-7 } \\
\text { MDA-MB-231 }\end{array}$ & $\begin{array}{l}\uparrow \mathrm{DTX} \text { anticancer potential; } \downarrow \text { dose, } \\
\uparrow \text { apoptosis }\end{array}$ & [207] \\
\hline 3 & $\begin{array}{l}\text { TQ-loaded Soluplus-Solutol HS15 } \\
\text { mixed micelles } 2\end{array}$ & SH-SY5Y & $\begin{array}{c}\uparrow \text { solubility (10-fold), } \\
\uparrow \text { neuroblastoma cell migration }\end{array}$ & [185] \\
\hline 4 & $\begin{array}{l}\text { TQ- Chitosan NPs } \\
(12.5-200 \mu \mathrm{g} / \mathrm{mL})\end{array}$ & HepG2 & $\begin{array}{c}\downarrow \text { cancer cells proliferation, } \\
\uparrow \text { antimetastasis }\end{array}$ & [181] \\
\hline 5 & $\begin{array}{l}\text { TQ-loaded methoxy poly } \\
\text { (ethylene glycol)-b-poly(“- } \\
\text { caprolactone-NPs }\end{array}$ & $\begin{array}{c}\text { MCF-7, } \\
\text { PANC-1, Caco-2 } \\
\text { Balb/c mice }\end{array}$ & $\begin{array}{l}\uparrow \text { oral BA (1.3-fold), } \uparrow \text { Solubility, } \\
\uparrow \text { cancer cells selectivity }\end{array}$ & [183] \\
\hline 6 & TQ loaded Soy phytosomes & A549 & $\begin{array}{l}\text { Improved release pattern; } \uparrow \text { the } \\
\text { dose-dependent anticancer effect, } \\
\text { †apoptotic induction }\end{array}$ & [184] \\
\hline 7 & $\begin{array}{l}\text { TQ-capped iron oxide NPs } \\
\text { (TQ-IONPs) }\end{array}$ & MDA-MB-231 & $\begin{array}{c}\uparrow \mathrm{BA} \text {; } \uparrow \text { cellular uptake of } \\
\text { TQ-IONPs; synergize the } \\
\text { chemo-photothermal effect }\end{array}$ & [205] \\
\hline 8 & $\begin{array}{l}\text { TQ loaded radio-iodinated folic } \\
\text { acid-chitosan NPs }\end{array}$ & $\begin{array}{l}\text { SKOV-3 } \\
\text { Caco-2 }\end{array}$ & $\begin{array}{l}\text { Folate receptor-mediated NPs } \\
\quad \uparrow \text { cellular internalization, } \\
\uparrow \text { targeting to ovarian cancer cell }\end{array}$ & [195] \\
\hline 9 & $\begin{array}{l}\text { TQ loaded technetium-99m based } \\
\text { NPs ( }{ }^{99 m} \text { Tc-TQ-NPs) }\end{array}$ & $\begin{array}{l}\text { Rhabdo-myosarcoma } \\
\text { cancer cells line }\end{array}$ & $\begin{array}{l}\uparrow \text { internalization and } \\
\downarrow \text { externalization of } \\
\text { radiopharmaceuticals; } \\
\uparrow \text { anticancer potential }\end{array}$ & [203] \\
\hline 10 & $\begin{array}{c}\text { Cockle-shell-derived aragonite } \\
\mathrm{CaCl}_{3} \mathrm{NPs} \text { for co-delivery of DOX } \\
\text { and TQ }\end{array}$ & MBA MD231 3D & $\begin{array}{c}\text { Co-delivery } \downarrow \text { cellular migration } \\
\text { and invasion, }\end{array}$ & [186] \\
\hline 11 & $\begin{array}{l}\text { Glyceryl monooleate, cubosome } \\
\text { for TQ delivery }\end{array}$ & $\begin{array}{c}\text { MCF-7 } \\
\text { MDA-MB-231 }\end{array}$ & $\begin{array}{c}\uparrow \text { cytoplasmic accumulation; } \\
\downarrow \text { cancer cells viability; } \uparrow \text { antitumor } \\
\text { activity, } \uparrow \text { apoptosis }\end{array}$ & [187] \\
\hline
\end{tabular}


Table 5. Cont.

\begin{tabular}{|c|c|c|c|c|}
\hline S.N & Formulations & Animal Model/Cell Line & Major Finding & Ref. \\
\hline 12 & PLGA-PEG-Pluronic-TQ-NPs & $\begin{array}{c}\text { Tamoxifen resistant breast } \\
\text { cancer cells UACC 732, } \\
\text { MCF-7 }\end{array}$ & $\begin{array}{c}\uparrow E E \text {, sustained release, } \uparrow \text { targeted } \\
\text { delivery, selective cytotoxicity to } \\
\text { UACC } 732\end{array}$ & [174] \\
\hline 13 & $\begin{array}{l}\text { Vitamin-E-TPGS lipospheres for } \\
\text { codelivery of cabazitaxel and TQ }\end{array}$ & $\begin{array}{c}\text { MCF-7 } \\
\text { MDA-MB-231 }\end{array}$ & $\begin{array}{l}\uparrow c e l l u l a r \text { internalization } \\
\uparrow \text { anticancer potential, }\end{array}$ & [176] \\
\hline 14 & $\begin{array}{c}\text { Chitosan grafted lipidic } \\
\text { nanocapsules for co-delivery of } \\
\text { DTX and TQ }\end{array}$ & $\begin{array}{l}\text { TNBC } \\
\text { MCF-7 }\end{array}$ & $\begin{array}{c}\uparrow \text { intracellular dual drug payload, } \\
\text { escape endosomal effect, } \\
\uparrow \text { anti-angiogenic effect, } \\
\uparrow \text { cytotoxicity }\end{array}$ & [170] \\
\hline 15 & $\begin{array}{l}\text { Carum- and TQ loaded niosomes } \\
\text { for target breast cancer cells }\end{array}$ & $\begin{array}{l}\text { MCF-7, } \\
\text { CaSki, } \\
\text { SiHa }\end{array}$ & $\begin{array}{c}\uparrow \text { solubility, } \uparrow \mathrm{BA} \text { and } \uparrow \text { permeability, } \\
\downarrow \text { Cell Migration, } \uparrow \text { cytotoxicity }\end{array}$ & [10] \\
\hline 16 & $\begin{array}{l}\text { TQ and Cur loaded fluorescent } \\
\text { liposomes }\end{array}$ & A549 & $\begin{array}{c}\uparrow \text { cellular internalization } \\
\downarrow \text { cellular proliferation, } \\
\uparrow \text { cancer cells cytotoxicity }\end{array}$ & [204] \\
\hline 17 & TQ loaded mesoporous silica NPs & $\begin{array}{l}\text { HeLa } \\
\text { MCF-7 }\end{array}$ & $\begin{array}{c}\downarrow \text { effective dose (8-fold), } \\
\uparrow \text { aqueous solubility, } \\
\uparrow \text { cellular internalization } \\
\downarrow \text { cell migration, } \\
\uparrow \text { cytotoxicity, } \uparrow \text { apoptosis }\end{array}$ & [178] \\
\hline 18 & TQ-NLC & $\begin{array}{l}\text { HepG2 } \\
\text { 3T3 }\end{array}$ & $\begin{array}{l}\uparrow \text { cellular accumulation driven by } \\
\text { time and dose; modulate cellular } \\
\text { morphology, } \uparrow \text { anticancer potential }\end{array}$ & [182] \\
\hline 19 & $\begin{array}{l}\text { TQ loaded SLN of phospholipon } \\
\text { 90G }\end{array}$ & $\begin{array}{l}\text { Carrageenan induced paw } \\
\text { edema in rat }\end{array}$ & $\begin{array}{c}\uparrow \mathrm{BA}, \uparrow \text { anti-inflammatory potential } \\
\downarrow \text { paw edema, } \\
\uparrow \text { antioxidant potential }\end{array}$ & [1] \\
\hline 20 & Ethosomes for topical TQ delivery & $\begin{array}{c}\text { Carrageenan rat paw } \\
\text { edema }\end{array}$ & $\begin{array}{c}\uparrow \mathrm{EE}, \uparrow \text { skin deposition } \\
\downarrow \text { skin irritation }\end{array}$ & [51] \\
\hline 21 & $\begin{array}{l}\text { TQ loaded chitosan, pluronic F127 } \\
\text { liposome for topical delivery }\end{array}$ & $\begin{array}{c}\text { Carrageenan-induced paw } \\
\text { edema }\end{array}$ & 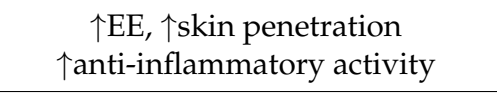 & [52] \\
\hline 22 & $\begin{array}{l}\text { SNEDDSs containing black seed } \\
\text { oil and cur }\end{array}$ & $\begin{array}{l}\text { Carrageenan-induced paw } \\
\text { edema }\end{array}$ & $\begin{array}{c}\uparrow \text { entrapment efficiency, } \\
\uparrow \text { transdermal penetration } \\
\uparrow \text { anti-inflammatory activity }\end{array}$ & [208] \\
\hline 23 & $\begin{array}{c}\text { black seed oil loaded egg yolk } \\
\text { liposomes }\end{array}$ & $\begin{array}{l}\text { Eddy hot plate method in } \\
\text { Swiss albino mice }\end{array}$ & $\begin{array}{c}\uparrow \mathrm{BA} ; \uparrow \mathrm{EE}, \\
\uparrow \text { anti-inflammatory activity }\end{array}$ & [209] \\
\hline 24 & $\begin{array}{l}\text { TQ and piperine loaded micro } \\
\text { vehicle of guar gum }\end{array}$ & HepG2 cell lines & $\begin{array}{c}\text { pH-responsive delivery } \\
\downarrow \text { lethal dose } \\
\uparrow \text { bactericidal activity } \\
\downarrow \text { minimum inhibitory dose }\end{array}$ & [206] \\
\hline 25 & $\begin{array}{l}\text { Bio-SNEDDSs for co-delivery of } \\
\text { cur and TQ }\end{array}$ & MCF-7 cells & $\uparrow$ drug loading, $\downarrow$ cell viability & [210] \\
\hline 26 & Fluorescent organic NPs & $\begin{array}{l}\text { A549, HeLa SiHa, } \\
\text { HEK-293T }\end{array}$ & $\uparrow \mathrm{BA}$, theranostic applications & [211] \\
\hline 27 & $\begin{array}{l}\text { TQ and resveratrol loaded silica } \\
\text { NPs }\end{array}$ & HeLa cell line & $\uparrow \mathrm{EE}, \uparrow$ drug loading, $\uparrow$ apoptosis & [212] \\
\hline 28 & $\begin{array}{c}\text { chitosan-based nanocarrier for the } \\
\text { encapsulation of NS oil }\end{array}$ & $\begin{array}{c}\text { HCT } 116 \text { (colorectal } \\
\text { carcinoma), PC3 (prostatic } \\
\text { cancer) }\end{array}$ & dose-dependent $\downarrow$ cell viability & [213] \\
\hline 29 & TQ Pluronic NPs & MCF7 cells & $\uparrow T Q$ encapsulation, $\uparrow$ cytotoxicity & [214] \\
\hline
\end{tabular}


Table 5. Cont.

\begin{tabular}{|c|c|c|c|c|}
\hline S.N & Formulations & Animal Model/Cell Line & Major Finding & Ref. \\
\hline 30 & $\begin{array}{c}\text { TQ-NP of } \\
\text { polystyrene-block-poly(ethylene } \\
\text { oxide) diblock polymer }\end{array}$ & $\begin{array}{l}\text { MCF-10-A cells } \\
\text { MCF-7 cells, } \\
\text { MDA-MB-231 cells }\end{array}$ & $\begin{array}{l}\uparrow \text { cellular uptake; } \\
\uparrow \text { cytotoxicity }\end{array}$ & [215] \\
\hline 31 & $\begin{array}{l}\mathrm{pH} \text {-sensitive multilamellar gold } \\
\text { niosomes along with Akt-siRNA }\end{array}$ & $\begin{array}{l}\text { tamoxifen-resistant T-47D } \\
\text { and Akt-overexpressing } \\
\text { MCF-7 cells }\end{array}$ & $\begin{array}{c}\uparrow \mathrm{TQ} \text { delivery at cancer cell; } \\
\uparrow \text { anticancer potential, resensitized } \\
\text { T-47D cells }\end{array}$ & [200] \\
\hline 32 & $\begin{array}{l}\text { polysaccharide microcontainers of } \\
\text { chitosan, xanthan gum soybean oil, } \\
\text { and Nile red for TQ delivery }\end{array}$ & $\begin{array}{l}\text { mouse melanoma } \\
\text { M-3 cell }\end{array}$ & $\begin{array}{l}\uparrow \text { cellular uptake, } \downarrow \text { nonspecific } \\
\text { toxicity; } \uparrow \text { antitumor effect }\end{array}$ & [216] \\
\hline 33 & Myristic acid-chitosan nanogels & MCF-7 & $\uparrow$ solubility, $\uparrow$ cellular uptake & [217] \\
\hline 34 & $\begin{array}{l}\text { ketoprofen and TQ loaded } \\
\text { mesoporous core-shell silica } \\
\text { spheres }\end{array}$ & $\begin{array}{l}\text { MDN- and XG-2-type } \\
\text { myeloma cancer cells lines } \\
\text { (IL-6 dependent) }\end{array}$ & $\begin{array}{l}\uparrow \text { cellular uptake and } \\
\text { accumulation, } \uparrow \text { apoptosis }\end{array}$ & [218] \\
\hline 35 & TQ loaded (PLGA)-NPs & MDA-MB-231 & $\uparrow E E, \uparrow$ cancer cells toxicity & [219] \\
\hline 36 & TQ loaded silver NPs & MDA-MB-231 & $\uparrow$ cancer cells radiosensitivity & [220] \\
\hline
\end{tabular}

Abbreviations: NS-Nigella sativa; EE-entrapment efficiency; DTX-docetaxel; DOX-doxorubicin; TQNPs—thymoquinone nanoparticle; PLGA—poly(lactic-co-glycolic acid); Cur_curcumin; SNEDDS—self-nanoemulsifying drug delivery systems.

Table 6. Surface-modified TQ nanocarrier in the management of cancer ( $\downarrow$ : decrease, $\uparrow:$ increase).

\begin{tabular}{|c|c|c|c|c|}
\hline S.N & Formulations & Animal Model/Cell Line & Major Finding & Ref. \\
\hline 1 & $\begin{array}{c}\text { Chitosan- (CS)-coated } \\
\text { poly(d,l-lactide-co-glycolide) NPs }\end{array}$ & MDA-MB-231 MCF-7 & $\begin{array}{c}\uparrow \text { Intestinal permeation; } \uparrow \mathrm{BA} ; \\
\downarrow \text { dose and dosing frequency, } \\
\quad \uparrow \text { antioxidant potential }\end{array}$ & [180] \\
\hline 2 & $\begin{array}{c}\text { Anisamide coated TQ loaded } \\
\text { lipidic core nanocapsules shell of } \\
\text { eudragit S100 }\end{array}$ & $\begin{array}{l}\text { HT-29, } \\
\text { HCT-116, } \\
\text { Сaco-2 }\end{array}$ & $\begin{array}{c}\text { Anisamide coating } \uparrow \text { colonic } \\
\text { delivery of TQ due to specific } \\
\text { binding with overexpressed sigma } \\
\text { receptor }\end{array}$ & [192] \\
\hline
\end{tabular}

RNA aptamer A10 coated TQ loaded planetary ball-milled NPs of starch PCL, and PEG for specific bindings to prostate-specific membrane antigen overexpressed $\mathrm{ABC}$ transporter genes
DOX resistant C4-2B-R and

LNCaP-R cells with a high expression of $\mathrm{Hh}$ $\uparrow$ targeted delivery

$\uparrow$ circulations time, resensitized cancer cells for DOX
[193]

$\uparrow$ ROS related cell death,

$\uparrow$ water-solubility, $\mathrm{pH}$-dependent cellular delivery, $\uparrow$ apoptosis

$\downarrow$ cell migration at a low dose;

$\uparrow$ circulation time; $\uparrow$ cancer cells targeting MDA-MB-468), murine (4T1), chick embryos

MCF-7 and

MDA-MB-231

MDA-MB-231

IDA-MB-231,

PEGylation $\uparrow$ circulation time;

Re-sensitized the resistant TNBC cells; $\downarrow$ side effects; DTX and TQ acid-decorated Pluronic ${ }^{\circledR}$ NPs

PEGylated vitamin-E TPGS-lipidic

6 nanocapsules for co-delivery of

\footnotetext{
$7 \quad$ Chitosan coated PLGA-NPs for TQ delivery

Poly-L-lysine and PEG-coated polysaccharide nanocontainers of 8 diethylaminoethyl dextran/xanthan gum for TQ delivery
}

A375

$\uparrow$ cellular accumulation; sustained

$\uparrow$ anti-metastatic effects
MCF-7 cells

$\uparrow$ cellular accumulation $\uparrow$ cytotoxicity 
Table 6. Cont

\begin{tabular}{|c|c|c|c|c|}
\hline S.N & Formulations & Animal Model/Cell Line & Major Finding & Ref. \\
\hline 9 & $\begin{array}{c}\text { Eudragit L-100 chitosan, HPMC, } \\
\text { and PVA NPs of TQ for colon } \\
\text { cancer treatment }\end{array}$ & Caco-2 & $\begin{array}{c}\uparrow \text { colonic drug delivery } \\
\uparrow \text { cytotoxicity }\end{array}$ & {$[202]$} \\
\hline 10 & $\begin{array}{c}\text { PEGylated liposome of } \\
\text { dihexadecanoyl-sn-glycero-3- } \\
\text { phosphocholine for co-delivery of } \\
\text { DTX and TQ }\end{array}$ & MCF-7 & $\begin{array}{c}\uparrow \text { drug encapsulation } \\
\downarrow \text { docetaxel dose, } \\
\uparrow \text { cancer cells cytotoxicity }\end{array}$ & {$[171]$} \\
\hline 11 & $\begin{array}{c}\text { Transferrin decorated TQ loaded } \\
\text { PEG-PLGA-NPs }\end{array}$ & & $\begin{array}{c}\uparrow \text { cellular accumulation } \\
\downarrow \text { therapeutic dose } \\
\downarrow \text { onset time, } \uparrow \text { cytotoxicity }\end{array}$ & {$[196]$} \\
\hline 12 & $\begin{array}{l}\text { AS1411-conjugated nanodroplets } \\
\text { of phospholipids } \\
\text { 1,2-dipalmitoyl-sn-glycero-3- } \\
\text { phosphocholine }\end{array}$ & MDA-MB-231 & $\begin{array}{l}\text { Specific binding with } \\
\text { overexpressed nucleolin on to } \\
\text { cancer cell surface, } \\
\uparrow \text { cytotoxic potential }\end{array}$ & {$[197]$} \\
\hline 13 & $\begin{array}{l}\text { PEGylated LMW TQ-loaded } \\
\text { chitosan nanocapsules }\end{array}$ & MCF 7, HEK 293 & $\begin{array}{c}\uparrow \text { absorption, } \uparrow \mathrm{BA} \\
\uparrow \text { cancer cells targeting }\end{array}$ & {$[175]$} \\
\hline
\end{tabular}

Abbreviations: BA—bioavailability; CS—chitosan; PEG-polyethylene glycol; LMW-low molecular weight; PLGA-poly(lactic-coglycolic acid); PVA — polyvinyl alcohol; HPMC — hydroxypropyl methylcellulose; TPGS-D- $\alpha$-tocopheryl polyethylene glycol succinate; DTX-docetaxel; PCL-polycaprolactone; ROS-reactive oxygen species.

\section{Role of TQ in Toxicity Reduction}

TQ is systemically well-tolerated with a large safety profile dose ( $\left.\mathrm{LD}_{50}, 2.5 \mathrm{~g} / \mathrm{kg}\right)$ [3] and has the potential to reduce oxidative stress and systemic toxicity as the dose increases. The intravenous dose of $25 \mathrm{mg} / \mathrm{kg}$ thymoquinone nanostructured lipid carrier (TQ-NLC) was found safe in female Sprague Dawley rats [221]. It shows antiproliferative effect at $20 \mu \mathrm{M}$, genotoxicity at concentration $\geq 1.25 \mu \mathrm{M}$, and cellular narcosis at between 2.5 and $20 \mu \mathrm{M}$ concentrations in the rat hepatocyte [222]. TQ $(10 \mathrm{mg} / \mathrm{kg})$ ameliorated sodium arsenate $(20 \mathrm{mg} / \mathrm{kg})$-induced neurotoxicity by increasing the levels of norepinephrine, dopamine, superoxide dismutase, and catalase, and decreases serotonin, nitrate, and tumor necrosis factor alpha (TNF- $\alpha$ ) levels in the cerebellum, cortex, and brain stem regions [223]. In another study, the neuroprotective effect of TQ $(10 \mathrm{mg} / \mathrm{kg} /$ day $)$ was observed on electromagnetic radiation-induced oxidative stress [224]. Similarly, glutamate and iron oxide nanoparticle-induced toxicity were also attenuated by TQ [5]. A combined formulation of Costus speciosus, Fumaria indica, Cichorium intybus, and TQ (CFCT) (25 mg/kg per oral) decreases cisplatin-induced hepatorenal toxicity in rats through membrane stabilization and decreasing aspartate aminotransferase, alanine aminotransferase, and alkaline phosphatase serum levels [225].

\section{Recent Update on Patents of Thymoquinone}

The latest patent literature search on thymoquinone and its loaded nanocarriers reported potential applications in the prevention, balancing, and treatment of multiple physiological conditions such as cancer, inflammations, dermal disorders, anxiety, and stress-related disorders; treatment of female urinary tract infections; and management of immunological diseases, etc. TQ was patented alone and in combinations for the treatment of inflammatory symptoms, including the eicosapentaenoic acid pathway [226]. Additionally, TQ and H5WYG peptide-loaded nanomicelles were also patented for targeted cancer drug delivery [227] and TQ-loaded nanodroplet emulsions for cancer targeting [228]. TQloaded nanocarriers are not limited to cancer targeting. Aminoglycoside-thymoquinoneloaded nano-liposomal formulations have been patented for aminoglycoside antibiotic delivery [229]. Authors rightfully assume an increase in patent outcomes when pure thymoquinone is converted to nanocarrier-loaded thymoquinone for various pharmacological 
applications. The patents illustrating the pharmacological significance of thymoquinone and related nanocarriers are recorded in Table 7.

Table 7. Patents of thymoquinone (TQ) and their nanocarrier systems related to inflammation and cancer ( $\downarrow$ : decrease, $\uparrow:$ increase).

\begin{tabular}{|c|c|c|c|c|c|}
\hline S.N & Patent no & $\begin{array}{c}\text { Type of } \\
\text { Formulations }\end{array}$ & Product Claim and Activity & Outcome & Reference \\
\hline 1 & $\begin{array}{l}\text { WO2016024145A1WIPO } \\
\text { (PCT) }\end{array}$ & TQ derivative & Cancer treatment & $\uparrow$ Anticancer effects & [230] \\
\hline 2 & $\begin{array}{l}\text { WO2018134852A1WIPO } \\
\text { (PCT) }\end{array}$ & $\begin{array}{c}\text { Vesicular } \\
\text { formulations }\end{array}$ & $\begin{array}{l}\text { Treatment of dermal } \\
\text { inflammatory disorders }\end{array}$ & $\uparrow$ Bioavailability & {$[231]$} \\
\hline 3 & $\begin{array}{c}\text { WO2013030669A4WIPO } \\
\text { (PCT) }\end{array}$ & $\begin{array}{c}\mathrm{TQ}, \mathrm{TQ}+ \\
\text { eicosapentaenoic acid }\end{array}$ & $\begin{array}{l}\text { Inflammation management } \\
\text { including eicosapentaenoic acid }\end{array}$ & $\downarrow$ Inflammatory symptoms & {$[232]$} \\
\hline 4 & $\begin{array}{l}\text { WO2016167730A1WIPO } \\
\text { (PCT) }\end{array}$ & Nanomicelles & $\begin{array}{l}\text { Nanomicelles loaded with drug } \\
\text { and H5WYG peptides for } \\
\text { anticancer activity }\end{array}$ & $\begin{array}{l}\uparrow \text { Targeted delivery for cancer } \\
\text { cells }\end{array}$ & {$[227]$} \\
\hline 5 & US20160101124A1 & $\begin{array}{l}\text { Nanoliposome } \\
\text { loaded with TQ and } \\
\text { aminoglycoside }\end{array}$ & $\begin{array}{c}\text { Nano-liposomal } \\
\text { aminoglycoside-TQ } \\
\text { formulations for administration } \\
\text { to the mammal }\end{array}$ & $\begin{array}{c}\uparrow \text { bactericidal activity, } \downarrow \text { renal } \\
\text { toxicity }\end{array}$ & {$[229]$} \\
\hline 6 & WO-2016005786-A1 & $\begin{array}{l}\text { The liposome of TQ } \\
\text { and taxane, }\end{array}$ & $\begin{array}{l}\text { Liposomal formulations } \\
\text { comprising TQ and taxane, and } \\
\text { methods of treating cancer } \\
\text { using the same }\end{array}$ & $\begin{array}{l}\text { Synergize anticancer effect, } \\
\uparrow \text { capsulation efficiency of the } \\
\text { taxane } \uparrow \text { liposomes stability }\end{array}$ & [233] \\
\hline 7 & CN-110420203-A & TQ & $\begin{array}{l}\text { Application of the TQ in } \\
\text { preparation prevention } \\
\text { intravascular stent restenosis } \\
\text { medicaments }\end{array}$ & $\begin{array}{l}\downarrow \text { intravascular diseases such as } \\
\text { in-stent restenosis }\end{array}$ & [234] \\
\hline 8 & US10485837B2 & black cumin extract. & $\begin{array}{l}\text { NS seeds component for } \\
\text { management of anxiety, stress, } \\
\text { and sleep disorders }\end{array}$ & Improve cognitive function & [235] \\
\hline 9 & WO-2011126544-A2 & $\begin{array}{c}\text { TQ+ gemc- } \\
\text { itabine/oxaliplatin, }\end{array}$ & $\begin{array}{l}\text { TQ analogs for the treatment of } \\
\text { pancreatic cancer }\end{array}$ & $\begin{array}{c}\downarrow \text { drug resistance, } \\
\uparrow \text { chemotherapeutic activity } \\
\text { against pancreatic cancer }\end{array}$ & [236] \\
\hline 10 & US-6218434-B1 & $\begin{array}{l}\text { TQ and } \\
\text { dithymoquinone }\end{array}$ & $\begin{array}{c}\text { Use of the naturally occurring } \\
\text { quinones TQ and } \\
\text { dithymoquinone as } \\
\text { antineoplastic and cytotoxic } \\
\text { agents }\end{array}$ & $\begin{array}{c}\downarrow \text { drug sensitivity against } \\
\text { multi-drug resistant human } \\
\text { cancers }\end{array}$ & {$[237]$} \\
\hline 11 & CN-103288618-A & TQ synthesis method & $\begin{array}{l}\text { A synthesis method of TQ } \\
\text { serving as blood vessel } \\
\text { inhibition medicament }\end{array}$ & $\begin{array}{l}\text { A Synthesis method of TQ } \\
\text { serving for blood vessel } \\
\text { inhibition drug }\end{array}$ & {$[238]$} \\
\hline 12 & CN-103833871-A & $\begin{array}{l}\text { Hyaluronic acid- } \\
\text { adipodihydrazide- } \\
\text { TQ-grafted } \\
\text { polymer }\end{array}$ & $\begin{array}{l}\text { TQ grafted polymer for tumors } \\
\text { specific delivery }\end{array}$ & $\begin{array}{c}\uparrow \text { tumors targeting, } \\
\text { pH-dependent drug release }\end{array}$ & {$[239]$} \\
\hline 13 & US-8029831-B2 & $\begin{array}{l}\text { TQ containing NS } \\
\text { seed extract }+ \\
\text { cranberry fruit } \\
\text { extract/ }\end{array}$ & $\begin{array}{c}\text { Management of microbial } \\
\text { infections of the female urinary } \\
\text { tract. }\end{array}$ & $\begin{array}{l}\downarrow \text { Urine } \mathrm{pH}, \uparrow \text { antimicrobial } \\
\text { activity, } \downarrow \text { inflammation and } \\
\text { pain, } \downarrow \text { physiological stress. }\end{array}$ & {$[240]$} \\
\hline 14 & DE-19844022-C1 & $\begin{array}{l}\text { Iron-binding glyco } \\
\text { proteins (lactoferrin) } \\
\text { and/or 10-hydroxy- } \\
\text { 2-decenoic acid + TQ }\end{array}$ & $\begin{array}{c}\text { use of iron-binding } \\
\text { glycoproteins and/or } \\
\text { 10-hydroxy-2-decenoic acid in } \\
\text { combination with TQ for } \\
\text { treatment of AIDS and other } \\
\text { immunodeficiency diseases. }\end{array}$ & $\downarrow$ HIV plaques & {$[241]$} \\
\hline 15 & US20190192686A1 & Nanodroplet micelle & Cancer management & $\begin{array}{l}\uparrow \text { targeted delivery of anticancer } \\
\text { drugs, } \downarrow \text { systemic toxicity. }\end{array}$ & {$[228]$} \\
\hline
\end{tabular}




\section{Clinical Trials OF Thymoquinone}

TQ has the potential to correct various physiological conditions of the body. It is widely investigated from dietary supplementation to chemoprevention. To date, a total of 10 clinical trials (Table 8) of thymoquinone claiming its effect on malignant lesions, aphtha, chronic periodontitis, type 2 diabetes mellitus, oral submucous fibrosis, pediatric major thalassemia, and supportive care in patients with COVID-19 are ongoing worldwide, the details of which are mentioned in Table 8. Moreover, recently, a clinical trial of TQ was registered to analyze efficacy and safety for best supportive measures (Guidelines on Clinical Management of COVID-19 issued by MOHFW, India) against COVID-19 patients. The confirmed COVID-19 patients were assigned as Cohort A and Cohort B. Cohort A patients received $50 \mathrm{mg} \mathrm{TQ}$ once a day for 14 days along with the best supportive measure, while Cohort B patients received the best supportive measure only. The trial was primarily evaluated for virologic (change in positive COVID-19 status on days 8 and 15) and clinical outcomes (proportion of patients on WHO progression scale 0 to 10 on days 8 and 15). A human trial (CTRI/2020/12/029514) of TQ tablets (dose of $50 \mathrm{mg} ; 25 \mathrm{mg} ; 12.5 \mathrm{mg}$ ) was registered to measure safety and tolerability and to analyze pharmacokinetic behavior in normal healthy adults under fasting conditions. A trial (NCT04686461) of thymoquinone extract is underway to investigate the effects against arsenical keratosis. In this trial, TQloaded topical ointment was used to treat 34 patients with arsenical keratosis at two-week intervals. The TQ ointment formulation was found to reduce the keratotic nodular size as well as improvement of the lesion calculated using the Likert Scale. 
Table 8. Some recent thymoquinone clinical trials.

\begin{tabular}{|c|c|c|c|c|c|c|c|c|c|}
\hline S.N & Clinical Trial ID & Title & Trial Status & $\begin{array}{l}\text { Age and Patient } \\
\text { Inclusion Criteria }\end{array}$ & Intervention & Conditions & Sponsor & Target Size & Source \\
\hline 1 & NCT03208790 & $\begin{array}{l}\text { Clinical and } \\
\text { immunohistochemical } \\
\text { evaluation of the cancer } \\
\text { chemopreventive effect of } \\
\text { thymoquinone compared to } \\
\text { placebo on oral potentially } \\
\text { malignant lesions among an } \\
\text { Egyptian population: a } \\
\text { randomized clinical trial }\end{array}$ & Phase 2 & $\begin{array}{l}18-25 \text { years } \\
\text { Patients with any } \\
\text { known potentially } \\
\text { malignant lesion } \\
\text { confirmed } \\
\text { histologically }\end{array}$ & $\begin{array}{c}100 \mathrm{mg} \\
200 \mathrm{mg} \\
\text { Placebo oral capsule }\end{array}$ & Premalignant Lesion & $\begin{array}{l}\text { Cairo University, } \\
\text { Egypt }\end{array}$ & 81 & $\begin{array}{c}\text { https: } \\
\text { // clinicaltrials.gov/ } \\
\text { show /NCT03208790; } \\
\text { accessed on } 12 \\
\text { January } 2021\end{array}$ \\
\hline 2 & IRCT2016100914106N5 & $\begin{array}{l}\text { Preparation of oral gel-made } \\
\text { from thymoquinone (TQ), and } \\
\text { a clinical study investigating } \\
\text { the efficacy of it on patients } \\
\text { with aphtha }\end{array}$ & 2 & $\begin{array}{l}\text { Patient possessing } \\
\text { aphthous ulcer }\end{array}$ & & $\begin{array}{l}\text { Recurrent Aphthous } \\
\text { Stomatitis }\end{array}$ & $\begin{array}{l}\text { Kermanshah } \\
\text { University of } \\
\text { Medical Science, } \\
\text { Iran }\end{array}$ & 56 & $\begin{array}{l}\text { http://en.irct.ir/ } \\
\text { trial/13800; accessed } \\
\text { on } 12 \text { January } 2021\end{array}$ \\
\hline 3 & IRCT2016021826637N1 & $\begin{array}{l}\text { Evaluation effect of } \\
\text { mucoadhesive NS in the } \\
\text { treatment of chronic } \\
\text { periodontitis }\end{array}$ & 2 & $\begin{array}{l}\text { Patients who had } \\
\text { not undertaken } \\
\text { periodontal therapy } \\
\text { in the past } 3 \text { months }\end{array}$ & $\begin{array}{c}\text { Mucoadhesive } \\
\text { Locally Delivery NS } \\
\text { extract } 0.2 \% \text { and } \\
\text { Thymoquinone } \\
0.02 \% \text {. }\end{array}$ & $\begin{array}{c}\text { Chronic } \\
\text { periodontitis }\end{array}$ & $\begin{array}{l}\text { The ethics } \\
\text { committee of } \\
\text { Kermanshah } \\
\text { University of } \\
\text { Medical Science, } \\
\text { Iran }\end{array}$ & 20 & $\begin{array}{l}\text { http:/ / en.irct.ir/ } \\
\text { trial/22014; accessed } \\
\text { on } 12 \text { January } 2021\end{array}$ \\
\hline 4 & NCT03776448 & $\begin{array}{l}\text { The effect of } 2 \mathrm{~g} \text { daily } \\
\text { supplementation of } \\
\text { thymoquinone -containing } \\
\text { sativa nigra oil on blood } \\
\text { glucose levels of adults: a } \\
\text { placebo-controlled } \\
\text { double-blinded randomized } \\
\text { controlled trial }\end{array}$ & N/A & $\begin{array}{l}18-60 \text { years of } \\
\text { regular Student or } \\
\text { Faculty in Sulaiman } \\
\text { Al Rajhi Colleges }\end{array}$ & $18-60$ years & Diabetes mellitus & $\begin{array}{l}\text { Sulaiman Al Rajhi } \\
\text { Colleges, Saudi } \\
\text { Arabia }\end{array}$ & 30 & $\begin{array}{c}\text { https: } \\
\text { //clinicaltrials.gov/ } \\
\text { show/NCT03776448; } \\
\text { accessed on } 12 \\
\text { January } 2021\end{array}$ \\
\hline 5 & CTRI/2018/11/016334 & $\begin{array}{l}\text { A randomized, open-label, } \\
\text { prospective, three-arm, } \\
\text { parallel, multicenter study to } \\
\text { evaluate efficacy and safety of } \\
\text { metformin with/without } \\
\text { concomitant administration of } \\
\text { thymoquinone in patients } \\
\text { with type } 2 \text { diabetes mellitus. }\end{array}$ & 2 & $\begin{array}{l}\text { Patients aged 18-65 } \\
\text { years with type 2 } \\
\text { diabetes mellitus } \\
\text { and (BMI) between } \\
\text { 18-30 kg per meter } \\
\text { square }\end{array}$ & & $\begin{array}{l}\text { Type } 2 \text { diabetes } \\
\text { mellitus without } \\
\text { complications }\end{array}$ & $\begin{array}{c}\text { Intas } \\
\text { Pharmaceuticals } \\
\text { Ltd., India }\end{array}$ & 60 & $\begin{array}{l}\text { http:// www.ctri.nic. } \\
\text { in/Clinicaltrials/ } \\
\text { pmaindet2.php? } \\
\text { trialid=28562; } \\
\text { accessed on } 12 \\
\text { January } 2021\end{array}$ \\
\hline 6 & CTRI/2020/05/025167 & $\begin{array}{l}\text { Evaluation of efficacy and } \\
\text { safety of thymoquinone } \\
\text { compared to best supportive } \\
\text { care in patients with covid-19 }\end{array}$ & Phase 2 & $\begin{array}{l}\text { Confirmed } \\
\text { COVID-19 patient } \\
\text { (either sex) aged } \\
18-65 \text { years }\end{array}$ & $\begin{array}{l}50 \mathrm{mg} \text { tablet for } 14 \\
\text { days as an add-on to } \\
\text { best supportive as } \\
\text { per guidelines of } \\
\text { clinical management } \\
\text { of COVID-19 as } \\
\text { issued by MOHFW }\end{array}$ & $\begin{array}{c}\mathrm{RR}<20, \mathrm{HR}<90, \\
\text { oxygen saturation } \\
\text { (pulse oximetry) } \\
>93 \% \text { on room air at } \\
\text { screening }\end{array}$ & $\begin{array}{c}\text { Intas } \\
\text { Pharmaceuticals } \\
\text { Ltd., India }\end{array}$ & 100 & $\begin{array}{l}\text { http://ctri.nic.in/ } \\
\text { Clinicaltrials/ } \\
\text { showallp.php?mid1 } \\
\text { =43378\&EncHid= } \\
\text { \&userName= } \\
\text { thymoquinone; } \\
\text { accessed on 12 } \\
\text { January 2021 }\end{array}$ \\
\hline
\end{tabular}


Table 8. Cont.

\begin{tabular}{|c|c|c|c|c|c|c|c|c|c|}
\hline S.N & Clinical Trial ID & Title & Trial Status & $\begin{array}{l}\text { Age and Patient } \\
\text { Inclusion Criteria }\end{array}$ & Intervention & Conditions & Sponsor & Target Size & Source \\
\hline 7 & NCT04476420 & $\begin{array}{l}\text { Comparison of NS oil with } \\
\text { conventional management on } \\
\text { clinical outcomes in oral } \\
\text { submucous fibrosis }\end{array}$ & Phase 3 & $\begin{array}{l}18 \text { years clinically } \\
\text { diagnosed patients } \\
\text { (either sex) of oral } \\
\text { submucous fibrosis }\end{array}$ & $\begin{array}{c}\text { Topical application } \\
\text { of N. sativa seed oil } \\
\text { over buccal mucosa } \\
\text { ( } 1 \mathrm{~mL}) \text { three times a } \\
\text { day for } 10 \mathrm{~min}(3-5 \\
\text { min on each side) } \\
\end{array}$ & $\begin{array}{l}\text { Oral submucous } \\
\text { fibrosis }\end{array}$ & $\begin{array}{l}\text { Ziauddin University, } \\
\text { Pakistan }\end{array}$ & 40 & $\begin{array}{l}\text { https: / / clinicaltrials. } \\
\text { gov/ct2/show/ } \\
\text { NCT04476420; } \\
\text { accessed on 12 } \\
\text { January } 2021\end{array}$ \\
\hline 8 & NC T04292314 & $\begin{array}{l}\text { Impact of combination } \\
\text { therapy between } \\
\text { hydroxyurea, omega 3, NS, } \\
\text { and honey on } \\
\text { antioxidant-oxidant status } \\
\text { and reduction of iron } \\
\text { overload in pediatric major } \\
\text { thalassemia }\end{array}$ & Phase 3 & $\begin{array}{l}\text { Any case with the } \\
\text { full manifestation of } \\
\beta \text {-Thalassemia } \\
\text { major disease } \\
\text { Aged from } 7-15 \\
\text { years old }\end{array}$ & $\begin{array}{l}1 \mathrm{~g} \text { black seed oil } \\
\text { contains } 1 \% \\
\text { thymoquinone per } \\
\text { day for } 8 \\
\text { consecutive months } \\
\text { up to } 10 \text { months }\end{array}$ & & $\begin{array}{l}\text { Beni-Suef University } \\
\text { (Egypt)Maternity } \\
\text { and Children } \\
\text { Hospital, Makkah } \\
\text { University of } \\
\text { Arizona (Saudi } \\
\text { Arabia) }\end{array}$ & 350 & $\begin{array}{c}\text { https: } \\
\text { // clinicaltrials.gov/ } \\
\text { ct2/show /NCT042 } \\
\text { 92314?cond= } \\
\text { thymoquinone\& } \\
\text { draw=2\&rank=3; } \\
\text { accessed on 12 } \\
\text { January 2021 }\end{array}$ \\
\hline 9 & CTRI/2020/12/029514 & $\begin{array}{l}\text { An open-label, balanced, } \\
\text { randomized, three-treatment, } \\
\text { single-period, single oral dose, } \\
\text { parallel, exploratory } \\
\text { pharmacokinetic study of } \\
\text { thymoquinone tablet } 12.5 \mathrm{mg} \text {, } \\
25 \mathrm{mg}, 50 \mathrm{mg} \text { in normal, } \\
\text { healthy, adult, human subjects } \\
\text { under fasting condition }\end{array}$ & Not yet recruiting & $\begin{array}{c}18.00-45.00 \text { year(s) } \\
\text { A normal, healthy, } \\
\text { adult having a Body } \\
\text { Mass Index between } \\
18.5 \text { to } 30.0\end{array}$ & $\begin{array}{c}\text { Dose-12.5 mg; } 25 \\
\mathrm{mg} ; 50 \mathrm{mg} \\
\text { Frequency - a single } \\
\text { oral dose; } \\
\text { Dosage form- } \\
\text { tablet; } \\
\text { Route of } \\
\text { administration-oral }\end{array}$ & $\begin{array}{c}\text { Not having any } \\
\text { significant diseases }\end{array}$ & $\begin{array}{c}\text { Intas } \\
\text { Pharmaceuticals } \\
\text { Limited, Corporate } \\
\text { House, } \\
\text { Ahmedabad- } \\
\text { 380054, Gujarat, } \\
\text { India }\end{array}$ & 12 & $\begin{array}{l}\text { http://ctri.nic.in/ } \\
\text { Clinicaltrials/ } \\
\text { pmaindet2.php? } \\
\text { trialid=49799\& } \\
\text { EncHid= } \\
\text { \&userName= } \\
\text { thymoquinone; } \\
\text { accessed on 12 } \\
\text { January 2021 }\end{array}$ \\
\hline
\end{tabular}




\section{Conclusions and Prospects}

TQ is a molecule that has multifaceted modes of action, including anti-arthritic and antineoplastic activities through modulating inflammatory and apoptotic pathways. However, its biological instability, rapid metabolism, poor water solubility, narrow bioavailability, inadequate cellular availability, and lack of targeting halt its transition from research to clinical application. Extensive literature analysis revealed that nanotechnology upgraded drug delivery patterns in cancer and arthritic disease through significant improvement in pharmacokinetics and target-oriented active molecules delivery, while decreasing their off-target side effects. To maintain the biological stability of TQ during formulation design or delivering alone, site-specific availability is among the major challenges to utilizing its maximum therapeutic potential in arthritis and cancer management.

The role of TQ individually and its diverse types of nanoformulations for targeted delivery to tumorigenic cells and synovial tissues, with longer circulating time and higher synovial accumulation, improved anti-inflammatory and anticancer potential. The nanoformulation delivery of $\mathrm{TQ}$ results in significantly enhanced targeting payload and promising upgrades to its anti-inflammatory and anticancer efficacy.

Nanoparticles are emerging carrier systems for the delivery of a wide range of therapeutic molecules. NPs are extremely attractive due to their important properties (size surface area and charge). Their use, as a drug carrier system or in theranostic applications including personalized medicine, might pave the way for a future strategy of prevention and counteraction of multiple diseases.

In this review, we vitally analyzed and reported the possible mechanistic approach of thymoquinone, such as the downregulation of various cytokines, inflammatory factors, and apoptotic pathways for the management of rheumatoid arthritis and cancer. Moreover, their toxicity reduction potential was also reported. An extensive review of their patent and clinical trials worldwide was also reported.

With the deep dive that we undertook in this review, it was revealed that formulations can transform the applicability of the nanocarrier-based formulation of thymoquinone; however, these studies can be dynamic. Significant dots in research have been recognized that need to be connected: various pre-clinical and human trials are taking place worldwide to ascertain the applicability of thymoquinone in humans; there are a lack of comparative findings on various nanoformulations to optimize the best regimen for TQ delivery against rheumatoid arthritis and cancer; the nonavailability of toxicity/safety data for thymoquinone-loaded NPs and human studies specifically exploring the pharmaceutical importance of nanoparticulate systems on arthritic and cancer milieu.

Funding: This research received no external funding.

Institutional Review Board Statement: Not applicable.

Informed Consent Statement: Not applicable.

Data Availability Statement: Not applicable.

Conflicts of Interest: The authors declare no conflict of interest.

$\begin{array}{ll}\text { Abbreviation } & \\ \text { TQ } & \text { Thymoquinone } \\ \text { NS } & \text { Nigella sativa } \\ \text { RA } & \text { Rheumatoid Arthritis } \\ \text { MTX } & \text { Methotrexate } \\ \text { MDA } & \text { Malondialdehyde } \\ \text { BA } & \text { Bioavailability (BA) } \\ \text { MAPK } & \text { Mitogen-activated protein kinase } \\ \text { LPS } & \text { Lipopolysaccharides } \\ \text { DTX } & \text { Docetaxel } \\ \text { CBZ } & \text { Cabazitaxel }\end{array}$




\begin{tabular}{|c|c|}
\hline HA & Hyaluronic acid \\
\hline PVP & Polyvinylpyrrolidone \\
\hline DMARDs & Disease-modifying antirheumatic drugs \\
\hline PGE2 & Prostaglandin E2 \\
\hline GSSG & Glutathione \\
\hline MMP & Matrix metalloproteinase \\
\hline RANKL & Receptor-activated nuclear factor kappa-B ligand \\
\hline $\operatorname{cox}$ & Cyclooxygenase \\
\hline ROS & Reactive oxygen species \\
\hline STAT3 & Signal transducer and activator of transcription-3 \\
\hline PARP & Poly-(ADP-ribose) polymerase \\
\hline $\operatorname{Mdm} 2$ & Murine double minute-2 \\
\hline MOMP & Mitochondrial outer membrane permeability \\
\hline TQ-NPs & Thymoquinone Nanoparticles \\
\hline NADPH & Nicotinamide adenine dinucleotide phosphate oxidase \\
\hline IL & Interleukin \\
\hline TNF- $\alpha$ & Tumor necrosis factor alpha \\
\hline TLR & Toll-like receptors \\
\hline NF- $k B$ & Nuclear factor kappa light chain enhancer of activated B cells \\
\hline NLRP3 & NOD-like receptor family pyrin domain containing 3 \\
\hline FCA & Freund's complete adjuvant \\
\hline PLC1 & Polo-like kinase 1 \\
\hline PI3K & Phosphoinositides, including 3-kinase \\
\hline JAK/STAT & Janus kinase signal transducers and transcription \\
\hline Fe-NTA & Fe (III) nitrilotriacetic acid \\
\hline miRNA & microRNA \\
\hline $\operatorname{lncRNA}$ & Long non-coding RNAs \\
\hline PTEN & Phosphatase and tensin homolog \\
\hline Eca109 cells & Esophageal cancer cells \\
\hline $\operatorname{miR}-34 a$ & MicroRNA-34a \\
\hline MBC & Metastatic breast cancers \\
\hline DTX & Docetaxel \\
\hline PEG & Polyethylene \\
\hline TNBC & Triple negative breast cancer \\
\hline PLL & poly-L-lysine \\
\hline PVP & Polyvinylpyrrolidone \\
\hline NFATc1 & Nuclear factor of activated T-cells, cytoplasmic 1 \\
\hline ROS & Reactive oxygen species \\
\hline fMLF & N-Formylmethionine-leucyl-phenylalanine \\
\hline eEF-2K; & Eukaryotic elongation factor- 2 kinase \\
\hline NLRP3 & NACHT, LRR, and pyrin domain-containing protein 3 \\
\hline DOX & Doxorubicin \\
\hline SOD & Superoxide dismutase \\
\hline LC-3 & Light chain 3-II \\
\hline PPAR- $\gamma$ & Peroxisome proliferator-activated receptor gamma \\
\hline UHRF1 & Ubiquitin-like, containing PHD and RING finger domains-1 \\
\hline p-mTOR & Phosphorylated mechanistic target of rapamycin \\
\hline NFKB & Nuclear factor kappa-light-chain-enhancer of activated B cells \\
\hline 4E-BP1 & Eukaryotic translation initiation factor 4 E-binding protein 1 \\
\hline eIF4E & Eukaryotic translation initiation factor $4 \mathrm{E}$ \\
\hline p70S6K & Ribosomal protein S6 kinase beta-1 also known as p70S6K kinase \\
\hline PI3K & Phosphoinositides, including 3-kinase \\
\hline IRAK1 & Interleukin-1 receptor-associated kinase 1 \\
\hline FAK & Focal adhesion kinase \\
\hline Hes1 & Hairy and enhancer of split-1 \\
\hline VEGF & Vascular endothelial growth factor \\
\hline IRAK1 & Interleukin-1 receptor-associated kinase 1 , \\
\hline
\end{tabular}




$\begin{array}{ll}\text { TWIST1 } & \text { Twist-related protein 1 } \\ \text { DNMT1 } & \text { DNA Methyltransferase 1, } \\ \text { HDAC1 } & \text { Histone deacetylase 1 } \\ \text { Oct-4 } & \text { Octamer binding transcription factor-4 } \\ \text { Nestin } & \text { Neuroepithelial stem cell protein } \\ \text { MDM2 } & \text { Mouse double minute 2 homolog } \\ \text { p-GSK3 } 3 & \text { Glycogen synthase kinase } 3 \text { beta } \\ \text { TRAIL } & \text { Tumor necrosis factor-related apoptosis-inducing ligand } \\ \text { IKK1 } & \text { Inhibitor of nuclear factor kappa B } \\ \text { PRAP } & \text { Prolactin receptor associated protein } \\ \text { UHRF1 } & \text { Ubiquitin-like, containing PHD and RING finger domains 1 } \\ \text { HDAC } & \text { Histone deacetylases } \\ \text { BAX } & \text { BCL2 Associated X } \\ \text { ZEB1 } & \text { Zinc Finger E-Box Binding Homeobox 1 } \\ \text { LKB1 } & \text { Liver kinase B1 } \\ \text { AMPK } & \text { AMP-activated protein kinase } \\ \text { AIF } & \text { Apoptosis-inducing factor } \\ \text { ERK1/2 } & \text { Extracellular signal-regulated protein kinase } \\ \text { CDK-2 } & \text { Cyclin-dependent kinase-2; } \\ \text { HCC } & \text { Hepatocellular carcinoma } \\ \text { RANTES } & \text { Regulated upon activation normal T cell expressed and presumably secreted } \\ \text { RES } & \text { Reticuloendothelial system }\end{array}$

\section{References}

1. Rathore, C.; Upadhyay, N.K.; Sharma, A.; Lal, U.R.; Raza, K.; Negi, P. Phospholipid nanoformulation of thymoquinone with enhanced bioavailability: Development, characterization and anti-inflammatory activity. J. Drug Deliv. Sci. Technol. 2019, 52, 316-324. [CrossRef]

2. Wang, X.; Fang, G.; Yang, Y.; Pang, Y. The newly discovered natural compounds against rheumatoid arthritis—An overview. Phytochem. Lett. 2019, 34, 50-58. [CrossRef]

3. Ardah, M.T.; Merghani, M.M.; Haque, M.E. Thymoquinone prevents neurodegeneration against MPTP in vivo and modulates $\alpha$-synuclein aggregation in vitro. Neurochem. Int. 2019, 128, 115-126. [CrossRef] [PubMed]

4. Khan, M.A.; Aldebasi, Y.H.; Alsuhaibani, S.A.; Alsahli, M.A.; Alzohairy, M.A.; Khan, A.; Younus, H. Therapeutic potential of thymoquinone liposomes against the systemic infection of Candida albicans in diabetic mice. PLoS ONE 2018, 13, e0208951. [CrossRef] [PubMed]

5. Ansari, M.O.; Parveen, N.; Ahmad, F.; Wani, A.L.; Afrin, S.; Rahman, Y.; Jameel, S.; Khan, Y.A.; Siddique, H.R.; Tabish, M.; et al. Evaluation of DNA interaction, genotoxicity and oxidative stress induced by iron oxide nanoparticles both in vitro and in vivo: Attenuation by thymoquinone. Sci. Rep. 2019, 9, 1-14. [CrossRef] [PubMed]

6. Khan, M.A.; Afzal, M. Chemical composition of Nigella sativa Linn: Part 2 Recent advances. Inflammopharmacology 2016, 24, 67-79. [CrossRef]

7. Faisal, R.; Ahmad, N.; Fahad, Y.S.; Chiragh, S. Anti-Arthritic Effect of Thymoquinone in Comparison with Methotrexate on Pristane Induced Arthritis in Female Sprague Dawley Rats. J. Ayub Med. Coll. Abbottabad 2018, 30, 3-7.

8. Ahmad, A.; Mishra, R.K.; Vyawahare, A.; Kumar, A.; Rehman, M.U.; Qamar, W.; Khan, A.Q.; Khan, R. Thymoquinone (2Isopropyl-5-methyl-1, 4-benzoquinone) as a chemopreventive/anticancer agent: Chemistry and biological effects. Saudi Pharm. J. 2019, 27, 1113-1126. [CrossRef]

9. Bamosa, A.O.; Kaatabi, H.; Lebdaa, F.M.; Al Elq, A.-M.; Al-Sultanb, A. Effect of Nigella sativa seeds on the glycemic control of patients with type 2 diabetes mellitus. Indian J. Physiol. Pharmacol. 2011, 54, 344-354.

10. Barani, M.; Mirzaei, M.; Torkzadeh-Mahani, M.; Adeli-Sardou, M. Evaluation of Carum-loaded Niosomes on Breast Cancer Cells:Physicochemical Properties, In Vitro Cytotoxicity, Flow Cytometric, DNA Fragmentation and Cell Migration Assay. Sci. Rep. 2019, 9, 1-10. [CrossRef]

11. Alkharfy, K.M.; Ahmad, A.; Khan, R.M.A.; Al-Shagha, W.M. Pharmacokinetic plasma behaviors of intravenous and oral bioavailability of thymoquinone in a rabbit model. Eur. J. Drug Metab. Pharmacokinet. 2014, 40, 319-323. [CrossRef]

12. Rasheeda, K.; Samyuktha, D.; Fathima, N.N. Self-association of type I collagen directed by thymoquinone through alteration of molecular forces. Int. J. Biol. Macromol. 2019, 140, 614-620. [CrossRef] [PubMed]

13. Nagi, M.N.; Almakki, H.A. Thymoquinone supplementation induces quinone reductase and glutathione transferase in mice liver: Possible role in protection against chemical carcinogenesis and toxicity. Phytother. Res. 2009, 23, 1295-1298. [CrossRef] [PubMed]

14. Darakhshan, S.; Pour, A.B.; Colagar, A.H.; Sisakhtnezhad, S. Thymoquinone and its therapeutic potentials. Pharmacol. Res. 2015, 95-96, 138-158. [CrossRef] [PubMed]

15. Mohammadabadi, M.; Mozafari, M. Enhanced efficacy and bioavailability of thymoquinone using nanoliposomal dosage form. $J$. Drug Deliv. Sci. Technol. 2018, 47, 445-453. [CrossRef] 
16. Khalife, K.H.; Lupidi, G. Nonenzymatic reduction of thymoquinone in physiological conditions. Free Radic. Res. 2007, 41, 153-161. [CrossRef]

17. Islam, M.T.; Sultana, N.; Alam Riaz, T.; Ferdous, J.; Guha, B.; Mohagon, S.; Mutsuddy, R.; Santos, J.V.D.O.; Dos Reis, A.C.; Braga, A.L.; et al. Thymoquinone is knocking at the door of clinical trial. Int. Arch. Med. 2016, 9. [CrossRef]

18. Badary, O.A.; Taha, R.A.; El-Din, A.M.G.; Abdel-Wahab, M.H. Thymoquinone is a Potent Superoxide Anion Scavenger. Drug Chem. Toxicol. 2003, 26, 87-98. [CrossRef]

19. Mahmoud, Y.K.; Abdelrazek, H.M. Cancer: Thymoquinone antioxidant/pro-oxidant effect as potential anticancer remedy. Biomed. Pharmacother. 2019, 115, 108783. [CrossRef]

20. Widdifield, J. Preventing Rheumatoid Arthritis: A Global Challenge. Clin. Ther. 2019, 41, 1355-1365. [CrossRef]

21. Sigaux, J.; Biton, J.; André, E.; Semerano, L.; Boissier, M.-C. Air pollution as a determinant of rheumatoid arthritis. Jt. Bone Spine 2019, 86, 37-42. [CrossRef]

22. Cush, J.J. Rheumatoid Arthritis. Med. Clin. N. Am. 2021, 105, 355-365. [CrossRef]

23. Boissier, M.-C.; Biton, J.; Semerano, L.; Decker, P.; Bessis, N. Origins of rheumatoid arthritis. Jt. Bone Spine 2020, 87, 301-306. [CrossRef]

24. Qamar, T.; Mukherjee, S. Genetic approaches for the diagnosis and treatment of rheumatoid arthritis through personalized medicine. Gene Rep. 2021, 23, 101173. [CrossRef]

25. Siouti, E.; Andreakos, E. The many facets of macrophages in rheumatoid arthritis. Biochem. Pharmacol. 2019, 165, 152-169. [CrossRef] [PubMed]

26. Hajialilo, M.; Ghorbanihaghjo, A.; Maddahi, S.; Khabbazi, A.; Mahdavi, A.M.; Rashtchizadeh, N. Association between serum Tolllike receptor 4 and 8-hydroxy-2'-deoxyguanosine levels with disease activity in rheumatoid arthritis patients. Egypt. Rheumatol. 2020, 42, 95-99. [CrossRef]

27. Tada, Y.; Koarada, S.; Morito, F.; Mitamura, M.; Inoue, H.; Suematsu, R.; Ohta, A.; Miyake, K.; Nagasawa, K. Toll-like receptor homolog RP105 modulates the antigen-presenting cell function and regulates the development of collagen-induced arthritis. Arthritis Res. Ther. 2008, 10, R121. [CrossRef]

28. McInnes, I.B.; Schett, G. Pathogenetic insights from the treatment of rheumatoid arthritis. Lancet 2017, 389, 2328-2337. [CrossRef]

29. Chatzidionysiou, K.; Fragoulis, G.E. Established rheumatoid arthritis-Redefining the concept. Best Pr. Res. Clin. Rheumatol. 2019, 33, 101476. [CrossRef] [PubMed]

30. Hansildaar, R.; Vedder, D.; Baniaamam, M.; Tausche, A.-K.; Gerritsen, M.; Nurmohamed, M.T. Cardiovascular risk in inflammatory arthritis: Rheumatoid arthritis and gout. Lancet Rheumatol. 2021, 3, e58-e70. [CrossRef]

31. Jayashree, S.; Nirekshana, K.; Guha, G.; Bhakta-Guha, D. Cancer chemotherapeutics in rheumatoid arthritis: A convoluted connection. Biomed. Pharmacother. 2018, 102, 894-911. [CrossRef] [PubMed]

32. Acar, M.; Sütçü, M.; Salman, N.; Somer, A. The Risk of Tuberculosis and TNF-alpha Inhibitors. J. Pediatr. Infect. 2017, 11, 71-75. [CrossRef]

33. Law, S.T.; Taylor, P.C. Role of biological agents in treatment of rheumatoid arthritis. Pharmacol. Res. 2019, 150, 104497. [CrossRef] [PubMed]

34. Arjumand, S.; Shahzad, M.; Shabbir, A.; Yousaf, M.Z. Thymoquinone attenuates rheumatoid arthritis by downregulating TLR2, TLR4, TNF- $\alpha$, IL-1, and NFkB expression levels. Biomed. Pharmacother. 2019, 111, 958-963. [CrossRef] [PubMed]

35. Umar, S.; Zargan, J.; Umar, K.; Ahmad, S.; Katiyar, C.K.; Khan, H.A. Modulation of the oxidative stress and inflammatory cytokine response by thymoquinone in the collagen induced arthritis in Wistar rats. Chem. Interact. 2012, 197, 40-46. [CrossRef] [PubMed]

36. Boudiaf, K.; Hurtado-Nedelec, M.; Belambri, S.A.; Marie, J.-C.; Derradji, Y.; Benboubetra, M.; El-Benna, J.; Dang, P.M.-C. Thymoquinone strongly inhibits fMLF-induced neutrophil functions and exhibits anti-inflammatory properties in vivo. Biochem. Pharmacol. 2016, 104, 62-73. [CrossRef]

37. Umar, S.; Hedaya, O.; Singh, A.K.; Ahmed, S. Thymoquinone inhibits TNF- $\alpha$-induced inflammation and cell adhesion in rheumatoid arthritis synovial fibroblasts by ASK1 regulation. Toxicol. Appl. Pharmacol. 2015, 287, 299-305. [CrossRef] [PubMed]

38. Vaillancourt, F.; Silva, P.; Shi, Q.; Fahmi, H.; Fernandes, J.C.; Benderdour, M. Elucidation of molecular mechanisms underlying the protective effects of thymoquinone against rheumatoid arthritis. J. Cell. Biochem. 2010, 112, 107-117. [CrossRef]

39. Thummuri, D.; Jeengar, M.K.; Shrivastava, S.; Nemani, H.; Ramavat, R.N.; Chaudhari, P.; Naidu, V. Thymoquinone prevents RANKL-induced osteoclastogenesis activation and osteolysis in an in vivo model of inflammation by suppressing NF-KB and MAPK Signalling. Pharmacol. Res. 2015, 99, 63-73. [CrossRef]

40. Taka, E.; Mazzio, E.A.; Goodman, C.B.; Redmon, N.; Flores-Rozas, H.; Reams, R.R.; Darling-Reed, S.; Soliman, K.F. Antiinflammatory effects of thymoquinone in activated BV-2 microglial cells. J. Neuroimmunol. 2015, 286, 5-12. [CrossRef]

41. Chen, W.-P.; Tang, J.-L.; Bao, J.-P.; Wu, L.-D. Thymoquinone inhibits matrix metalloproteinase expression in rabbit chondrocytes and cartilage in experimental osteoarthritis. Exp. Biol. Med. 2010, 235, 1425-1431. [CrossRef] [PubMed]

42. Tekeoglu, I.; Dogan, A.; Ediz, L.; Budancamanak, M.; Demirel, A. Effects of thymoquinone (volatile oil of black cumin) on rheumatoid arthritis in rat models. Phytother. Res. 2007, 21, 895-897. [CrossRef] [PubMed]

43. Pop, R.M.; Sabin, O.; Suciu, Ș.; Vesa, S.C.; Socaci, S.A.; Chedea, V.S.; Bocsan, I.C.; Buzoianu, A.D. Nigella Sativa's AntiInflammatory and Antioxidative Effects in Experimental Inflammation. Antioxidants 2020, 9, 921. [CrossRef]

44. van de Veerdonk, F.L.; Netea, M.G.; Dinarello, C.A.; Joosten, L.A. Inflammasome activation and IL-1 $\beta$ and IL-18 processing during infection. Trends Immunol. 2011, 32, 110-116. [CrossRef] [PubMed] 
45. Ciążyńska, M.; Bednarski, I.A.; Narbutt, J.; Lesiak, A. NLRP1 and NLRP3 inflammasomes as a new approach to skin carcinogenesis (Review). Oncol. Lett. 2020, 19, 1649-1656. [CrossRef] [PubMed]

46. Bordoni, L.; Fedeli, D.; Nasuti, C.; Maggi, F.; Papa, F.; Wabitsch, M.; De Caterina, R.; Gabbianelli, R. Antioxidant and AntiInflammatory Properties of Nigella sativa Oil in Human Pre-Adipocytes. Antioxidants 2019, 8, 51. [CrossRef]

47. Xiao, S.; Tang, Y.; Lv, Z.; Lin, Y.; Chen, L. Nanomedicine-Advantages for their use in rheumatoid arthritis theranostics. J. Control. Release 2019, 316, 302-316. [CrossRef] [PubMed]

48. Pham, C.T.N. Nanotherapeutic approaches for the treatment of rheumatoid arthritis. Wiley Interdiscip. Rev. Nanomed. Nanobiotechnol. 2011, 3, 607-619. [CrossRef]

49. Fang, Z.; Pan, S.; Gao, P.; Sheng, H.; Li, L.; Shi, L.; Zhang, Y.; Cai, X. Stimuli-responsive charge-reversal nano drug delivery system: The promising targeted carriers for tumor therapy. Int. J. Pharm. 2020, 575, 118841. [CrossRef] [PubMed]

50. García, M.C. 13-Stimuli-responsive polymersomes for drug delivery applications. In Stimuli Responsive Polymeric Nanocarriers for Drug Delivery Applications; Makhlouf, A.S.H., Abu-Thabit, N.Y., Eds.; Woodhead Publishing: Cambridge, UK, 2019 ; pp. 345-392.

51. Kausar, H.; Mujeeb, M.; Ahad, A.; Moolakkadath, T.; Aqil, M.; Ahmad, A.; Akhter, H. Optimization of ethosomes for topical thymoquinone delivery for the treatment of skin acne. J. Drug Deliv. Sci. Technol. 2019, 49, 177-187. [CrossRef]

52. Mostafa, M.; Alaaeldin, E.; Aly, U.F.; Sarhan, H.A. Optimization and Characterization of Thymoquinone-Loaded Liposomes with Enhanced Topical Anti-inflammatory Activity. AAPS PharmSciTech 2018, 19, 3490-3500. [CrossRef] [PubMed]

53. Dzaye, O.; Bødtker, H.; Reiter-Brennan, C.; Blaha, M.J.; Mortensen, M.B. Danish National Trends in Cardiovascular Disease and Cancer Drug Expenditure in Relation to Trends in Cardiovascular Disease and Cancer Deaths. Am. J. Med. 2020, 133, 1350-1353. [CrossRef] [PubMed]

54. Hausman, D.M. What Is Cancer? Perspect. Biol. Med. 2019, 62, 778-784. [CrossRef]

55. Dawson, M.A.; Kouzarides, T. Cancer Epigenetics: From Mechanism to Therapy. Cell 2012, 150, 12-27. [CrossRef] [PubMed]

56. Mahaur, S.; Upadhyay, S.; Pal, R.R. Indolizine: In-silico identification of inhibitors against mutated BCR-ABL protein of chronic myeloid leukemia. Res. J. Pharmacol. Pharmacodyn. 2020, 12, 151-158. [CrossRef]

57. Graham, T.A.; Sottoriva, A. Measuring cancer evolution from the genome. J. Pathol. 2017, 241, 183-191. [CrossRef]

58. Khan, A.; Tania, M.; Fu, S.; Fu, J. Thymoquinone, as an anticancer molecule: From basic research to clinical investigation. Oncotarget 2017, 8, 51907-51919. [CrossRef]

59. Fardi, M.; Solali, S.; Hagh, M.F. Epigenetic mechanisms as a new approach in cancer treatment: An updated review. Genes Dis. 2018, 5, 304-311. [CrossRef]

60. Groves, M.D. The pathogenesis of neoplastic meningitis. Curr. Oncol. Rep. 2003, 5, 15-23. [CrossRef]

61. Khan, A.; Tania, M.; Fu, J. Epigenetic role of thymoquinone: Impact on cellular mechanism and cancer therapeutics. Drug Discov. Today 2019, 24, 2315-2322. [CrossRef]

62. Pang, J.; Shen, N.; Yan, F.; Zhao, N.; Dou, L.; Wu, L.-C.; Seiler, C.L.; Yu, L.; Yang, K.; Bachanova, V.; et al. Thymoquinone exerts potent growth-suppressive activity on leukemia through DNA hypermethylation reversal in leukemia cells. Oncotarget 2017, 8 , 34453-34467. [CrossRef] [PubMed]

63. Imran, M.; Rauf, A.; Khan, I.A.; Shahbaz, M.; Qaisrani, T.B.; Fatmawati, S.; Abu-Izneid, T.; Imran, A.; Rahman, K.U.; Gondal, T.A. Thymoquinone: A novel strategy to combat cancer: A review. Biomed. Pharmacother. 2018, 106, 390-402. [CrossRef] [PubMed]

64. Qadi, S.A.; Hassan, M.A.; Sheikh, R.A.; Baothman, O.A.; Zamzami, M.A.; Choudhry, H.; Al-Malki, A.L.; Albukhari, A.; Alhosin, M. Thymoquinone-Induced Reactivation of Tumor Suppressor Genes in Cancer Cells Involves Epigenetic Mechanisms. Epigenetics Insights 2019, 12, 2516865719839011. [CrossRef] [PubMed]

65. Alobaedi, O.H.; Talib, W.H.; Basheti, I.A. Antitumor effect of thymoquinone combined with resveratrol on mice transplanted with breast cancer. Asian Pac. J. Trop. Med. 2017, 10, 400-408. [CrossRef] [PubMed]

66. Rajput, S.; Kumar, B.P.; Dey, K.K.; Pal, I.; Parekh, A.; Mandal, M. Molecular targeting of Akt by thymoquinone promotes G1 arrest through translation inhibition of cyclin D1 and induces apoptosis in breast cancer cells. Life Sci. 2013, 93, 783-790. [CrossRef] [PubMed]

67. Kou, B.; Liu, W.; Zhao, W.; Duan, P.; Yang, Y.; Yi, Q.; Guo, F.; Li, J.; Zhou, J.; Kou, Q. Thymoquinone inhibits epithelialmesenchymal transition in prostate cancer cells by negatively regulating the TGF- $\beta / \mathrm{Smad} 2 / 3$ signaling pathway. Oncol. Rep. 2017, 38, 3592-3598. [CrossRef]

68. Lei, X.; Lv, X.; Liu, M.; Yang, Z.; Ji, M.; Guo, X.; Dong, W. Thymoquinone inhibits growth and augments 5-fluorouracil-induced apoptosis in gastric cancer cells both in vitro and in vivo. Biochem. Biophys. Res. Commun. 2012, 417, 864-868. [CrossRef] [PubMed]

69. Feng, L.-M.; Wang, X.-F.; Huang, Q.-X. Thymoquinone induces cytotoxicity and reprogramming of EMT in gastric cancer cells by targeting PI3K/Akt/mTOR pathway. J. Biosci. 2017, 42, 547-554. [CrossRef] [PubMed]

70. Norwood, A.A.; Tan, M.; May, M.; Tucci, M.; Benghuzzi, H. Comparison of potential chemotherapeutic agents, 5-fluoruracil, green tea, and thymoquinone on colon cancer cells. Biomed. Sci. Instrum. 2006, 42, 350-356. [PubMed]

71. Zhang, L.; Bai, Y.; Yang, Y. Thymoquinone chemosensitizes colon cancer cells through inhibition of NF-кB. Oncol. Lett. 2016, 12, 2840-2845. [CrossRef]

72. Kundu, J.; Chun, K.-S.; Aruoma, O.I.; Kundu, J.K. Mechanistic perspectives on cancer chemoprevention/chemotherapeutic effects of thymoquinone. Mutat. Res./Fundam. Mol. Mech. Mutagen. 2014, 768, 22-34. [CrossRef] [PubMed] 
73. Baillie, K.E.; Stirling, P.C. Beyond Kinases: Targeting Replication Stress Proteins in Cancer Therapy. Trends Cancer 2021, 7, 430-446. [CrossRef]

74. Bai, T.; Lian, L.-H.; Wu, Y.-L.; Wan, Y.; Nan, J.-X. Thymoquinone attenuates liver fibrosis via PI3K and TLR4 signaling pathways in activated hepatic stellate cells. Int. Immunopharmacol. 2013, 15, 275-281. [CrossRef] [PubMed]

75. Dalli, T.; Beker, M.; Terzioglu-Usak, S.; Akbas, F.; Elibol, B. Thymoquinone activates MAPK pathway in hippocampus of streptozotocin-treated rat model. Biomed. Pharmacother. 2018, 99, 391-401. [CrossRef] [PubMed]

76. Kandeil, M.A.; Mahmoud, M.O.; Abdel-Razik, A.-R.H.; Gomaa, S.B. Thymoquinone and geraniol alleviate cisplatin-induced neurotoxicity in rats through downregulating the p38 MAPK/STAT-1 pathway and oxidative stress. Life Sci. 2019, 228, 145-151. [CrossRef] [PubMed]

77. Zhou, Y.; Jianhua, C.; Rehse, P.H. Thymoquinone and Poloxin are slow-irreversible inhibitors to human Polo-like kinase 1 Polo-box domain. J. Med. Coll. PLA 2010, 25, 136-142. [CrossRef]

78. Afrose, S.S.; Junaid, M.; Akter, Y.; Tania, M.; Zheng, M.; Khan, M.A. Targeting kinases with thymoquinone: A molecular approach to cancer therapeutics. Drug Discov. Today 2020, 25, 2294-2306. [CrossRef]

79. AbuKhader, M. Thymoquinone in the clinical treatment of cancer: Fact or fiction? Pharmacogn. Rev. 2013, 7, 117-120. [CrossRef]

80. Zidan, A.-A.A.; El-Ashmawy, N.E.; Khedr, E.G.; Ebeid, E.-Z.M.; Salem, M.L.; Mosalam, E.M. Loading of doxorubicin and thymoquinone with F2 gel nanofibers improves the antitumor activity and ameliorates doxorubicin-associated nephrotoxicity. Life Sci. 2018, 207, 461-470. [CrossRef]

81. Fishbein, A.; Hammock, B.D.; Serhan, C.N.; Panigrahy, D. Carcinogenesis: Failure of resolution of inflammation? Pharmacol. Ther. 2021, 218, 107670. [CrossRef]

82. Farkhondeh, T.; Samarghandian, S.; Hozeifi, S.; Azimi-Nezhad, M. Therapeutic effects of thymoquinone for the treatment of central nervous system tumors: A review. Biomed. Pharmacother. 2017, 96, 1440-1444. [CrossRef]

83. Ma, J.; Zhang, Y.; Deng, H.; Liu, Y.; Lei, X.; He, P.; Dong, W. Thymoquinone inhibits the proliferation and invasion of esophageal cancer cells by disrupting the AKT/GSK -3ß/Wnt signaling pathway via PTEN upregulation. Phytother. Res. 2020, 34, 3388-3399. [CrossRef] [PubMed]

84. Chae, I.G.; Song, N.-Y.; Kim, D.-H.; Lee, M.-Y.; Park, J.-M.; Chun, K.-S. Thymoquinone induces apoptosis of human renal carcinoma Caki-1 cells by inhibiting JAK2/STAT3 through pro-oxidant effect. Food Chem. Toxicol. 2020, 139, 111253. [CrossRef] [PubMed]

85. Noel, B.; Singh, S.K.; Lillard, J.W.; Singh, R. Role of natural compounds in preventing and treating breast cancer. Front. Biosci. (Sch. ed.) 2020, 12, 137-160.

86. Pandey, M.K.; Gupta, S.C.; Nabavizadeh, A.; Aggarwal, B.B. Regulation of cell signaling pathways by dietary agents for cancer prevention and treatment. Semin. Cancer Biol. 2017, 46, 158-181. [CrossRef]

87. Bimonte, S.; Albino, V.; Barbieri, A.; Tamma, M.L.; Nasto, A.; Palaia, R.; Molino, C.; Bianco, P.; Vitale, A.; Schiano, R.; et al. Dissecting the roles of thymoquinone on the prevention and the treatment of hepatocellular carcinoma: An overview on the current state of knowledge. Infect. Agents Cancer 2019, 14, 1-5. [CrossRef]

88. Talib, W.H. Regressions of Breast Carcinoma Syngraft Following Treatment with Piperine in Combination with Thymoquinone. Sci. Pharm. 2017, 85, 27. [CrossRef]

89. Martucciello, S.; Masullo, M.; Cerulli, A.; Piacente, S. Natural Products Targeting ER Stress, and the Functional Link to Mitochondria. Int. J. Mol. Sci. 2020, 21, 1905. [CrossRef]

90. Veena, M.S.; Raychaudhuri, S.; Basak, S.K.; Venkatesan, N.; Kumar, P.; Biswas, R.; Chakrabarti, R.; Lu, J.; Su, T.; Gallagher-Jones, M.; et al. Dysregulation of hsa-miR-34a and hsa-miR-449a leads to overexpression of PACS-1 and loss of DNA damage response (DDR) in cervical cancer. J. Biol. Chem. 2020, 295, 17169-17186. [CrossRef]

91. Valcourt, D.M.; Day, E.S. Dual Regulation of miR-34a and Notch Signaling in Triple-Negative Breast Cancer by Antibody/miRNA Nanocarriers. Mol. Ther.-Nucleic Acids 2020, 21, 290-298. [CrossRef]

92. Imani, S.; Wei, C.; Cheng, J.; Khan, A.; Fu, S.; Yang, L.; Tania, M.; Zhang, X.; Xiao, X.; Zhang, X.; et al. MicroRNA-34a targets epithelial to mesenchymal transition-inducing transcription factors (EMT-TFs) and inhibits breast cancer cell migration and invasion. Oncotarget 2017, 8, 21362-21379. [CrossRef] [PubMed]

93. Salem, A.A.; El Haty, I.A.; Abdou, I.M.; Mu, Y. Interaction of human telomeric G-quadruplex DNA with thymoquinone: A possible mechanism for thymoquinone anticancer effect. Biochem. Biophys. Acta (BBA)-Gen. Subj. 2015, 1850, 329-342. [CrossRef]

94. Zubair, H.; Khan, H.Y.; Sohail, A.; Azim, S.; Ullah, M.F.; Ahmad, A.; Sarkar, F.H.; Hadi, S.M. Redox cycling of endogenous copper by thymoquinone leads to ROS-mediated DNA breakage and consequent cell death: Putative anticancer mechanism of antioxidants. Cell Death Dis. 2013, 4, e660. [CrossRef] [PubMed]

95. Karki, N.; Aggarwal, S.; Laine, R.A.; Greenway, F.; Losso, J.N. Cytotoxicity of juglone and thymoquinone against pancreatic cancer cells. Chem. Interact. 2020, 327, 109142. [CrossRef] [PubMed]

96. Barkat, M.A.; Pottoo, F.H.; Beg, S.; Rahman, M.; Ahmad, F.J. Evidence-Based Review on Clinical Potential of Thymoquinone in Breast Cancer. Nanomed. Bioact. 2020, 471-486. [CrossRef]

97. Guler, E.M.; Sisman, B.H.; Kocyigit, A.; Hatiboglu, M.A. Investigation of cellular effects of thymoquinone on glioma cell. Toxicol. Rep. 2021, 8, 162-170. [CrossRef] 
98. Kabil, N.; Bayraktar, R.; Kahraman, N.; Mokhlis, H.A.; Calin, G.A.; Lopez-Berestein, G.; Ozpolat, B. Thymoquinone inhibits cell proliferation, migration, and invasion by regulating the elongation factor 2 kinase (eEF-2K) signaling axis in triple-negative breast cancer. Breast Cancer Res. Treat. 2018, 171, 593-605. [CrossRef]

99. Fröhlich, T.; Reiter, C.; Saeed, M.E.M.; Hutterer, C.; Hahn, F.; Leidenberger, M.; Friedrich, O.; Kappes, B.; Marschall, M.; Efferth, T.; et al. Synthesis of Thymoquinone-Artemisinin Hybrids: New Potent Antileukemia, Antiviral, and Antimalarial Agents. ACS Med. Chem. Lett. 2018, 9, 534-539. [CrossRef]

100. Bhattacharjee, M.; Upadhyay, P.; Sarker, S.; Basu, A.; Das, S.; Ghosh, A.; Ghosh, S.; Adhikary, A. Combinatorial therapy of Thymoquinone and Emodin synergistically enhances apoptosis, attenuates cell migration and reduces stemness efficiently in breast cancer. Biochem. Biophys. Acta (BBA)-Gen. Subj. 2020, 1864, 129695. [CrossRef]

101. Jehan, S.; Zhong, C.; Li, G.; Bakhtiar, S.Z.; Li, D.; Sui, G. Thymoquinone Selectively Induces Hepatocellular Carcinoma Cell Apoptosis in Synergism With Clinical Therapeutics and Dependence of p53 Status. Front. Pharmacol. 2020, 11. [CrossRef]

102. Ahmad, I.; Muneer, K.M.; Tamimi, I.A.; Chang, M.E.; Ata, M.O.; Yusuf, N. Thymoquinone suppresses metastasis of melanoma cells by inhibition of NLRP3 inflammasome. Toxicol. Appl. Pharmacol. 2013, 270, 70-76. [CrossRef] [PubMed]

103. Ballout, F.; Monzer, A.; Fatfat, M.; El Ouweini, H.; Jaffa, M.A.; Abdel-Samad, R.; Darwiche, N.; Abou-Kheir, W.; Gali-Muhtasib, $\mathrm{H}$. Thymoquinone induces apoptosis and DNA damage in 5-Fluorouracil-resistant colorectal cancer stem/progenitor cells. Oncotarget 2020, 11, 2959-2972. [CrossRef]

104. Bashir, A.O.; El-Mesery, M.E.; Anwer, R.; Eissa, L.A. Thymoquinone potentiates miR-16 and miR-375 expressions in hepatocellular carcinoma. Life Sci. 2020, 254, 117794. [CrossRef] [PubMed]

105. Kandeil, M.A.; Gomaa, S.B.; Mahmoud, M.O. The effect of some natural antioxidants against cisplatin-induced neurotoxicity in rats: Behavioral testing. Heliyon 2020, 6, e04708. [CrossRef] [PubMed]

106. Vcherashniaya, A.V.; Martinovich, I.V.; Martinovich, G.G.; Shadyro, O.I.; Cherenkevich, S.N. A Raman Spectroscopic Study of Thymoquinone Antitumor Action. J. Appl. Spectrosc. 2020, 87, 1-5. [CrossRef]

107. Racoma, I.O.; Meisen, W.H.; Wang, Q.-E.; Kaur, B.; Wani, A.A. Thymoquinone Inhibits Autophagy and Induces CathepsinMediated, Caspase-Independent Cell Death in Glioblastoma Cells. PLoS ONE 2013, 8, e72882. [CrossRef]

108. Lee, H.J.; Kim, M.J.; Kim, Y.S.; Choi, M.Y.; Cho, G.J.; Choi, W.S. UHRF1 silences gelsolin to inhibit cell death in early stage cervical cancer. Biochem. Biophys. Res. Commun. 2020, 526, 1061-1068. [CrossRef] [PubMed]

109. Dera, A.A.; Rajagopalan, P.; Al Fayi, M.; Ahmed, I.; Chandramoorthy, H.C. Indirubin-3-monoxime and thymoquinone exhibit synergistic efficacy as therapeutic combination in in-vitro and in-vivo models of Lung cancer. Arch. Pharm. Res. 2020, 43, 655-665. [CrossRef]

110. Alghamdi, A.A.; Mohammed, M.R.S.; Zamzami, M.A.; Al-Malki, A.L.; Qari, M.H.; Khan, M.I.; Choudhry, H. Untargeted Metabolomics Identifies Key Metabolic Pathways Altered by Thymoquinone in Leukemic Cancer Cells. Nutrients 2020, $12,1792$. [CrossRef]

111. Ha, J.H.; Jayaraman, M.; Radhakrishnan, R.; Gomathinayagam, R.; Yan, M.; Song, Y.S.; Isidoro, C.; Dhanasekaran, D.N. Differential effects of thymoquinone on lysophosphatidic acid-induced oncogenic pathways in ovarian cancer cells. J. Tradit. Complement. Med. 2020, 10, 207-216. [CrossRef]

112. Zhang, M.; Du, H.; Wang, L.; Yue, Y.; Zhang, P.; Huang, Z.; Lv, W.; Ma, J.; Shao, Q.; Ma, M.; et al. Thymoquinone suppresses invasion and metastasis in bladder cancer cells by reversing EMT through the Wnt/ $\beta$-catenin signaling pathway. Chem. Interact. 2020, 320, 109022. [CrossRef]

113. Boyacioglu, O. Interdependence of cytotoxic activities of bioactive components in black seed (Nigella sativa L.) essential oil and intracellular zinc levels. Fresenius Environ. Bull. 2020, 29, 2746-2751.

114. Costa, J.; Keser, V.; Jackson, C.; Saraiva, N.; Guerreiro, Í.; Almeida, N.; Camões, S.; Manguinhas, R.; Castro, M.; Miranda, J.; et al. A multiple endpoint approach reveals potential in vitro anticancer properties of thymoquinone in human renal carcinoma cells. Food Chem. Toxicol. 2020, 136, 111076. [CrossRef] [PubMed]

115. Bashmail, H.A.; AlAmoudi, A.A.; Noorwali, A.; Hegazy, G.A.; Ajabnoor, G.M.; Al-Abd, A.M. Thymoquinone Enhances Paclitaxel Anti-Breast Cancer Activity via Inhibiting Tumor-Associated Stem Cells Despite Apparent Mathematical Antagonism. Molecules 2020, 25, 426. [CrossRef]

116. El-Far, A.H.; Darwish, N.H.E.; Mousa, S.A. Senescent Colon and Breast Cancer Cells Induced by Doxorubicin Exhibit Enhanced Sensitivity to Curcumin, Caffeine, and Thymoquinone. Integr. Cancer Ther. 2020, 19, 1534735419901160. [CrossRef] [PubMed]

117. Ünal, T.D.; Hamurcu, Z.; Delibaşı, N.; Çınar, V.; Güler, A.; Gökçe, S.; Nurdinov, N.; Ozpolat, B. Thymoquinone Inhibits Proliferation and Migration of MDA-MB-231 Triple Negative Breast Cancer Cells by Suppressing Autophagy, Beclin-1 and LC3. Anti-Cancer Agents Med. Chem. 2021, 21, 355-364. [CrossRef] [PubMed]

118. Alshyarba, M.; Otifi, H.; Al Fayi, M.; A Dera, A.; Rajagopalan, P. Thymoquinone inhibits IL-7-induced tumor progression and metastatic invasion in prostate cancer cells by attenuating matrix metalloproteinase activity and Akt/NF- $\mathrm{BB}$ signaling. Biotechnol. Appl. Biochem. 2020. [CrossRef] [PubMed]

119. Aslan, M.; Afşar, E.; Kırımlıglu, E.; Çeker, T.; Yılmaz, Ç. Antiproliferative Effects of Thymoquinone in MCF-7 Breast and HepG2 Liver Cancer Cells: Possible Role of Ceramide and ER Stress. Nutr. Cancer 2021, 73, 460-472. [CrossRef]

120. Alhosin, M.; Razvi, S.S.I.; Sheikh, R.A.; Khan, J.A.; Zamzami, M.A.; Choudhry, H. Thymoquinone and Difluoromethylornithine (DFMO) Synergistically Induce Apoptosis of Human Acute T Lymphoblastic Leukemia Jurkat Cells Through the Modulation of Epigenetic Pathways. Technol. Cancer Res. Treat. 2020, 19, 1533033820947489. [CrossRef] 
121. Korff, J.M.; Menke, K.; Schwermer, M.; Falke, K.; Schramm, A.; Längler, A.; Zuzak, T.J. Antitumoral Effects of Curcumin (Curcuma longa L.) and Thymoquinone (Nigella sativa L.) on Neuroblastoma Cell Lines. Complement. Med. Res. 2021, 28, 164-168. [CrossRef]

122. Al-Mutairi, A.; Rahman, A.; Rao, M.S. Low Doses of Thymoquinone and Ferulic Acid in Combination Effectively Inhibit Proliferation of Cultured MDA-MB 231 Breast Adenocarcinoma Cells. Nutr. Cancer 2021, 73, 282-289. [CrossRef] [PubMed]

123. Krylova, N.G.; Drobysh, M.S.; Semenkova, G.N.; Kulahava, T.A.; Pinchuk, S.V.; Shadyro, O.I. Cytotoxic and antiproliferative effects of thymoquinone on rat C6 glioma cells depend on oxidative stress. Mol. Cell. Biochem. 2019, 462, 195-206. [CrossRef] [PubMed]

124. Liou, Y.; Chen, P.; Chu, S.; Kao, S.; Chang, Y.; Hsieh, Y.; Chang, H. Thymoquinone suppresses the proliferation of renal cell carcinoma cells via reactive oxygen species-induced apoptosis and reduces cell stemness. Environ. Toxicol. 2019, 34, 1208-1220. [CrossRef] [PubMed]

125. Butt, A.S.; Nisar, N.; Mughal, T.A.; Ghani, N.; Altaf, I. Anti-oxidative and anti-proliferative activities of extracted phytochemical compound thymoquinone. J. Pak. Med. Assoc. 2019, 69, 1479-1485. [CrossRef]

126. Park, J.E.; Kim, D.-H.; Ha, E.; Choi, S.M.; Choi, J.-S.; Chun, K.-S.; Joo, S.H. Thymoquinone induces apoptosis of human epidermoid carcinoma A431 cells through ROS-mediated suppression of STAT3. Chem. Interact. 2019, 312, 108799. [CrossRef] [PubMed]

127. Hsu, H.-H.; Chen, M.-C.; Day, C.H.; Lin, Y.-M.; Li, S.-Y.; Tu, C.-C.; Padma, V.V.; Shih, H.-N.; Kuo, W.-W.; Huang, C.-Y. Thymoquinone suppresses migration of LoVo human colon cancer cells by reducing prostaglandin E2 induced COX-2 activation. World J. Gastroenterol. 2017, 23, 1171-1179. [CrossRef]

128. Ulasli, S.S.; Celik, S.; Gunay, E.; Ozdemir, M.; Hazman, O.; Ozyurek, A.; Koyuncu, T.; Unlu, M. Anticancer Effects of Thymoquinone, Caffeic Acid Phenethyl Ester and Resveratrol on A549 Non-small Cell Lung Cancer Cells Exposed to Benzo(a)pyrene. Asian Pac. J. Cancer Prev. 2013, 14, 6159-6164. [CrossRef]

129. Singh, S.K.; Apata, T.; Gordetsky, J.B.; Singh, R. Docetaxel Combined with Thymoquinone Induces Apoptosis in Prostate Cancer Cells via Inhibition of the PI3K/AKT Signaling Pathway. Cancers 2019, 11, 1390. [CrossRef]

130. Fatfat, M.; Fakhoury, I.; Habli, Z.; Mismar, R.; Gali-Muhtasib, H. Thymoquinone enhances the anticancer activity of doxorubicin against adult T-cell leukemia in vitro and in vivo through ROS-dependent mechanisms. Life Sci. 2019, 232, 116628. [CrossRef]

131. Chen, M.-C.; Lee, N.-H.; Hsu, H.-H.; Ho, T.-J.; Tu, C.-C.; Hsieh, D.J.-Y.; Lin, Y.-M.; Chen, L.-M.; Kuo, W.-W.; Huang, C.-Y. Thymoquinone Induces Caspase-Independent, Autophagic Cell Death in CPT-11-Resistant LoVo Colon Cancer via Mitochondrial Dysfunction and Activation of JNK and p38. J. Agric. Food Chem. 2015, 63, 1540-1546. [CrossRef]

132. Das, S.; Dey, K.K.; Dey, G.; Pal, I.; Majumder, A.; MaitiChoudhury, S.; Kundu, S.C.; Mandal, M. Antineoplastic and Apoptotic Potential of Traditional Medicines Thymoquinone and Diosgenin in Squamous Cell Carcinoma. PLoS ONE 2012, 7, e46641. [CrossRef] [PubMed]

133. Hatiboglu, M.A.; Kocyigit, A.; Guler, E.M.; Akdur, K.; Khan, I.; Nalli, A.; Karatas, E.; Tuzgen, S. Thymoquinone Enhances the Effect of Gamma Knife in B16-F10 Melanoma Through Inhibition of Phosphorylated STAT3. World Neurosurg. 2019, 128, e570-e581. [CrossRef] [PubMed]

134. Samarghandian, S.; Azimi-Nezhad, M.; Farkhondeh, T. Thymoquinone-induced antitumor and apoptosis in human lung adenocarcinoma cells. J. Cell. Physiol. 2019, 234, 10421-10431. [CrossRef] [PubMed]

135. Ndreshkjana, B.; Çapci, A.; Klein, V.; Chanvorachote, P.; Muenzner, J.; Huebner, K.; Steinmann, S.; Erlenbach-Wuensch, K.; Geppert, C.I.; Agaimy, A.; et al. Combination of 5-fluorouracil and thymoquinone targets stem cell gene signature in colorectal cancer cells. Cell Death Dis. 2019, 10, 1-16. [CrossRef] [PubMed]

136. Lee, S.-R.; Mun, J.-Y.; Jeong, M.-S.; Lee, H.-H.; Roh, Y.-G.; Kim, W.-T.; Kim, M.-H.; Heo, J.; Choi, Y.H.; Kim, S.J.; et al. Thymoquinone-Induced Tristetraprolin Inhibits Tumor Growth and Metastasis through Destabilization of MUC4 mRNA. Int. J. Mol. Sci. 2019, 20, 2614. [CrossRef] [PubMed]

137. Santoso, R.A.; Lienaningrum, A.S.; Bangun, E.D.; Reformatika, H.G.; Susidarti, R.A.; Meiyanto, E. Black cumin (Nigella sativa L.) and awar-awar (Ficus septica burm. F.) combination extract inhibits proliferation and modulates cell cycle on HeLa cell. In Proceedings of the Fourth Huntsville Gamma-Ray Burst Symposium, Huntsville, AL, USA, 15-20 September 1997 ; p. 020023.

138. Dera, A.; Rajagopalanz, P. Thymoquinone attenuates phosphorylation of AKT to inhibit kidney cancer cell proliferation. J. Food Biochem. 2019, 43, e12793. [CrossRef]

139. Lee, Y.-M.; Kim, G.-H.; Park, E.-J.; Oh, T.-I.; Lee, S.; Kan, S.-Y.; Kang, H.; Kim, B.M.; Kim, J.H.; Lim, J.-H. Thymoquinone Selectively Kills Hypoxic Renal Cancer Cells by Suppressing HIF-1 $\alpha$-Mediated Glycolysis. Int. J. Mol. Sci. 2019, 20, 1092. [CrossRef]

140. Butt, A.S.; Nisar, N.; Ghani, N.; Altaf, I.; Mughal, T.A. Isolation of thymoquinone from Nigella sativa L. and Thymus vulgaris L., and its anti-proliferative effect on HeLa cancer cell lines. Trop. J. Pharm. Res. 2019, 18, 37. [CrossRef]

141. Khan, A.; Aldebasy, Y.H.; Alsuhaibani, S.A.; Khan, M.A. Thymoquinone Augments Cyclophosphamide-Mediated Inhibition of Cell Proliferation in Breast Cancer Cells. Asian Pac. J. Cancer Prev. 2019, 20, 1153-1160. [CrossRef]

142. Suriyah, W.H.; Kasmuri, A.R.; Ni Foong, F.H.; Afriza, D.; Ichwan, S.J.A. Comparison of the in vitro and in vivo toxic effects of thymoquinone using oral cancer HSC-3 and HSC-4 cell lines, oral fibroblasts, HACAT cell line, and Zebrafish embryos. Mater. Today Proc. 2019, 16, 2108-2114. [CrossRef]

143. Chaleshtori, J.S.; Heidari-Sureshjani, E.; Moradi, F.; Heidarian, E. The Effects of Thymoquinone on Viability, and Anti-apoptotic Factors (BCL-XL, BCL-2, MCL-1) in Prostate Cancer (PC3) Cells: An In Vitro and Computer-Simulated Environment Study. Adv. Pharm. Bull. 2019, 9, 490-496. [CrossRef] 
144. Sanjarin, F.; Sabouni, F.; Rashid, M. Thymoquinone Effects on Cell Viability, Apoptosis and VEGF-A Gene Expression Level in AGS(CRL-1739) Cell Line. Anti-Cancer Agents Med. Chem. 2019, 19, 820-826. [CrossRef]

145. Ren, X.; Luo, W. Exploration of pro-apoptotic effect of Thymoquinone on oral squamous cell carcinoma cells through PI3K/Akt signaling pathway. Cell. Mol. Biol. 2019, 65, 61-64. [CrossRef]

146. Zhang, Y.; Fan, Y.; Huang, S.; Wang, G.; Han, R.; Lei, F.; Luo, A.; Jing, X.; Zhao, L.; Gu, S.; et al. Thymoquinone inhibits the metastasis of renal cell cancer cells by inducing autophagy via AMPK/mTOR signaling pathway. Cancer Sci. 2018, 109, 3865-3873. [CrossRef] [PubMed]

147. Bashmail, H.A.; AlAmoudi, A.A.; Noorwali, A.; Hegazy, G.A.; Ajabnoor, G.; Choudhry, H.; Al-Abd, A.M. Thymoquinone synergizes gemcitabine anti-breast cancer activity via modulating its apoptotic and autophagic activities. Sci. Rep. 2018, 8, 1-11. [CrossRef] [PubMed]

148. Kou, B.; Kou, Q.; Ma, B.; Zhang, J.; Sun, B.; Yang, Y.; Li, J.; Zhou, J.; Liu, W. Thymoquinone inhibits metastatic phenotype and epithelial-mesenchymal transition in renal cell carcinoma by regulating the LKB1/AMPK signaling pathway. Oncol. Rep. 2018, 40, 1443-1450. [CrossRef]

149. Zhang, M.; Du, H.; Huang, Z.; Zhang, P.; Yue, Y.; Wang, W.; Liu, W.; Zeng, J.; Ma, J.; Chen, G.; et al. Thymoquinone induces apoptosis in bladder cancer cell via endoplasmic reticulum stress-dependent mitochondrial pathway. Chem. Interact. 2018, 292, 65-75. [CrossRef]

150. Subburayan, K.; Thayyullathil, F.; Pallichankandy, S.; Rahman, A.; Galadari, S. Par-4-dependent p53 up-regulation plays a critical role in thymoquinone-induced cellular senescence in human malignant glioma cells. Cancer Lett. 2018, 426, 80-97. [CrossRef]

151. Khazaei, M.; Pazhouhi, M.; Sariri, R.; Khazaei, M.R.; Moradi, M.T. Synergistic effect of temozolomide and thymoquinone on human glioblastoma multiforme cell line (U87MG). J. Cancer Res. Ther. 2018, 14, 1023-1028. [CrossRef]

152. Ibrahim, A.; Alhosin, M.; Papin, C.; Ouararhni, K.; Omran, Z.; Zamzami, M.A.; Al-Malki, A.L.; Choudhry, H.; Mély, Y.; Hamiche, A.; et al. Thymoquinone challenges UHRF1 to commit auto-ubiquitination: A key event for apoptosis induction in cancer cells. Oncotarget 2018, 9, 28599-28611. [CrossRef]

153. Hatiboglu, M.A.; Kocyigit, A.; Guler, E.M.; Akdur, K.; Nalli, A.; Karatas, E.; Tuzgen, S. Thymoquinone Induces Apoptosis in B16-F10 Melanoma Cell Through Inhibition of p-STAT3 and Inhibits Tumor Growth in a Murine Intracerebral Melanoma Model. World Neurosurg. 2018, 114, e182-e190. [CrossRef] [PubMed]

154. Öztürk, E.; Kaymak, E.; Akin, A.T.; Karabulut, D.; Ünsal, H.M.; Yakan, B. Thymoquinone is a protective agent that reduces the negative effects of doxorubicin in rat testis. Hum. Exp. Toxicol. 2020, 39, 1364-1373. [CrossRef] [PubMed]

155. Alghamdi, F.; Al-Seeni, M.N.; Ghoneim, M.A. Potential synergistic antioxidant effect of thymoquinone and vitamin E on cisplatin-induced acute nephropathy in rats. Clin. Nutr. Exp. 2020, 32, 29-37. [CrossRef]

156. Hossen, M.J.; Yang, W.S.; Kim, D.; Aravinthan, A.; Kim, J.-H.; Cho, J.Y. Thymoquinone: An IRAK1 inhibitor with in vivo and in vitro anti-inflammatory activities. Sci. Rep. 2017, 7, srep42995. [CrossRef] [PubMed]

157. Özenver, N.; Efferth, T. Small molecule inhibitors and stimulators of inducible nitric oxide synthase in cancer cells from natural origin (phytochemicals, marine compounds, antibiotics). Biochem. Pharmacol. 2020, 176, 113792. [CrossRef] [PubMed]

158. Mosalam, E.M.; Zidan, A.-A.A.; Mehanna, E.T.; Mesbah, N.M.; Abo-Elmatty, D.M. Thymoquinone and pentoxifylline enhance the chemotherapeutic effect of cisplatin by targeting Notch signaling pathway in mice. Life Sci. 2020, 244, 117299. [CrossRef]

159. Alabdullah, S.W.; Alsamir, S.A.; AlRufaei, I.A. Effect of Thymoquinone on some biochemical and hormonal indices and their protective effect on the genital organs of rats after cancer induction in Laboratory. EurAsian J. BioSci. 2020, 14, 567-573.

160. Helmy, S.A.; El-Mesery, M.; El-Karef, A.; Eissa, L.A.; El Gayar, A.M. Thymoquinone upregulates TRAIL/TRAILR2 expression and attenuates hepatocellular carcinoma in vivo model. Life Sci. 2019, 233, 116673. [CrossRef]

161. Shahin, Y.; Elguindy, N.; Abdel Bary, A.; Balbaa, M. The protective mechanism of Nigella sativa against diethylnitrosamineinduced hepatocellular carcinoma through its antioxidant effect and EGFR/ERK1/2 signaling. Environ. Toxicol. 2018, 33, 885-898. [CrossRef]

162. Pu, Y.; Hu, S.; Chen, Y.; Zhang, Q.; Xia, C.; Deng, H.; Wang, Y.; Hu, Q. Thymoquinone loaded calcium alginate and polyvinyl alcohol carrier inhibits the 7,12-dimethylbenz[a]anthracene-induced hamster oral cancer via the down-regulation of PI3K/AKT/mTOR signaling pathways. Environ. Toxicol. 2021, 36, 339-351. [CrossRef]

163. Abdelbaky, N.W.; Abdelazem, A.Z.; Hashem, K.S. Thymoquinone Attenuates 6-Mercaptopurine Induced Testicular Toxicity in Albino Rats: Possible Mechanisms are Involved. Adv. Anim. Vet. Sci. 2020, 8, 653-660. [CrossRef]

164. Pal, R.R.; Parashar, P.; Singh, I.; Saraf, S.A. Tamanu oil potentiated novel sericin emulgel of levocetirizine: Repurposing for topical delivery against DNCB-induced atopic dermatitis, QbD based development and in vivo evaluation. J. Microencapsul. 2019, 36, 432-446. [CrossRef]

165. Pal, R.R.; Maurya, A.K.; Parashar, P.; Saraf, S.A. A Comparative Study of Levocetirizine Loaded Vesicular and Matrix Type System for Topical Application: Appraisal of Therapeutic Potential against Atopic Dermatitis. J. Pharm. Innov. 2020, 1-12. [CrossRef]

166. Kalyane, D.; Raval, N.; Maheshwari, R.; Tambe, V.; Kalia, K.; Tekade, R.K. Employment of enhanced permeability and retention effect (EPR): Nanoparticle-based precision tools for targeting of therapeutic and diagnostic agent in cancer. Mater. Sci. Eng. C Mater. Biol. Appl. 2019, 98, 1252-1276. [CrossRef] [PubMed]

167. Zhao, J.; Chen, X.; Ho, K.-H.; Cai, C.; Li, C.-W.; Yang, M.; Yi, C. Nanotechnology for diagnosis and therapy of rheumatoid arthritis: Evolution towards theranostic approaches. Chin. Chem. Lett. 2021, 32, 66-86. [CrossRef] 
168. Maurya, P.; Singh, S.; Mishra, N.; Pal, R.; Singh, N.; Parashar, P.; Saraf, S.A. Chapter 20-Albumin-based nanomaterials in drug delivery and biomedical applications. In Biopolymer-Based Nanomaterials in Drug Delivery and Biomedical Applications; Bera, H., Hossain, C.M., Saha, S., Eds.; Academic Press: Cambridge, MA, USA, 2021; pp. 465-496.

169. Golombek, S.K.; May, J.-N.; Theek, B.; Appold, L.; Drude, N.; Kiessling, F.; Lammers, T. Tumor targeting via EPR: Strategies to enhance patient responses. Adv. Drug Deliv. Rev. 2018, 130, 17-38. [CrossRef] [PubMed]

170. Zafar, S.; Akhter, S.; Ahmad, I.; Hafeez, Z.; Alam Rizvi, M.M.; Jain, G.K.; Ahmad, F.J. Improved chemotherapeutic efficacy against resistant human breast cancer cells with co-delivery of Docetaxel and Thymoquinone by Chitosan grafted lipid nanocapsules: Formulation optimization, in vitro and in vivo studies. Colloids Surf. B Biointerfaces 2020, 186, 110603. [CrossRef]

171. Odeh, F.; Naffa, R.; Azzam, H.; Mahmoud, I.S.; Alshaer, W.; Al Bawab, A.; Ismail, S. Co-encapsulation of thymoquinone with docetaxel enhances the encapsulation efficiency into PEGylated liposomes and the chemosensitivity of MCF7 breast cancer cells to docetaxel. Heliyon 2019, 5, e02919. [CrossRef] [PubMed]

172. Bhatt, P.; Lalani, R.; Vhora, I.; Patil, S.; Amrutiya, J.; Misra, A.; Mashru, R. Liposomes encapsulating native and cyclodextrin enclosed paclitaxel: Enhanced loading efficiency and its pharmacokinetic evaluation. Int. J. Pharm. 2018, 536, 95-107. [CrossRef]

173. Zafar, S.; Akhter, S.; Garg, N.; Selvapandiyan, A.; Jain, G.K.; Ahmad, F.J. Co-encapsulation of docetaxel and thymoquinone in mPEG-DSPE-vitamin E TPGS-lipid nanocapsules for breast cancer therapy: Formulation optimization and implications on cellular and in vivo toxicity. Eur. J. Pharm. Biopharm. 2020, 148, 10-26. [CrossRef]

174. Ahmad, R.; Kaus, N.H.M.; Hamid, S. Synthesis and characterization of PLGA-PEG thymoquinone nanoparticles and its cytotoxicity effects in tamoxifen-resistant breast cancer cells. In Cancer Biology and Advances in Treatment; Springer: Berlin/Heidelberg, Germany, 2020; pp. 65-82.

175. Kumar, V.S.; Devi, R.P.; Hemananthan, E. In vitro studies to analyze the stability and bioavailability of thymoquinone encapsulated in the developed nanocarrier. J. Dispers. Sci. Technol. 2019, 41, 243-256. [CrossRef]

176. Kommineni, N.; Saka, R.; Bulbake, U.; Khan, W. Cabazitaxel and thymoquinone co-loaded lipospheres as a synergistic combination for breast cancer. Chem. Phys. Lipids 2019, 224, 104707. [CrossRef]

177. Borodina, T.; Gileva, A.; Akasov, R.; Trushina, D.; Burov, S.; Klyachko, N.; González-Alfaro, Y.; Bukreeva, T.; Markvicheva, E. Fabrication and evaluation of nanocontainers for lipophilic anticancer drug delivery in 3D in vitro model. J. Biomed. Mater. Res. Part B Appl. Biomater. 2021, 109, 527-537. [CrossRef] [PubMed]

178. Goel, S.; Mishra, P. Thymoquinone loaded mesoporous silica nanoparticles retard cell invasion and enhance in vitro cytotoxicity due to ROS mediated apoptosis in HeLa and MCF-7 cell lines. Mater. Sci. Eng. C 2019, 104, 109881. [CrossRef]

179. Shahein, S.A.; Aboul-Enein, A.M.; Higazy, I.M.; Abou-Elella, F.; Lojkowski, W.; Ahmed, E.R.; Mousa, S.A.; AbouAitah, K. Targeted anticancer potential against glioma cells of thymoquinone delivered by mesoporous silica core-shell nanoformulations with pH-dependent release. Int. J. Nanomed. 2019, 14, 5503-5526. [CrossRef] [PubMed]

180. AlShehri, S.; Imam, S.S.; Rizwanullah, M.; Fakhri, K.U.; Alam Rizvi, M.M.; Mahdi, W.; Kazi, M. Effect of Chitosan Coating on PLGA Nanoparticles for Oral Delivery of Thymoquinone: In Vitro, Ex Vivo, and Cancer Cell Line Assessments. Coatings 2020, 11, 6. [CrossRef]

181. Sharifi, F.; Yesil-Celiktas, O.; Kazan, A.; Maharjan, S.; Saghazadeh, S.; Firoozbakhsh, K.; Firoozabadi, B.; Zhang, Y.S. A hepatocellular carcinoma-bone metastasis-on-a-chip model for studying thymoquinone-loaded anticancer nanoparticles. Bio-Des. Manuf. 2020, 3, 1-14. [CrossRef]

182. Azmy, N.; Haron, A.S.; Alwi, S.S.S. Thymoquinone-loaded nanostructured lipid carrier reduces proliferation of human liver cancer cells, HepG2. Malays. J. Med. Health Sci. 2019, 15, 38-43.

183. Sunoqrot, S.; Alfaraj, M.; Hammad, A.; Kasabri, V.; Shalabi, D.; Deeb, A.; Ibrahim, L.H.; Shnewer, K.; Yousef, I. Development of a Thymoquinone Polymeric Anticancer Nanomedicine through Optimization of Polymer Molecular Weight and Nanoparticle Architecture. Pharmaceutics 2020, 12, 811. [CrossRef]

184. Alhakamy, N.A.; Badr-Eldin, S.M.; A Fahmy, U.; Alruwaili, N.K.; Awan, Z.A.; Caruso, G.; Alfaleh, M.A.; Alaofi, A.L.; Arif, F.O.; Ahmed, O.A. Thymoquinone-Loaded soy-phospholipid-based phytosomes exhibit anticancer potential against human lung cancer cells. Pharmaceutics 2020, 12, 761. [CrossRef] [PubMed]

185. Bergonzi, M.C.; Vasarri, M.; Marroncini, G.; Barletta, E.; Degl'Innocenti, D. Thymoquinone-Loaded Soluplus ${ }^{\circledR}-$ Solutol ${ }^{\circledR}$ HS15 Mixed Micelles: Preparation, In Vitro Characterization, and Effect on the SH-SY5Y Cell Migration. Molecules 2020, $25,4707$. [CrossRef] [PubMed]

186. Ibiyeye, K.M.; Zuki, A.B.Z. Cockle Shell-Derived Aragonite CaCO3 Nanoparticles for Co-Delivery of Doxorubicin and Thymoquinone Eliminates Cancer Stem Cells. Int. J. Mol. Sci. 2020, 21, 1900. [CrossRef]

187. Mehanna, M.M.; Sarieddine, R.; Alwattar, J.K.; Chouaib, R.; Gali-Muhtasib, H. Anticancer Activity of Thymoquinone Cubic Phase Nanoparticles Against Human Breast Cancer: Formulation, Cytotoxicity and Subcellular Localization. Int. J. Nanomed. 2020, 15, 9557-9570. [CrossRef] [PubMed]

188. Ibrahim, W.N.; Rosli, L.M.B.M.; Doolaanea, A.A. Formulation, Cellular Uptake and Cytotoxicity of Thymoquinone-Loaded PLGA Nanoparticles in Malignant Melanoma Cancer Cells. Int. J. Nanomed. 2020, 15, 8059-8074. [CrossRef]

189. Vhora, I.; Patil, S.; Bhatt, P.; Gandhi, R.; Baradia, D.; Misra, A. Receptor-targeted drug delivery: Current perspective and challenges. Ther. Deliv. 2014, 5, 1007-1024. [CrossRef] [PubMed] 
190. Caveliers, V.; Everaert, H.; John, C.S.; Lahoutte, T.; Bossuyt, A. Sigma receptor scintigraphy with N-[2-(1'-piperidinyl)ethyl]-3(123)I-iodo-4-methoxybenzamide of patients with suspected primary breast cancer: First clinical results. J. Nucl. Med. 2002, 43, 1647-1649. [PubMed]

191. Banerjee, R.; Tyagi, P.; Li, S.; Huang, L. Anisamide-targeted stealth liposomes: A potent carrier for targeting doxorubicin to human prostate cancer cells. Int. J. Cancer 2004, 112, 693-700. [CrossRef] [PubMed]

192. Ramzy, L.; Metwally, A.A.; Nasr, M.; Awad, G.A.S. Novel thymoquinone lipidic core nanocapsules with anisamidepolymethacrylate shell for colon cancer cells overexpressing sigma receptors. Sci. Rep. 2020, 10, 1-15. [CrossRef]

193. Singh, S.K.; Gordetsky, J.B.; Bae, S.; Acosta, E.P.; Lillard, J.J.W.; Singh, R. Selective Targeting of the Hedgehog Signaling Pathway by PBM Nanoparticles in Docetaxel-Resistant Prostate Cancer. Cells 2020, 9, 1976. [CrossRef]

194. Bhattacharya, S.; Ghosh, A.; Maiti, S.; Ahir, M.; Debnath, G.H.; Gupta, P.; Bhattacharjee, M.; Ghosh, S.; Chattopadhyay, S.; Mukherjee, P.; et al. Delivery of thymoquinone through hyaluronic acid-decorated mixed Pluronic ${ }^{\circledR}$ nanoparticles to attenuate angiogenesis and metastasis of triple-negative breast cancer. J. Control. Release 2020, 322, 357-374. [CrossRef]

195. Ince, I.; Yıldırım, Y.; Güler, G.; Medine, E.I.; Ballıca, G.; Kuşdemir, B.C.; Göker, E. Synthesis and characterization of folic acidchitosan nanoparticles loaded with thymoquinone to target ovarian cancer cells. J. Radioanal. Nucl. Chem. 2020, 324, 71-85. [CrossRef]

196. Upadhyay, P.; Sarker, S.; Ghosh, A.; Gupta, P.; Das, S.; Ahir, M.; Bhattacharya, S.; Chattopadhyay, S.; Ghosh, S.; Adhikary, A. Transferrin-decorated thymoquinone-loaded PEG-PLGA nanoparticles exhibit anticarcinogenic effect in non-small cell lung carcinoma via the modulation of miR-34a and miR-16. Biomater. Sci. 2019, 7, 4325-4344. [CrossRef] [PubMed]

197. Murphy, E.M.; Centner, C.S.; Bates, P.J.; Malik, M.T.; Kopechek, J.A. Delivery of thymoquinone to cancer cells with as1411conjugated nanodroplets. PLoS ONE 2020, 15, e0233466. [CrossRef] [PubMed]

198. Reyes-Reyes, E.M.; Teng, Y.; Bates, P.J. A New Paradigm for Aptamer Therapeutic AS1411 Action: Uptake by Macropinocytosis and Its Stimulation by a Nucleolin-Dependent Mechanism. Cancer Res. 2010, 70, 8617-8629. [CrossRef]

199. Tokunaga, E.; Kimura, Y.; Mashino, K.; Oki, E.; Kataoka, A.; Ohno, S.; Morita, M.; Kakeji, Y.; Baba, H.; Maehara, Y. Activation of PI3K/Akt signaling and hormone resistance in breast cancer. Breast Cancer 2006, 13, 137-144. [CrossRef] [PubMed]

200. Rajput, S.; Puvvada, N.; Kumar, B.N.P.; Sarkar, S.; Konar, S.; Bharti, R.; Dey, G.; Mazumdar, A.; Pathak, A.; Fisher, P.B.; et al. Overcoming Akt Induced Therapeutic Resistance in Breast Cancer through siRNA and Thymoquinone Encapsulated Multilamellar Gold Niosomes. Mol. Pharm. 2015, 12, 4214-4225. [CrossRef]

201. Kumar, S.R.; Thangam, R.; Vivek, R.; Srinivasan, S.; Ponpandian, N. Synergetic effects of thymoquinone-loaded porous PVPylated $\mathrm{Fe}_{3} \mathrm{O}_{4}$ nanostructures for efficient $\mathrm{pH}$-dependent drug release and anticancer potential against triple-negative cancer cells. Nanoscale Adv. 2020, 2, 3209-3221. [CrossRef]

202. Sweety, J.P.; Sowparani, S.; Mahalakshmi, P.; Selvasudha, N.; Yamini, D.; Geetha, K.; Ruckmani, K. Fabrication of stimuli gated nanoformulation for site-specific delivery of thymoquinone for colon cancer treatment-Insight into thymoquinone's improved physicochemical properties. J. Drug Deliv. Sci. Technol. 2020, 55, 101334. [CrossRef]

203. Tariq, S.; Naqvi, S.A.R.; Naz, S.; Mubarik, M.S.; Yaseen, M.; Riaz, M.; Shah, S.M.A.; Rafi, M.; Roohi, S. Dose-Dependent Internalization and Externalization Integrity Study of Newly Synthesized 99mTc-Thymoquinone Radiopharmaceutical as Cancer Theranostic Agent. Dose-Response 2020, 18, 1559325820914189. [CrossRef]

204. Fahmy, H.M. In vitro study of the cytotoxicity of thymoquinone/curcumin fluorescent liposomes. Naunyn-Schmiedeberg's Arch. Pharmacol. 2019, 392, 1465-1476. [CrossRef] [PubMed]

205. Fathy, M.M. Multifunctional Thymoquinone-Capped Iron Oxide Nanoparticles for Combined Chemo-Photothermal Therapy of Cancer. J. Supercond. Nov. Magn. 2020, 33, 2125-2131. [CrossRef]

206. Das, S.; Bera, D.; Pal, K.; Mondal, D.; Karmakar, P.; Das, S.; Dey, A. Guar gum micro-vehicle mediated delivery strategy and synergistic activity of thymoquinone and piperine: An in vitro study on bacterial and hepatocellular carcinoma cells. J. Drug Deliv. Sci. Technol. 2020, 60, 101994. [CrossRef]

207. Alkhatib, M.H.; Bawadud, R.S.; Gashlan, H.M. Incorporation of docetaxel and thymoquinone in borage nanoemulsion potentiates their antineoplastic activity in breast cancer cells. Sci. Rep. 2020, 10, 1-12. [CrossRef] [PubMed]

208. Altamimi, M.A.; Kazi, M.; Albgomi, M.H.; Ahad, A.; Raish, M. Development and optimization of self-nanoemulsifying drug delivery systems (SNEDDS) for curcumin transdermal delivery: An anti-inflammatory exposure. Drug Dev. Ind. Pharm. 2019, 45, 1073-1078. [CrossRef] [PubMed]

209. Rushmi, Z.T.; Akter, N.; Mow, R.J.; Afroz, M.; Kazi, M.; de Matas, M.; Rahman, M.; Shariare, M.H. The impact of formulation attributes and process parameters on black seed oil loaded liposomes and their performance in animal models of analgesia. Saudi Pharm. J. 2017, 25, 404-412. [CrossRef]

210. Kazi, M.; A Nasr, F.; Noman, O.; Alharbi, A.; Alqahtani, M.S.; Alanazi, F.K. Development, Characterization Optimization, and Assessment of Curcumin-Loaded Bioactive Self-Nanoemulsifying Formulations and Their Inhibitory Effects on Human Breast Cancer MCF-7 Cells. Pharmaceutics 2020, 12, 1107. [CrossRef]

211. Guria, S.; Ghosh, A.; Upadhyay, P.; Das, M.K.; Mishra, T.; Adhikary, A.; Adhikari, S. Small-Molecule Probe for Sensing Serum Albumin with Consequential Self-Assembly as a Fluorescent Organic Nanoparticle for Bioimaging and Drug-Delivery Applications. ACS Appl. Bio Mater. 2020, 3, 3099-3113. [CrossRef]

212. Khattabi, A.M.; Alqdeimat, D.A.; Sabbar, E.; Talib, W.H. In Vitro Characteristics of a Combination of Thymoquinone-Resveratrol Loaded and Targeted Nanodrug Delivery System. Jordan J. Pharm. Sci. 2020, 13, 53-63. 
213. Dawaba, A.M.; Dawaba, H.M. Application of Optimization Technique to Develop Nano-Based Carrier of Nigella Sativa Essential Oil: Characterization and Assessment. Recent Pat. Drug Deliv. Formul. 2020, 13, 228-240. [CrossRef]

214. Kaus, N.H.M.; Shaarani, S.; Hamid, S.S. The Influence of pluronic F68 and F127 nanocarrier on physicochemical properties, in vitro release, and antiproliferative activity of thymoquinone drug. Pharmacogn. Res. 2017, 9, 12-20. [CrossRef]

215. Fakhoury, I.; Saad, W.; Bouhadir, K.; Nygren, P.; Schneider-Stock, R.; Gali-Muhtasib, H. Uptake, delivery, and anticancer activity of thymoquinone nanoparticles in breast cancer cells. J. Nanopart. Res. 2016, 18, 210. [CrossRef]

216. Akasov, R.; Borodina, T.; Zaytseva, E.; Sumina, A.; Bukreeva, T.; Burov, S.; Markvicheva, E. Ultrasonically Assisted Polysaccharide Microcontainers for Delivery of Lipophilic Antitumor Drugs: Preparation and in Vitro Evaluation. ACS Appl. Mater. Interfaces 2015, 7, 16581-16589. [CrossRef] [PubMed]

217. Dehghani, H.; Hashemi, M.; Entezari, M.; Mohsenifar, A. The Comparison of Anticancer Activity of Thymoquinone and Nanothymoquinone on Human Breast Adenocarcinoma. Iran. J. Pharm. Res. IJPR 2015, 14, 539-546. [PubMed]

218. El-Toni, A.M.; Khan, A.; Ibrahim, M.A.; Labis, J.P.; Badr, G.; Al-Hoshan, M.; Yin, S.; Sato, T. Synthesis of double mesoporous core-shell silica spheres with tunable core porosity and their drug release and cancer cell apoptosis properties. J. Colloid Interface Sci. 2012, 378, 83-92. [CrossRef] [PubMed]

219. Ganea, G.M.; Fakayode, S.O.; Losso, J.N.; Van Nostrum, C.F.; Sabliov, C.M.; Warner, I.M. Delivery of phytochemical thymoquinone using molecular micelle modified poly(D, L lactide-co-glycolide) (PLGA) nanoparticles. Nanotechnology 2010, $21,285104$. [CrossRef]

220. Fathy, M.M. Biosynthesis of Silver Nanoparticles Using Thymoquinone and Evaluation of Their Radio-Sensitizing Activity. BioNanoSci. 2019, 10, 260-266. [CrossRef]

221. Yazan, L.S.; Mohd Azlan, S.; Zakarial Ansar, F.; Gopalsamy, B. Acute toxicity study of intravenous administration of thymoquinone-loaded nanostructured lipid carrier (TQ-NLC) in Sprague Dawley rats. Malays. J. Med. Health Sci. 2019, 15, 51-57.

222. Khader, M.; Bresgen, N.; Eckl, P. In vitro toxicological properties of thymoquinone. Food Chem. Toxicol. 2009, 47, 129-133. [CrossRef] [PubMed]

223. Kassab, R.B.; El-Hennamy, R.E. The role of thymoquinone as a potent antioxidant in ameliorating the neurotoxic effect of sodium arsenate in female rat. Egypt. J. Basic Appl. Sci. 2017, 4, 160-167. [CrossRef]

224. Yahyazadeh, A.; Altunkaynak, B.Z. Investigation of the neuroprotective effects of thymoquinone on rat spinal cord exposed to $900 \mathrm{MHz}$ electromagnetic field. J. Chem. Neuroanat. 2019, 100, 101657. [CrossRef]

225. Abuzinadah, M.F.; Ahmad, A. Pharmacological studies on the efficacy of a thymoquinone-containing novel polyherbal formulation against cisplatin-induced hepatorenal toxicity in rats. J. Food Biochem. 2019, 44, e13131. [CrossRef] [PubMed]

226. Crede, P. Treatment of Inflammatory Disease or Disorder and Compositions Therefor. U.S. Patent 20140213558A1, 31 July 2014.

227. Özen, O.A.; Özgül, M.; Aydin, M. Nanomicelles for the Treatment of Cancer. WO2016167730A1, 20 October 2016.

228. Malik, M.T.; Kopechek, J.A.; Bates, P.J. Targeted Nanodroplet Emulsions for Treating Cancer. U.S. Patent US20190192686A1, 27 June 2019.

229. Halwani, M.A.; Balkhy, H.H. Nano-Liposomal Aminoglycoside-Thymoquinone Formulations. WO2016061117A1, 21 April 2016.

230. Salem, A.E.; El Haty, I.; Abdou, I.; Adem, A.; Attoub, S. Thymoquinone Derivatives for Treatment of Cancer. U.S. Patent US10501428B2, 10 December 2019.

231. Poonam, N.; Charul, R.; Sharma, I.S. Improved Vesicular Formulation of Thymoquinone for the Treatment of Dermal Inflammatory Disorders and Method Thereof. WO2018134852A1, 26 July 2018.

232. Crede, P. Compositions Comprising Thymoquinone for the Treatment of Inflammatory Diseases. WO2013030669A4, 17 July 2013.

233. Odeh, F.; Ismail, S. Liposomal Formulations Comprising Thymoquinone and Taxane, and Method of Treating Cancer Using Same. WO2016005786A1, 14 January 2016.

234. Zhu, N.; Xiang, Y.; Zhao, X.; Cai, C.; Chen, H.; Wenbing, J.; Wang, Y.; Zeng, C. Application of the Thymoquinone in Preparation Prevention Intravascular Stent Restenosis Medicaments. CN110420203A, 8 November 2019.

235. Madhavamenon, K.I.; Maliakel, B.P.; Ittiyavirah, S.P.; Ramalingam, K. Composition of Nigella Sativaseeds to Treat Anxiety, Stress and Sleep Disorders with Significant Memory Enhancement Properties and a Process for Producing the Same. U.S. Patent US10485837B2, 26 November 2019.

236. Fazlul, H.S.; Ramzi, M.M. Thymoquinone Analogs for the Treatment of Pancreatic Cancer. WO2011126544A2, 13 October 2011.

237. Crooks, P.A.; Worthen, D.R.; Ghosheh, O.A. Use of the Naturally-Occurring Quinones Thymoquinone and Dithymoquinone as Antineoplastic and Cytotoxic Agents. U.S. Patent US6218434B1, 17 April 2001.

238. Wan, X.; Wu, H. Synthesis Method of Thymoquinone Serving as Blood Vessel Inhibition Medicament. CN103288618A, 9 November 2013.

239. Jianping, Z.; Ma, Z.; Lifa, Z. Hyaluronic Acid-Adipodihydrazide-Thymoquinone Grafted Polymer as Well as Synthesis Method and Application of Hyaluronic Acid-Adipodihydrazide-Thymoquinone Grafted Polymer. CN-103833871-A, 4 June 2014.

240. Pacioretty, L.; Babish, J. Formulations Containing Thymoquinone For Urinary Health. U.S. Patent US8029831B2, 4 October 2011.

241. Mekkawi, S.S.R. Use of Iron-Binding Glycoproteins and/or 10-Hydroxy-2-Decenoic Acid in Combination with Thymoquinone for Treating Immunodeficiency Diseases. DE19844022C1, 25 September 1998. 